\title{
Decision-making after Ultrasound Diagnosis of Fetal Abnormality
}

H.H. Bijma 
The work presented in this thesis was performed at the department of Obstetrics and Gynaecology, ErasmusMC and at the department of Public Health, University Medical Centre Rotterdam, The Netherlands

The printing of this thesis was financially supported by the Department of Public Health, ErasmusMC

The research of this thesis was partly funded by the Sophia Foundation for Scientific Research

\section{Front cover: H.H. Bijma}

(C) 2007, H.H. Bijma. All rights reserved. No part of this publication may be reproduced, stored in retrieval system, or transmitted, in any form or by any means, electronic, mechanical, photocopying, recording, or otherwise, without the prior permission from the proprietor.

(c) 2007, H.H. Bijma. Alle rechten voorbehouden. Niets uit deze uitgave mag worden verveelvoudigd, opgeslagen in een geautomatiseerd gegevensbestand, of openbaar gemaakt, in enige vorm of op enige wijze, hetzij elektronisch, mechanisch, door fotokopieën, opnamen, of op enig andere manier, zonder voorafgaande schriftelijke toestemming van de rechthebbende. 


\title{
Decision-making after Ultrasound Diagnosis of Fetal Abnormality
}

Besluitvorming na echoscopische diagnose van een foetale afwijking

\author{
Proefschrift \\ ter verkrijging van de graad van doctor aan de \\ Erasmus Universiteit Rotterdam \\ op gezag van de Rector Magnificus
}

Prof.dr. S.W.J. Lamberts

en volgens besluit van het College voor Promoties

De openbare verdediging zal plaatsvinden op woensdag 30 mei 2007 om 9.45 uur

door

Hilmar Henrike Bijma

geboren te Groningen

Erasmus Universiteit Rotterdam

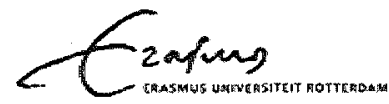




\section{Promotiecommissie}

Promotoren: $\quad$ Prof.dr. P.J. van der Maas

Prof.Jhr.dr. J.W. Wladimiroff

Overige leden: Prof.dr. J. Passchier

Prof.dr. E.A.P. Steegers

Prof.dr. D. Tibboel

Copromotoren: Dr. A. van der Heide

Dr. H.I.J. Wildschut 
Voor Bertwin 


\section{Contents}

\section{General introduction}

Chapter 1 General introduction

Decision-making by physicians

Chapter 2 Ultrasound diagnosis of fetal abnormalities: an analysis

of perinatal management of 318 consecutive pregnancies in a multidisciplinary setting

Chapter 3 Obstetricians' agreement on fetal prognosis after ultrasound diagnosis of fetal abnormalities

Chapter 4 Survival after non-aggressive obstetric management in cases of severe fetal abnormalities

Chapter 5 Impact of decision-making in a multidisciplinary perinatal team

\section{Decision-making by pregnant women}

Chapter 6 Parental decision-making after ultrasound diagnosis of a serious

Chapter $7 \quad$ Women's views on decision-making about their unborn child with congenital abnormality: a qualitative study.

Chapter 8 Ultrasound diagnosis of fetal abnormality: do pregnant women feel they have something to choose?

\section{General discussion}

Chapter 9 General discussion

Dankwoord, curriculum vitae, publications by the author 


\section{Chapter 1}

\section{General introduction}




\subsection{Congenital abnormalities}

Congenital abnormalities are the main cause of infant death in industrialised countries. ${ }^{1,2}$ Furthermore, these form the main diagnosis in end-of-life decisions in infants. $^{3}$ Congenital abnormalities are frequently diagnosed before birth, as most major congenital abnormalities can be detected by routine prenatal examination, including ultrasound. ${ }^{4-6}$ Table 1 gives a general picture of the nature and severity of congenital abnormalities as well as the possibilities and limits of prenatal diagnosis. This table is based on data derived from an unselected British population, which is comparable to the Dutch population. ${ }^{7}$

Ultrasound scanning is considered the most important tool for prenatal diagnosis of structural congenital abnormalities. It detects the majority but certainly not all of the congenital abnormalities. ${ }^{7}$ In centres for prenatal diagnosis for example, detection rates are $80-95 \% .{ }^{5,8}$ However, these vary with the nature of congenital abnormalities. For example, the detection rate of neural tube defects is $98 \%$ while congenital heart defects are prenatally identified by ultrasound in $38 \%{ }^{7}$ Furthermore, maternal obesity results in considerably lower detection rates. ${ }^{9}$

When severe congenital abnormalities are detected prenatally, couples may request for termination of pregnancy. ${ }^{7}$ In the majority of end-of-life decisions, suspicion of fetal abnormality was first aroused after ultrasound scan. ${ }^{7}$ Hence, the practice of ultrasound scanning is closely related to that of end-of-life-decisions.

\subsection{Ultrasound}

\section{Developments in fetal ultrasound}

Since the first ultrasound image of a fetus in 1963, ultrasound has evolved into the most important diagnostic tool in fetal medicine. ${ }^{10}$ First, only static images of the fetus were available. However, around 1977, the introduction of real-time scanning, allowing for moving images of the fetus, resulted in a further expansion of ultrasound diagnosis. Ultrasound became widely available. In a short period of time a myriad of reports on both normal and abnormal anatomy of the fetus appeared. Nowadays, ultrasound examination during pregnancy is routine practice in most industrialised countries. ${ }^{10,13,15}$ This is usually done by a two-scan regime: a dating scan in first trimester of pregnancy and a fetal abnormality scan at approximately 18 to 20 weeks' gestation. ${ }^{10}$

In countries with routine ultrasound screening, more than half of all congenital abnormalities are diagnosed prenatally, including $74 \%$ of the major abnormalities (i.e. abnormalities that have implications for the infant's health) and $46 \%$ of the minor abnormalities (i.e. abnormalities that have no implications for the infant's health). ${ }^{7,11}$

\section{Ultrasound screening}

The potential benefits and limitations of ultrasound population screening for fetal abnormalities has been debated extensively. ${ }^{5,10}$ To date, no conclusive data on the benefits of ultrasound screening have appeared. ${ }^{12}$ Randomized controlled trials have been done, but have used perinatal mortality and morbidity as outcome variables. Moreover, in the setting of these studies the expertise levels of sonographers varied much. Finally, these studies took place at a time that ultrasound was less advanced than it is now. ${ }^{13}$ These methodological problems are reflected in an enormous variation of reported over-all sensitivity for detection of congenital abnormalities, which ranges between $14 \%$ and $96 \%$. ${ }^{4-6}$ Apart from these methodological flaws, the use of perinatal mortality and morbidity as the only important outcome variable is questionable. ${ }^{13}$ Other outcome variables, such as pregnant women being informed, enhancing fetal-maternal attachment and preventing a 'wrongful life' are of relevance as well. ${ }^{12}$ These issues reflect the question what should be the aim of screening, the answer of which depends not only on medical data, but on moral choices as well. ${ }^{13-15}$ 
Table 1. Overview of prenatal detection of congenital abnormality when prenatal screening is offered routinely in an unselected population in Oxford, 1991-1995; births included all births over 20 weeks and all pregnancies terminated because of fetal abnormality detected at any age of gestation.

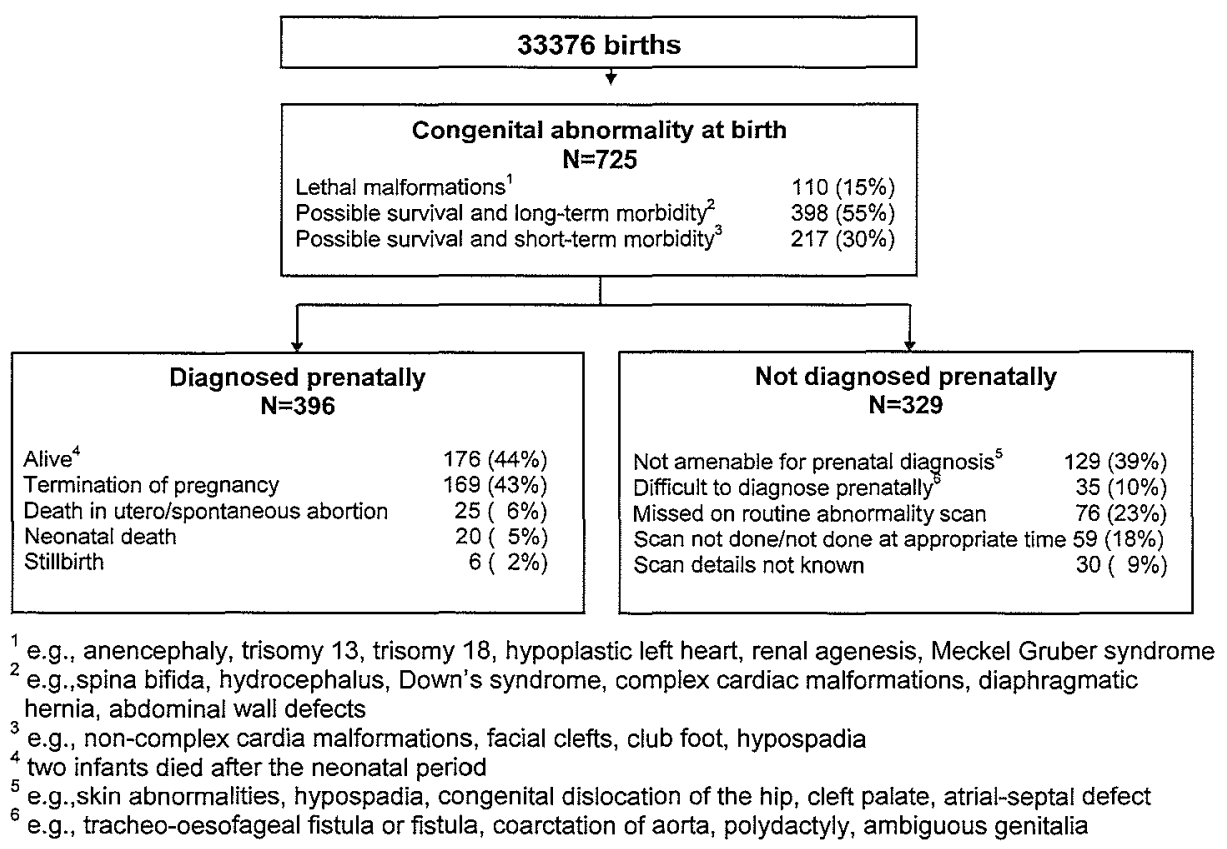

In the Netherlands, ultrasound screening has been debated. ${ }^{15}$ The government has decided that ultrasound is only to be offered on medical indication, i.e. targeted at women at increased risk of congenital abnormalities in offspring. ${ }^{15}$ This attitude should be seen within the Dutch sociocultural context. Dutch law typically forbids screening, unless certain conditions are fulfilled, including the availability of effective treatment for the condition. ${ }^{15}$ Furthermore, there are concerns about the implications of prenatal screening in the context of medicalisation of the pregnancy and regarding the societal position of handicapped people. ${ }^{15}$ Very recently, however, a trend towards offering all women ultrasound examination at 20 weeks gestational age is seen.

The government's decision not to offer routine ultrasound screening results in large practice variations in antenatal care, e.g., some women have no ultrasound examination at all, other women have a two-scan regime and some women opt for having a 'pleasure scan' in a commercial setting, which may however create false reassurance as many of these ultrasound examinations are not apt for detecting fetal abnormalities ${ }^{15} 16$ Unfortunately, there are no guidelines for timing of the ultrasound, counselling or qualifications of the sonographers. So even if women have had one or multiple ultrasound examinations, potentially detectable major fetal abnormalities can still be missed.

\section{Psychological effects of normal ultrasound}

Normal findings at ultrasound examination have strong beneficial psychological effects on the pregnant woman and her partner. For couples, ultrasound is a way of 'meeting' the unborn child (see text box 1). ${ }^{17-20}$ The personalisation of the fetus enhances both maternal-fetal bonding and bonding of the pregnant woman and her partner. ${ }^{19,21,22}$. A normal ultrasound reassures parents about the pregnancy. ${ }^{21,23-26}$ 
The positive effects of ultrasound are stronger when more feedback is provided, such as showing images on a second monitor, and explaining what can be seen. ${ }^{21,25}$

So, fetal ultrasound is highly appreciated by pregnant women and their partners. ${ }^{20,26-28}$ For most women it forms an integral part of obstetric care. ${ }^{27}$ However, frequently women lack information about the purposes for which an ultrasound is done and what are its technical limitations. Therefore, women are frequently unprepared for adverse findings. ${ }^{28,29}$

Text box 1. An illustrative reaction of a couple to a normal ultrasound

A couples reaction to a normal ultrasound: 'The baby becomes more real...once you see the scan, that all changes. It's no longer your imagination at work, but you have this real image of a little baby. You can see so much detail it is amazing, his little fingers and toes, his eyes, oh, everything. It is magical, so awe inspiring to see' Puddifoot JE. Johnson MP. The legitimacy of grieving: the partner's experience at miscarriage. Soc Sci Med 1997;45(6):837-45.

\section{Psychological effects of abnormal ultrasound}

The results of an abnormal ultrasound frequently come unexpectedly and are intensely shocking for the expecting parents, in particular when major congenital abnormalities are encountered. ${ }^{28,30}$ Pregnant women and their partners may have several reactions on the announcement of fetal abnormality. Firstly they may have negative feelings as associated with psychological traumas in general, such as anxiety, grief, anger, loneliness, hopelessness, prostration and guilt. ${ }^{29-31,33,34}$ These feelings may be aggravated by the loss of the imagined future, as the pregnancy may end in the daily reality of having no child or a severely handicapped child, requiring readjustments of the entire family. These feelings can be enhanced by the confrontation with reality, when having to decide about very pragmatic issues 'should I decorate the nursery?', 'should I make arrangements for the funeral?', and 'what should I tell my other child?'. Finally, some parents experience a loss of reference. The news of a fetal abnormality in an apparently uneventful pregnancy, usually comes so unexpectedly and is in such contrast with the pleasant experiences that often come with pregnancy, that parents often find it very difficult to grasp the facts. It seems so unreal that the child who is kicking inside the womb is severely disabled or will even die, that all meaning seems lost. When parents consider terminating the pregnancy, the ambivalent feelings they experience may enhance this loss of reference. On the one hand, they are committed to the wanted and intended pregnancy. On the other hand, they want to protect the unborn child, themselves and the family from the burden of severe disability. ${ }^{35}$

\subsection{End-of-life-decisions after ultrasound diagnosis of fetal abnormality}

End-of-life decisions after ultrasound diagnosis of fetal abnormality

With the burgeoning of ultrasound, questions around the appropriate obstetric management in case of sonographically established fetal abnormalities have arisen. Should we apply all means to keep alive a fetus with a very poor prognosis? Do medical professionals in the field of perinatal medicine agree on fetal prognosis after ultrasound diagnosis of fetal abnormality? How should obstetric and neonatal management be attuned? How do parents view upon end-of-life decisions regarding their unborn infant? These and other issues have opened a new field of research: end-of-life decision-making after ultrasound diagnosis of fetal abnormality. End-of-life decisions are decisions about medical interventions at the end of life, which certainly or probably hasten death. ${ }^{36}$ Two kinds of end-of-life decisions can be distinguished after ultrasound diagnosis of fetal abnormality: 1) non-aggressive obstetric management and 2) termination of pregnancy. 
Table 2. Studies evaluating determinants of parental decision-making after ultrasound diagnosis of fetal abnormality

\begin{tabular}{|c|c|c|c|c|c|c|}
\hline Author & Population & $N$ & Method & $\begin{array}{l}\text { Outcome } \\
\text { variable }\end{array}$ & Results & \\
\hline \multicolumn{7}{|l|}{ Determinants } \\
\hline Grevengood et al. ${ }^{53}$ & $\begin{array}{l}\text { isolated neural tube defect } \\
\text { identified }<24 \text { weeks GA } \\
\text { normal karyotype }\end{array}$ & 50 & $\begin{array}{l}\text { analysis decisions in case of anencephaly } \\
\text { analysis decisions in spina bifida laesions }>\mathrm{T} 9 \\
\text { analysis decisions in spina bifida laesions }<\mathrm{T} 9\end{array}$ & TOP & $\begin{array}{ll}\text { anencephaly } & : 23 / 23 \text { TOP } \\
\text { spina bifida }>\text { T9 } & : 5 / 5 \text { TOP } \\
\text { spina bifida }<\text { T9 } & : 16 / 22 \text { TOP } \\
\end{array}$ & \\
\hline Pryde et al..$^{54}$ & $\begin{array}{l}\text { abnormalities identified }<24 \\
\text { weeks GA } \\
\text { no abnormal karyotype }\end{array}$ & 159 & $\begin{array}{l}\text { GA stratiffed into early }(<14 \text { weeks } G A), \\
\text { mid ( } 15-19 \text { weeks GA), late) } \\
\text { (20-24 weeks GA diagnosis } \\
\text { Prognostic severity of abnormality } \\
\text { stratified into mild, uncertain, severe }\end{array}$ & TOP & $\begin{array}{l}\text { severity of abnormality } \\
\text { GA } \\
\text { maternal age } \\
\text { gravidity } \\
\text { parity }\end{array}$ & $\begin{array}{l}p<0.001 \\
\text { n.s. } \\
\text { n.s. } \\
\text { n.s. } \\
\text { n.s. }\end{array}$ \\
\hline Sheiner et $a^{5.5}$ & $\begin{array}{l}\text { abnormalities incompatible with } \\
\text { life or severe enough to } \\
\text { Significantly interfere with } \\
\text { normal living in Arab } \\
\text { Bedouin population }\end{array}$ & 188 & $\begin{array}{l}63 \text { cases } G A>24 \text { weeks } \\
125 \text { cases } G A<24 \text { weeks }\end{array}$ & TOP & $\begin{array}{l}\text { GA } \\
\text { previous uncompleted pregnancies } \\
\text { central nervous sylem abnormality } \\
\text { maternal age } \\
\text { gravidity } \\
\text { parity } \\
\text { previous perinatal death } \\
\text { congenital abnormality in family }\end{array}$ & $\begin{array}{l}\mathrm{p}<.01 \\
\mathrm{p}<.01 \\
\mathrm{p}<.01 \\
\text { n.s. } \\
\text { n.s. } \\
\text { n.s. } \\
\text { n.s. } \\
\text { n.s. }\end{array}$ \\
\hline Schechtman et al..$^{56}$ & $\begin{array}{l}\text { abnormalities identified }<24 \\
24 \text { weeks GA }\end{array}$ & 53630 & $\begin{array}{l}\text { severity of abnormality stratified on scale } 1-5 \text {, } \\
\text { as evaluated by sonographer }\end{array}$ & TOP & $\begin{array}{l}\text { educational level parents } \\
\text { severity of abnormality } \\
\text { chromosomal abnormalities } \\
\text { central nervous system abnormality } \\
\text { maternal age }\end{array}$ & $\begin{array}{l}p<.001 \\
p<.001 \\
p<.001 \\
p<.001 \\
\text { n.s. }\end{array}$ \\
\hline
\end{tabular}


A non-aggressive obstetric management refers to an obstetric management, in which interventions needed to sustain fetal life are forgone, because of poor fetal prognosis. A non-aggresive obstetric management was first reported in 1989, when Chervenak and McCullough described such management in 13 cases. They regard a non-aggressive obstetric management as permissible, and even preferable, when there is certainty of death or absence of cognitive developmental capacity as outcome of the congenital abnormality. ${ }^{37,38}$ Chervenak and McCullough argue that in such cases, the fetus does not benefit from obstetric intervention, whereas such intervention may harm the pregnant woman and interfere with her autonomy. ${ }^{37,38}$ However, empirical data that are needed for a balanced professional and societal debate about forgoing fetal life-sustaining treatment, are scarce. . $^{37,39,40}$

Termination of pregnancy is a management, in which the pregnancy is terminated with the explicit intention of hastening fetal death. Termination of pregnancy is done by induction of labour, which may be preceded by fetal intracardial potassium injection. The first termination of pregnancy after ultrasound diagnosis of fetal abnormality was reported by Campbell et al. in 1972. This concerned a fetus with anencephaly. ${ }^{41}$ Termination of pregnancy has far-reaching implications. It bears life-long lasting consequences and evokes very strong emotions of the couples involved. ${ }^{42,43}$

End-of-life decision-making after ultrasound diagnosis of fetal abnormality has to

take into account both the interest of the fetus and the pregnant woman. Therefore, it is usually done by multidisciplinary teams. ${ }^{44-48}$ These typically consist of obstetricians, neonatologists, paediatric surgeons, and other paediatric specialists, such as paediatric urologists, paediatric neurologists, and paediatric neurosurgeons. ${ }^{44-48}$ However, little is known about how decisions are being taken in these teams.

Parental decision-making after ultrasound diagnosis of fetal abnormality remains largely unknown. Table 2 shows the studies to date, which evaluate determinants of parental decision to choose for termination of pregnancy. Lower gestational age, a more severe abnormality, involvement of the central nervous system, previous uncompleted pregnancies, lower maternal educational level, and the presence of chromosomal abnormalities have been related with a higher rate of women deciding upon termination of pregnancy. However, these data are not conclusive and do not reflect why and in what way some factors are important for the parents. Sandelowski has studied parental decision-making concerning prenatal diagnosis of fetal abnormality in more depth. ${ }^{49}$ She interviewed 15 women and 12 of their partners. This study shows the concept of choice is contested. Women in comparable circumstances feel differently about whether or not they have a choice about the future of their pregnancy. ${ }^{49}$

\section{Legal context and current guidelines}

In the Netherlands, law prohibits termination of pregnancy at a gestational age of 24 weeks and beyond. However, in case of good clinical practice, physicians typically are not prosecuted by the public prosecutor. ${ }^{50-52}$ Good clinical practice is described in guidelines that were made by a collaborative group of the Ministry of Health, Ministry of Justice and the Dutch Society of Obstetricians and Gynaecologists. According to these guidelines, when parents insistently request for termination of pregnancy, this will be granted in case of extremely poor fetal prognosis. Fetal prognosis should be: 1) the infant has no chance of survival and the abnormalities 12 not be treated or the infant has a chance of extra-uterine survival but post-natal use of life-prolonging medical treatment is considered futile. ${ }^{51}$ 


\subsection{Research objectives}

This thesis aims at exploring decision-making after ultrasound diagnosis of fetal abnormality. The following issues and research questions are addressed:

1) The frequency of end-of-life decisions after ultrasound diagnosis of fetal abnormality

1. What is the frequency of end-of-life-decisions in a tertiary referral centre?

2. What is the estimated frequency of fetal end-of-life decisions in the Netherlands?

2) The process of decision-making after ultrasound diagnosis fetal abnormality

Physicians

1. To what extent can fetal prognosis after ultrasound diagnosis of fetal abnormality be classified, in the context of end-of-life decision-making?

2. What is inter- and intra-observer agreement about fetal prognosis after ultrasound diagnosis of fetal abnormality?

3. To what extent does decision-making in a multidisciplinary perinatal team enhance consensus about obstetric management decisions, neonatal management decisions, and hospital of delivery?

4. To what extent are decisions regarding obstetric and neonatal management attuned prenatally?

5. What is neonatal management in case of infants that are born alive after a non-aggressive obstetric management?

\section{Pregnant women}

6. How do pregnant women make decisions about the fetus?

3) Consequences of end-of-life decisions after ultrasound diagnosis of fetal abnormality

1. What is survival in utero, during delivery, and during the neonatal and postneonatal period in case of a non-aggressive obstetric management after ultrasound diagnosis of fetal abnormality?

2. What is the health status of children who survived after a non-aggressive obstetric management? 


\section{References}

1. Petrini J, Damus K, Russell R, Poschman K, Davidoff MJ, Mattison D. Contribution of birth defects to infant mortality in the United States. Teratology 2002;66 Suppl 1:S3-6.

2. Lee K, Khoshnood B, Chen L, Wall SN, Cromie WJ, Mittendorf RL. Infant mortality from congenital malformations in the United States, 1970-1997. Obstet Gynecol 2001;98:620-7.

3. van der Heide A, van der Maas PJ, van der Wal G, de Graaff CL, Kester JG, Kollee LA, et al. Medical end-of-life decisions made for neonates and infants in the Netherlands. Lancet 1997;350:251-5.

4. Lys F, De Wals P, Boriee-Grimee I, Billiet A, Vincotte-Mols M, Levi S. Evaluation of routine ultrasound examination for the prenatal diagnosis of malformation. Eur $\mathrm{J}$ Obstet Gynecol Reprod Biol 1989;30:101-9.

5. Levi S. Uitrasound in prenatal diagnosis: polemics around routine ultrasound screening for second trimester fetal malformations. Prenat Diagn 2002;22:285-95.

6. Carrera JM, Torrents M, Mortera C, Cusi V, Munoz A. Routine prenatal ultrasound screening for fetal abnormalities: 22 years' experience. Ultrasound Obstet Gynecol 1995;5:174-9.

7. Boyd PA, Chamberlain P, Hicks NR. 6-year experience of prenatal diagnosis in an unselected population in Oxford, UK. Lancet 1998;352:1577-81.

8. Wladimiroff JW, Cohen-Overbeek TE, Ursem NT, Bijma H, Los FJ. [Twenty years of experience in advanced ultrasound scanning for fetal abnormalities in Rotterdam] Geavanceerd ultrageluidonderzoek naar aangeboren afwijkingen in Rotterdam; 20 jaar ervaring. Ned Tijdschr Geneeskd 2003;147:2106-10.

9. Tabor A, Zdravkovic M, Perslev A, Moller LK, Pedersen BL. Screening for congenital malformations by ultrasonography in the general population of pregnant women: factors affecting the efficacy. Acta Obstet Gynecol Scand 2003;82:1092-8.

10. McNay MB, Fleming JE. Forty years of obstetric ultrasound 1957-1997: from A-scope to three dimensions. Ultrasound Med Biol 1999;25:3-56.

11. Grandjean H, Larroque D, Levi S. Sensitivity of routine ultrasound screening of pregnancies in the Eurofetus database. The Eurofetus Team. Ann N Y Acad Sci 1998;847:118-24.

12. Chamberlain P, Boyd PA. Commentary: evidence based practice and antenatal ultrasonography-the need for more studies. Bmj 1996;313:1254-5.

13. Romano PS, Waitzman NJ. Can decision analysis help us decide whether ultrasound screening for fetal abnormalities is worth it? Ann N Y Acad Sci 1998;847:154-72.

14. Getz L, Kirkengen AL. Ultrasound screening in pregnancy: advancing technology, soft markers for fetal chromosomal aberrations, and unacknowledged ethical dilemmas. Soc Sci Med 2003;56:2045-57.

15. Health Council of the Netherlands. Prenatal Screening: Down's syndrome, neural tube defects, routine-ultrasonography. The Hague: : Health Council of the Netherlands, 2001; publication no. $2001 / 11$.

16. Wildschut HI, ten Hoope-Bender P, Borkent-Polet M, Traas H, van Agt HM, de Kroon ML, et al. Practice variation of test procedures reportedly used in routine antenatal care in The Netherlands. Acta Obstet Gynecol Scand 1999;78:27-32.

17. Puddifoot JE, Johnson MP. The legitimacy of grieving: the partner's experience at miscarriage. Soc Sci Med 1997:45:837-45.

18. Kowalcek I, Huber $G$, Bieniakiewitz I, Lammers C, Brunk I, Gembruch U. The influence of gestational age on depressive reactions, stress and anxiety of pregnant women and their partners in relation to prenatal diagnosis. J Psychosom Obstet Gynaecol 2003;24:239-45.

19. Bricker L, Garcia J, Henderson J, Mugford M, Neilson J, Roberts T, et al. Ultrasound screening in pregnancy: a systematic review of the clinical effectiveness, cost-effectiveness and women's views. Health Technol Assess 2000;4(16):i-vi, 1-193.

20. Harris $G$, Connor L, Bisits A, Higginbotham N. "Seeing the baby": pleasures and dilemmas of ultrasound technologies for primiparous Australian women. Med Anthropol Quaterly 2004;18(1):23-47.

21. Reading AE, Cox DN. The effects of ultrasound examination on maternal anxiety levels. $J$ Behav Med 1982;5:237-47.

22. Sklansky M, Tang A, Levy D, Grossfeld P, Kashani I, Shaughnessy R, et al. Maternal psychological impact of fetal echocardiography. J Am Soc Echocardiogr 2002;15:159-66.

23. Harris CE. Aborting abnormal fetuses: the parental perspective. J Appl Philos 1991;8:57-68.

24. Bjorkhem $G$, Jorgensen $C$, Hanseus $K$. Parental reactions to fetal echocardiography. J Matern Fetal Med 1997;6:87-92.

25. Zlotogorski Z, Tadmor O, Duniec E, Rabinowitz R, Diamant $Y$. The effect of the amount of feedback on anxiety levels during ultrasound scanning. J Clin Ultrasound 1996;24:21-4.

26. Larsen T, Nguyen TH, Munk M, Svendsen L, Teisner L. Ultrasound screening in the $2^{\text {nd }}$ trimester. The pregnant woman's background knowledge, expectations, experiences and acceptances. Ultrasound Obstet Gynecol 2000;15:383-6.

27. Georges E. Fetal ultrasound imaging and the production of authoritative knowledge in Greece. Med Anthropol Quarterly 1996;10:157-75. 
28. Garcia J, Bricker L, Henderson J, Martin MA, Mugford M, Nielson J, et al. Women's views of pregnancy ultrasound: a systematic review. Birth 2002;29:225-50.

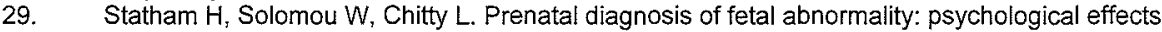
on women in low-risk pregnancies. Baillieres Best Pract Res Clin Obstet Gynaecol $2000 ; 14: 731-47$.

30. Detraux JJ, Gillot-de Vries F, Vanden Eynde S, Courtois A, Desmet A. Psychological impact of the announcement of a fetal abnormality on pregnant women and on professionals. Ann $N Y$ Acad Sci 1998;847:210-9.

31. Hunfeld JA, Wladimiroff JW, Passchier J, Venema-Van Uden MU, Frets PG, Verhage F. Emotional reactions in women in late pregnancy ( 24 weeks or longer) following the ultrasound diagnosis of a severe or lethal fetal malformation. Prenat Diagn 1993;13:603-12.

32. Langer M, Ringler M. Prospective counselling after prenatal diagnosis of fetal malformations: interventions and parental reactions. Acta Obstet Gynecol Scand 1989;68:323-9.

33. Leuthner SR, Bolger M, Frommelt M, Nelson R. The impact of abnormal fetal echocardiography on expectant parents' experience of pregnancy: a pilot study. J Psychosom Obstet Gynaecol 2003;24:121-9.

34. Mitchell LM. Women's experiences of unexpected ultrasound findings. J Midwifery Womens Health 2004:49:228-34.

35. Britt DW, Risinger ST, Mans MK, Evans MI. Devastation and relief: conflicting meanings of detected fetal abnormalities. Ultrasound Obstet Gynecol 2002;20:1-5.

36. Groenewoud JH. End-of-life-decisions in medicine, empirical studies on practices and attitudes in the Netherlands. ErasmusMC, University Hospital Rotterdam, 2002.

37. Chervenak FA, McCullough LB. Nonaggressive obstetric management. An option for some fetal abnormalities during the third trimester. Jama 1989;261:3439-40.

38. Chervenak FA, McCullough LB, Skupski D, Chasen ST. Ethical issues in the management of pregnancies complicated by fetal abnormalities. Obstet Gynecol Surv 2003;58:473-83.

39. Kirkinen P, Jouppila P, Herva R. Fatal fetal abnormalities. Route of delivery and effect of the development of antepartum diagnostics in the last 13 years. J Reprod Med 1992;37:645-8.

40. Spinnato JA, Cook VD, Cook CR, Voss DH. Aggressive intrapartum management of lethal fetal abnormalities: beyond fetal beneficence. Obstet Gynecol 1995;85:89-92.

41. Campbell S, Johnstone FD, Holt EM, May P. Anencephaly: early ultrasonic diagnosis and active management. Lancet 1972;2:1226-7.

42. White-Van Mourik MC, Connor JM, Ferguson-Smith MA. The psychosocial sequelae of a second trimester termination of pregnancy for fetal abnormality over a two year period. Birth Defects Orig Artic Ser 1992;28:61-74.

43. White-Van Mourik MC, Connor JM, Ferguson-Smith MA. Patient care before and after termination of pregnancy for neural tube defects. Prenat Diagn 1990;10:497-505.

44. Crombleholme TM, D'Alton M, Cendron M, Alman B, Goldberg MD, Klauber GT, et al. Prenatal diagnosis and the pediatric surgeon: the impact of prenatal consultation on perinatal management. J Pediatr Surg 1996;31:156-62.

45. Luks Fl, Carr SR, Feit LR, Rubin LP. Experience with a multidisciplinary antenatal diagnosis and management model in fetal medicine. J Matern Fetal Neonatal Med 2003;14:333-7.

46. Aite L, Trucchi A, Nahom A, Spina V, Bilancioni E, Bagolan P. Multidisciplinary management of fetal surgical abnormalities: the impact on maternal anxiety. Eur J Pediatr Surg 2002;12:90-4.

47. Kemp J, Davenport M, Pernet A. Antenatally diagnosed surgical abnormalities: the psychological effect of parental antenatal counseling. J Pediatr Surg 1998;33:1376-9.

48. Scher MS, Kidder BM, Shah D, Bangert BA, Judge NE. Pediatric neurology participation in a fetal diagnostic service. Pediatr Neurol 2004;30:338-44.

49. Sandelowski M, Jones LC. Healing fictions': stories of choosing in the aftermath of the detection of fetal abnormalities. Soc Sci Med 1996;42:353-61.

50. Bosma JM, van der Wal G, Hosman-Benjaminse SL. [Late pregnancy interruption in NoordHolland. II. Carefulness before and review afterwards] Late zwangerschapsafbreking in NoordHolland. II Zorgvuldigheid vooraf en toetsing achteraf. Ned Tijdschr Geneeskd 1996;140:605-9.

51. Ministry $H$. Late termination of pregnancy: care and assessment [Late zwangerschapsafbreking: zorgvuldigheid en toetsing]. Rijswijk, The Netherlands: Ministry of Health, Ministry of Justice, 1998.

52. NVOG [Model Reglement Medisch Handelen Late Zwangerschapsafbreking bij niet met het leven verenigbare afwijkingen vallend onder categorie 1; versie dd 221003], 2003.

53. Grevengood C, Shulman LP, Dungan JS, Martens P, Phillips OP, Emerson DS, et al. Severity of abnormality influences decision to terminate pregnancies affected with fetal neural tube defects. Fetal Diagn Ther 1994;9:273-7.

54. Pryde PG, Isada NB, Hallak M, Johnson MP, Odgers AE, Evans MI, Determinants of parental decision to abort or continue after non-aneuploid ultrasound-detected fetal abnormalities.

Obstet Gynecol 1992;80:52-6.

55. Sheiner E, Shoham-Vardi I, Weitzman D, Gohar J, Carmi R. Decisions regarding pregnancy termination among Bedouin couples referred to third level ultrasound clinic. Eur J Obstet Gynecol Reprod Biol 1998;76:141-6. 
56. Schechtman KB, Gray DL, Baty JD, Rothman SM. Decision-making for termination of pregnancies with fetal abnormalities: analysis of 53,000 pregnancies. Obstet Gynecol 2002;99:216-22. 


\section{Decision-making \\ by \\ physicians}





\section{Chapter 2}

\section{Ultrasound diagnosis of fetal abnormalities: an analysis of perinatal management of 318 consecutive pregnancies in a multidisciplinary setting}

H.H.Bijma, E.M.Schoonderwaldt, A.van der Heide, H.I.J.Wildschut, P.J.van der Maas, J.W.Wladimiroff Prenatal Diagnosis 2004;24:890-5. 


\section{Abstract}

Objectives

The objectives of this study are to analyse the perinatal management decisions made in a multidisciplinary setting following the prenatal diagnosis of fetal abnormalities and to evaluate to what extent, in clinical practice, decisions about obstetric management are attuned to those about neonatal management.

Methods

Data on perinatal management of 318 consecutive singleton pregnancies presented to a multidisciplinary perinatal team in a tertiary centre were collected retrospectively.

Results

The multidisciplinary perinatal team decided upon non-aggressive obstetric management in $20 \%$ of the cases and consented to termination of pregnancy in $10 \%$ of the cases. The multidisciplinary perinatal team decided upon neonatal management in $112(36 \%)$ of all fetuses. In $100(89 \%)$ of these fetuses standard neonatal management and in $12(11 \%)$ no neonatal lifesustaining treatment was decided upon. Implementation of the clinical-ethical decisions of the multidisciplinary perinatal team on the various management modalities ranged from $88 \%$ to $100 \%$.

\section{Conclusion}

The multidisciplinary perinatal team worked well in making decisions about obstetric management. In 30\% this concerned end-of-life-decisions. However, for the majority of cases, the perinatal team did not plan neonatal management before birth and thereby did not attune obstetric and neonatal management to each other. This probably reflects different attitudes towards end-of-life-decisions between obstetricians and neonatologists. However, to ensure a consistent perinatal management, a multidisciplinary perinatal team has to make prenatal decisions about both obstetric and neonatal management 


\section{Introduction}

The increasing possibilities of prenatal diagnosis confront us with raise important questions concerning medical management during pregnancy, delivery and the neonatal period. In case of a poor fetal prognosis, the appropriateness of interventions aimed at sustaining life can be questioned. ${ }^{1-4}$ Ethical aspects, diagnostic uncertainty, limited time and the involvement of parents whose future will be deeply affected by the decisions taken, complicate planning of perinatal management. ${ }^{5-7}$ As both obstetric and neonatal interventions affect outcome,often a multidisciplinary approach is widely adopted. ${ }^{7-12}$ However, different perspectives of the specialties involved may impede this process. ${ }^{13}$

To date, there are few studies evaluating to what extent, in clinical practice, obstetric and neonatal management are attuned to each other. Especially when end-of-life-decisions have to be taken, different attitudes of neonatologists and obstetricians may lead to inconsistencies in perinatal management. The objectives of this study are to analyse the perinatal management decisions made inclinical-ethical a multidisciplinary setting following the prenatal diagnosis of fetal abnormalities and to evaluate to what extent, in clinical practice, decisions about obstetric management are attuned to those about neonatal management.

\section{Patients and methods}

All singleton pregnancies scanned at the Fetal Medicine Unit of the Erasmus Medical Centre, University Hospital Rotterdam and presented to a multidisciplinary perinatal team between January 1996 and February 2001 were included. Obstetricians in the southwest region of the Netherlands refer women with a suspected fetal abnormality to the Fetal Medicine Unit for fetal abnormality scanning. Following the sonographic diagnosis of a fetal abnormality, the case is discussed by a team of physician-sonographers and obstetricians of the department of obstetrics and gynaecology to determine obstetric management. Subsequent referral to the multidisciplinary setting and inclusion in this study occurred for three reasons: (i) uncertainty about the diagnosis and/or prognosis; (ii) to discuss parental requests for pregnancy termination beyond 24 weeks of gestation which is the upper legal limit for pregnancy termination in the Netherlands; iii) when the infant is expected to be referred to the paediatric department after birth. The multidisciplinary perinatal team consists of medical specialists involved in perinatal care, such as obstetricians, neonatologists, paediatric surgeons, paediatric intensive care specialists, paediatric cardiologists, paediatric neurologists and clinical geneticists. Typically, decisions were made as follows: following the presentation of the case by a physician-sonographer, the multidisciplinary perinatal team establishes the diagnosis as well as the fetal prognosis. After discussing both the medical and ethical aspects, the perinatal team makes a decision about obstetric management, neonatal management and whether or not the infant should be delivered in a tertiary centre. Decision-making is based on both scientific evidence and clinical experience. End-of-life-decisions are made in accordance with national guidelines. ${ }^{14-16}$

A non-aggressive obstetric management or a termination of pregnancy after 24 weeks is only considered when the abnormalities are incompatible with life or for which the use of postnatal life-prolonging treatment is futile. In these cases, termination of pregnancy is only considered if requested for by the parents. Generally, decisions are as much as possible made in accordance with parental preferences. For the obstetric part of perinatal management three options are considered: standard management, non-aggressive management or termination of pregnancy. Standard management is defined as management aimed at the delivery of an infant in good physical condition and non-aggressive management as management in which not all interventions needed to sustain fetal life are made, because of poor fetal prognosis. For the neonatal part of perinatal management two options are considered: standard management or no life-sustaining treatment.

Retrospective collection of data was carried out by a physician (HB) experienced in prenatal care, who was not clinically involved in any of the cases. Ultrasound reports, minutes of multidisciplinary perinatal meetings as well as obstetric and paediatric records were reviewed. The nature of the decisions on perinatal management and the subsequent adherence to these decisions were studied. Fetal prognosis was assessed by expert opinions. 
Two physicians (HB and HW) experienced in prenatal diagnosis classified the prognosis for all cases according to an adapted version of the classification system of the Working Party on Late Pregnancy Termination in the Netherlands. ${ }^{14}$

Fetal prognosis was classified as poor, good or uncertain. A fetus with a lethal abnormality or with a non-lethal but severely disabling abnormality was classified as having a poor prognosis. A prognosis was classified as uncertain when at least one of the experts was not able to categorise the fetal abnormality as poor or good or when there was a disagreement between both experts on fetal prognosis. A close inter-observer-agreement was found (percentage of agreement $90 \%$, kappa $=0.78){ }^{17}$

\section{Results}

A total of 318 consecutive singleton pregnancies was included. Five cases were excluded from the analysis, because relevant data were not available.

Mean maternal age was 30.2 years (sd 5.4 years) and mean gestational age at the time of the first fetal abnormality scan was 28.4 weeks (range 12.6-40.0 weeks). In 225(72\%) women, gestational age was more than 24 weeks. Fetal karyotyping was performed in $281(90 \%)$ women, the results of which were known at the time of the multidisciplinary perinatal meeting in $166(56 \%)$ women. An abnormal karyotype was found in 17 fetuses. All karyotypes that were not yet known at the time of the perinatal meeting turned out to be normal.

Table 1. Management decision (in number and percentage) by prognosis of fetal abnormality

\begin{tabular}{|c|c|c|c|c|c|}
\hline & $\begin{array}{c}\text { Prognosis } \\
\text { Poor } \\
n=81\end{array}$ & $\begin{array}{c}\text { Good } \\
n=168\end{array}$ & $\begin{array}{c}\text { Uncertain } \\
n=64\end{array}$ & & 313 \\
\hline $\begin{array}{l}\text { Standard management } \\
\text { Non-aggressive } \\
\text { Termination of pregnancy } \\
\text { Other }\end{array}$ & $\begin{array}{ll}2 & (26 \% \\
3 & (46 \% \\
2 & (25 \% \\
3 & (4 \%)\end{array}$ & $\begin{array}{rr}15 & (93 \% \\
8 & (5 \%) \\
2 & (1 \%) \\
1 & (1 \%)\end{array}$ & $\begin{array}{ll}3 & (50 \% \\
1 & (30 \% \\
1 & (16 \% \\
3 & (5 \%)\end{array}$ & $\begin{array}{r}21 \\
64 \\
32 \\
7\end{array}$ & $\begin{array}{l}(67 \% \\
(20 \% \\
(10 \% \\
(2 \%)\end{array}$ \\
\hline
\end{tabular}

Table 1 shows the relationship between fetal prognosis and obstetric management as decided upon by the multidisciplinary perinatal team. Obstetric management was aimed at sustaining life in $210(67 \%)$ cases. In $96(30 \%)$ of the cases the multidisciplinary perinatal team decided upon pregnancy termination or non-aggressive obstetric management. In two cases, pregnancy classified as having a good fetal prognosis was terminated before 24 weeks, for reasons of respect for parental autonomy.

Table 2 and table 3 show obstetric and neonatal management as well as the place of delivery as advised by the multidisciplinary perinatal team. A non-aggressive approach was adopted in $26(32 \%)$ cases with multiple abnormalities and in $38(17 \%)$ cases with a single abnormality. Termination of pregnancy was decided upon in $18(22 \%)$ of the cases with multiple abnormalities and in 14(6\%) of the cases with single abnormalities. Within the group of fetuses with multiple abnormalities, when an abnormal karyotype was found, the multidisciplinary perinatal team never advised a standard obstetric management. When multiple abnormalities and a normal karyotype were found, standard obstetric management was advised in $22(54 \%)$ cases. In case of a single abnormality, the decision of the multidisciplinary perinatal team was related to the nature of the fetal abnormality. In case of intra-abdominal abnormality, abdominal wall defect, diaphragmatic hernia or lung abnormality, the multidisciplinary perinatal team usually advised a standard obstetric management. Finally, in instances of renal abnormality, intracranial abnormality, spina bifida, hydrocephalus or cardiac abnormality, standard obstetric management was advised in $22(73 \%), 13(62 \%), 8(47 \%), 6(35 \%)$ and $11(73 \%)$ cases respectively. 
Table 2. Management decisions (in number and percentage) are given according to karyotype result

\begin{tabular}{|c|c|c|c|c|c|c|c|c|}
\hline \multirow{2}{*}{ Obstetric management } & \multicolumn{8}{|c|}{ Multiple structural abnormalities } \\
\hline & \multicolumn{2}{|c|}{$\begin{array}{c}\text { Normal } \\
\text { karyotype } \\
n=41\end{array}$} & \multicolumn{2}{|c|}{$\begin{array}{c}\text { Abnormal } \\
\text { karyotype } \\
n=13\end{array}$} & \multicolumn{2}{|c|}{$\begin{array}{c}\text { Karyotype } \\
\text { unknown } \\
n=28\end{array}$} & \multicolumn{2}{|c|}{$\begin{array}{l}\text { Total } \\
n=82\end{array}$} \\
\hline $\begin{array}{l}\text { Standard management } \\
\text { Non-aggressive } \\
\text { Termination of pregnancy } \\
\text { Other }\end{array}$ & $\begin{array}{r}22 \\
13 \\
5 \\
1\end{array}$ & $\begin{array}{l}(54 \% \\
(32 \% \\
(12 \% \\
(2 \%)\end{array}$ & $\begin{array}{r}2 \\
11 \\
-\end{array}$ & $\begin{array}{l}(15 \%) \\
(85 \%) \\
-\end{array}$ & $\begin{array}{l}1 \\
1 \\
2 \\
2\end{array}$ & $\begin{array}{r}(46 \%) \\
(39 \%) \\
(7 \%) \\
(7 \%)\end{array}$ & 3 & $\begin{array}{l}(43 \%) \\
(32 \% \\
(22 \% \\
(4 \%)\end{array}$ \\
\hline $\begin{array}{l}\text { Neonatal management } \\
\text { Standard management } \\
\text { No life-sustaining } \\
\text { No decision }\end{array}$ & $\begin{array}{r}12 \\
3 \\
26\end{array}$ & $\begin{array}{l}(29 \%) \\
(7 \%) \\
(63 \%\end{array}$ & 15 & $\begin{array}{c}- \\
\overline{-} \\
(100 \%\end{array}$ & $\begin{array}{l}7 \\
2 \\
1\end{array}$ & $\begin{array}{r}(25 \%) \\
(7 \%) \\
(68 \%)\end{array}$ & 5 & $\begin{array}{l}(23 \%) \\
(6 \%) \\
(71 \%\end{array}$ \\
\hline $\begin{array}{l}\text { Hospital of delivery } \\
\text { Tertiary center } \\
\text { No tertiary center } \\
\text { No decision }\end{array}$ & $\begin{array}{r}27 \\
10 \\
4\end{array}$ & $\begin{array}{l}66 \% \\
(24 \% \\
(10 \%\end{array}$ & $\begin{array}{l}5 \\
5 \\
3\end{array}$ & $\begin{array}{l}(39 \%) \\
(39 \%) \\
(23 \%)\end{array}$ & $\begin{array}{l}1 \\
8 \\
2\end{array}$ & $\begin{array}{r}(64 \%) \\
(29 \%) \\
(7 \%)\end{array}$ & 9 & $\begin{array}{l}(61 \%) \\
(28 \% \\
(11 \%\end{array}$ \\
\hline
\end{tabular}

'Trisomy 18 (4), trisomy 13 (3), triploidy (3), trisomy 21 (1), monosomy 7 trisomy 10 (1),

46xy,ad(q)(p22) (1)

Table 3: see next page

Table 4. Actual obstetric management (in number and percentage) by planned obstetric management, actual neonatal management (in number and percentage) by planned neonatal management and actual hospital of delivery (in number and percentage) by planned hospital of delivery.

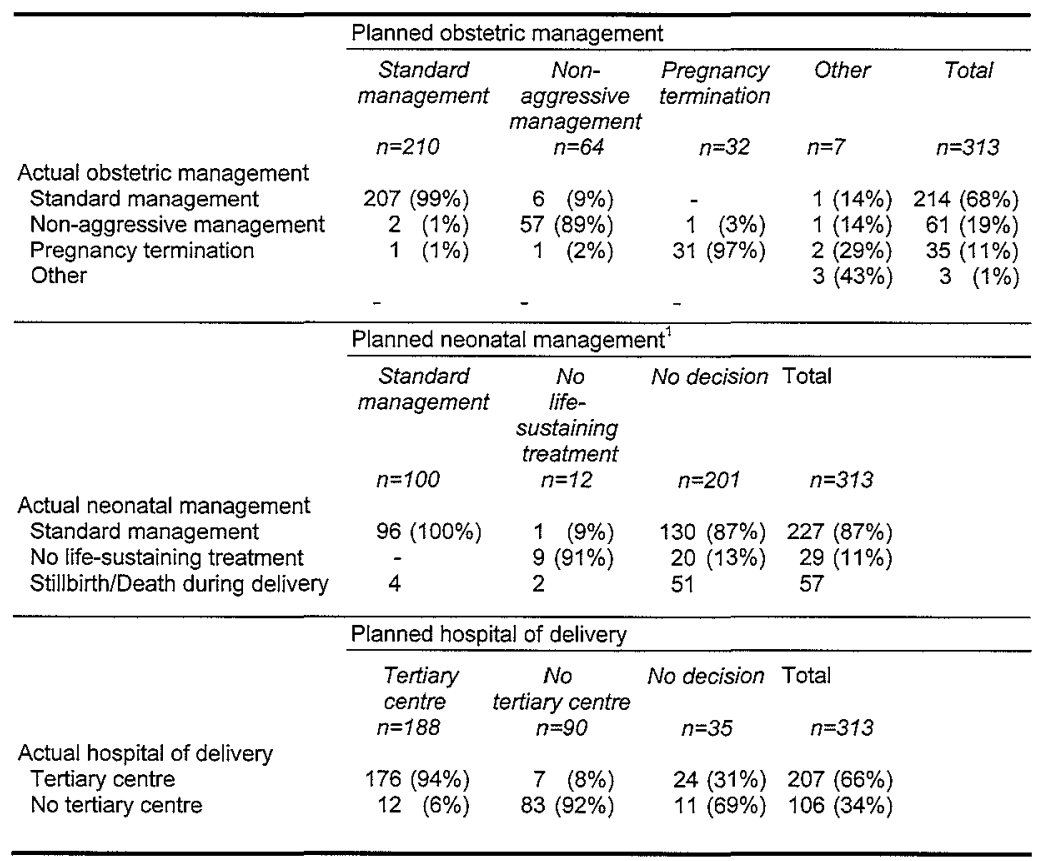

\footnotetext{
${ }^{1}$ Percentages of actual neonatal management were calculated after subtracting the infants that were not born aljve.
} 
Table 3. Management decisions (in number and percentage) in case of single structural abnormalities are given according to nature of the abnormality

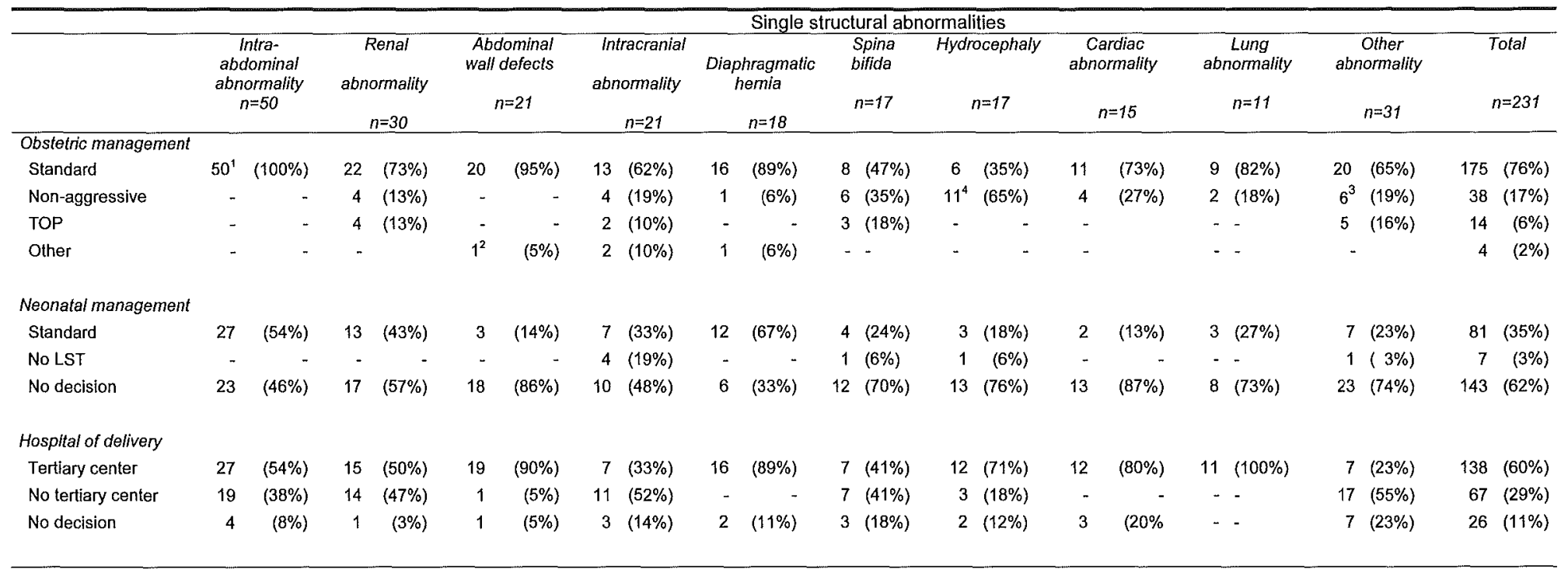

${ }^{1}$ Trisomy 21 in one case $;^{2}$ Trisomy $18 ;{ }^{3}$ trisomy 21 in one case ${ }_{+}^{4}$ balanced translocation $(13 ; 14)$ in one case; TOP: termination of pregnancy, LST: life-sustaining treatment 
Table 4 shows agreement between planned and actual perinatal management. Neonatal management was planned prenatally in $112(36 \%)$ cases. If planned prenatally, neonatal management was aimed at sustaining life in $100(89 \%)$ cases. If the 32 cases in which pregnancy termination was decided upon are disregarded, neonatal management was planned prenatally in $110 / 281(61 \%)$ of the fetuses and was aimed at sustaining fetal life in $100 / 110(91 \%)$. If one disregards the cases in which pregnancy termination was decided upon, obstetric management was aimed at sustaining life in $210 / 281(75 \%)$ of the fetuses. Implementation of the decision of the multidisciplinary perinatal team regarding the various management modalities ranged between $88 \%$ and $100 \%$.

Outcome one week after delivery was known for 312 infants. Twelve $(4 \%)$ pregnancies ended in stillbirth, $45(14 \%)$ infants died during delivery (28 as result of termination of pregnancy), 59(19\%) died in the first week of life ( 8 after termination of pregnancy). A total of $196(63 \%)$ infants was alive one week after delivery.

\section{Discussion}

Limited time and lack of diagnostic information, such as fetal karyotype and therefore prognosis, often complicated the process of perinatal management in the presence of single or multiple fetal abnormalities. In $10 \%$ of all cases the multidisciplinary perinatal team consented to pregnancy termination. In $20 \%$ of all cases the multidisciplinary perinatal team advised a non-aggressive obstetric management. In case of poor fetal prognosis the multidisciplinary perinatal team decided upon non-aggressive obstetric management in $46 \%$ of the cases and consented to parental request for termination of pregnancy in $25 \%$ of the cases. The multidisciplinary perinatal team more often decided to limit obstetric intervention aimed at sustaining fetal life in case of multiple abnormalities and in case of specific 1single abnormalities, such as central nervous, neural tube and renal abnormalities, as described by others. ${ }^{1,18-20}$

Neonatal management was planned prenatally only in $36 \%$ of the cases. If planned prenatally, neonatal management was aimed at sustaining the infant's life in $89 \%$, whereas prenatally planned obstetric management was aimed at sustaining fetal life in $67 \%$. If one disregards the cases in which termination of pregnancy was consented to, neonatal management was aimed at sustaining life in $91 \%$ and obstetric management in $75 \%$ of the cases. So, with or without taking into account termination of pregnancy, in case of prenatally detected fetal abnormalities, neonatal management was less often planned in advance than obstetric management and, if planned, was more often directed towards sustaining life. Different perspectives of obstetricians andchildcare specialists neonatologists might account for these differences. Firstly, the prognosis of a specific abnormality might be perceived differently. Neonatologists meet encounterthe infants whichinfants who at least survived until after birth, whereas obstetricians generally seesee a population with a worse prognosis. ${ }^{21-22}$ Secondly, uncertainty of ultrasound diagnosis is probably perceived differently. Whereas for an the obstetrician ultrasound usually provides a considerable amount of information otherwise not available, for a childcare specialist the neonatologist, diagnostic possibilities of prenatal ultrasound are rather limited compared to diagnostic possibilities after delivery. Thus, it might be that a specific diagnosis is perceived as more certain by the obstetrician than by the childcare specialistthe obstetrician perceives a specific diagnosis and its prognosis with more certainty than the neonatologist. Furthermore, there may be a discussion over whose best interests should be primarily served, the mother's' or the infant's.. For the obstetrician, the pregnant womans woman's' beneficience well-being might be paramount, whereas the childcare specialistneonatologist will tend to focus on the neonate. ${ }^{13}$

Further, consequences of refraining from medical interventions are more tangible for the childcare specialistneonatologist than for the obstetrician. In case of (complete) non-aggressive obstetric management the infant is not monitored and the obstetrician will not be confronted with signs of fetal distress. However, the childcare specialistneonatologist may be confronted with a live child in distress with a need for either therapeutic intervention or comfort care. Our data probably reflect differences between obstetricians and child care specialistneonatologists, resulting in a tendency of childcare specialistneonatologists to give a fetus the benefit of the doubt and to postpone clinical decisions until after birth. However, both obstetric and neonatal 
management affect the infant's well-being and they should be considered together in order not to worsen outcome, such as may occur when obstetrician labour-induced hypoxic damage is superimposed upon the initial problem, leading to severe disability.

The actual perinatal management usually wawas in accordance with the decision of the multidisciplinary perinatal team, indicating its importance for clinical practice. Our study has several limitations. Firstly, due to its retrospective nature, only the outcome of the multidisciplinary meeting could be studied, ignoring the process and the arguments that played a role. For future research we recommend that the decision making process in the multidisciplinary perinatal team is evaluated prospectively. Secondly, follow-up extended to one week after delivery and was assessed only as being alive or not. A more prolonged follow-up, including data on quality of life of the infant as well as experiences of the parents, is needed in order to further evaluate medical management. Thirdly, this study was done in one centre in the Netherlands, which may limit generalisation to other centres. However, in many perinatal centres end-of-life-decisions are taken in a multidisciplinary context. ${ }^{2,23,24}$

In the Netherlands there is a rather open societal and professional debate about end-of-life decision making, which is reflected in the accessibility of data on end-of-life-decisions in obstetric and neonatal records. Therefore, the Dutch setting provides the opportunity to evaluate differences between specialists which may remain undiscovered in settings where end-of-life-decisions are less widely accepted.

\section{Conclusion}

We have described the the clinical-ethical decisions on perinatal management of fetuses with one or more sonographically established fetal abnormalities as provided by a multidisciplinary perinatal team in a tertiary hospital setting. Planning perinatal management in case of ultrasound diagnosis of fetal abnormalities is often complicated by limited time and scarce diagnostic information Limited time and scarce diagnostic information often complicated planning perinatal management in case of ultrasound diagnosis of a fetal abnormality. The multidisciplinary perinatal team worked well in making decisions about obstetric management. In $30 \%$ this concerned end-of-life-decisions. However, for the majority of cases, the perinatal team did not plan neonatal management before birth and thereby did not attune obstetric and neonatal management to each other. This probably reflects different attitudes towards end-oflife-decisions between obstetricians and neonatologists. However, to ensure a consistent perinatal management, a multidisciplinary perinatal team has to make prenatal decisions about both obstetric and neonatal management. For clinical practice, this indicates the importance of a mutual understanding of the several specialities as well as the importance of joined decisionmaking.

\section{Acknowledgements}

We would like to thank all gynaecologists and paediatricians from the hospitals in the southwest region in the Netherlands for the provision of follow-up information for patients under their care. 


\section{References}

1. Chervenak, F.A. and L.B. McCullough, An ethically justified, clinically comprehensive management strategy for third-trimester pregnancies complicated by fetal anomalies. Obstet Gynecol, 1990.75:311-6.

2. Caniano, D.A. and F. Baylis, Ethical considerations in prenatal surgical consultation. Pediatr Surg Int, 1999.15:303-9.

3. Gross, M.L., Avoiding anomalous newborns: preemptive abortion, treatment thresholds and the case of baby Messenger. J Med Ethics, 2000:242-8.

4. Spinnato, J.A., et al., Aggressive intrapartum management of lethal fetal anomalies: beyond fetal beneficence. Obstet Gynecol, 1995.85:89-92.

5. Britt, D.W., et al., Devastation and relief: conflicting meanings of detected fetal anomalies. Ultrasound Obstet Gynecol, 2002. 20(1): 1-5.

6. Hunfeld, J.A., J.W. Wladimiroff, and J. Passchier, Pregnancy termination, perceived control, and perinatal grief. Psychol Rep, 1994.74:217-8.

7. Hoeldtke, N.J., Calhoun, B.C., Perinatal hospice. American Journal of Obstetrics and Gynecology, 2001.185:525-529.

8. Crombleholme, T.M., et al., Prenatal diagnosis and the pediatric surgeon: the impact of prenatal consultation on perinatal management. J Pediatr Surg, 1996. 31:156-62

9. Heling, K.S., et al., Fetal ovarian cysts: prenatal diagnosis, management and postnatal outcome. Ultrasound Obstet Gynecol, 2002.20:47-50.

10. Hedrick, H.L., et al., History of fetal diagnosis and therapy: Children's Hospital of Philadelphia experience. Fetal Diagn Ther, 2003.18:65-82.

11. Carpenter, M.W., F. Corrado, and J. Sung, Lethal fetal renal anomalies and obstetric outcome. Eur J Obstet Gynecol Reprod Biol, 2000.89:149-52.

12. Mirlesse, $V$., et al., Perinatal management of fetal cardiac anomalies in a specialized obstetricpediatrics center. Am J Perinatol, 2001.18:363-71.

13. Lenard, G., Ethical problems in prenatal diagnosis: pediatric considerations. Brain Dev, 1995. 17 Suppl:44-7.

14. Wladimiroff, J., Nota Late Zwangerschapsafbreking; Report on Late termination of Pregnancy (official views and guidelines of the Dutch Association of Gynecology and Obstetrics). 1994: Utrecht.

15. Dutch Paediatric Society, To do or not to do? Boundaries of Medical Action in Neonatology [Doen of laten. Grenzen van het medisch handelen in de neonatologie]. 1992, Nederlandse Vereniging voor Kindergeneeskunde: Utrecht.

16. Collaboration group 'Prudent medical practice regarding newborn's end-of-life' Auditing as mirror of medical practice [Toetsing als spiegel van de medische praktijk]. 1997: Rijswijk, The Netherlands.

17. Landis, J.R. and G.G. Koch, The measurement of observer agreement for categorical data. Biometrics, 1977, 33:159-74.

18. Drugan, A., et al., Determinants of parental decisions to abort for chromosome abnormalities. Prenatal Diagnosis, 1990.10:483-90.

19. Pryde, P., et al., Determinants of parental decision to abort or continue after non-aneuploid ultrasound-detected fetal abnormalities. Obstetrics \& Gynecology, 1992.80:263-273.

20. Hassed, S., et al., Perinatal lethal conditions: the effect of diagnosis on decision making. Obstetrics \& Gynecology, 1993. 82:37-42.

21. Allan, L.D., et al., Prospective diagnosis of 1,006 consecutive cases of congenital heart disease in the fetus. J Am Coll Cardiol, 1994. 23:1452-8.

22. Betremieux, P., et al., Perinatal management and outcome of prenatally diagnosed congenital diaphragmatic hernia: a 1995-2000 series in Rennes University Hospital. Prenat Diagn, 2002. 22:988-94.

23. Guillem, P., et al., Trends in elective terminations of pregnancy between 1989 and 2000 in a French county (the Isere). Prenat Diagn, 2003. 23:877-83.

24. Gagin, R., et al., The decision-making process for requests for late termination of pregnancy in Israel. Health Soc Work, 2001. 26:98-104. 



\section{Chapter 3}

\section{Obstetrician's agreement on fetal prognosis after ultrasound diagnosis of fetal abnormalities}

H.H.Bijma, H.I.J.Wildschut, A.van der Heide, P.J.van der Maas, J.W.Wladimiroff.

Prenatal Diagnosis 2004;24:713-8. 


\begin{abstract}
Introduction

After ultrasound diagnosis of a severe fetal abnormality is made, difficult decisions may arise regarding obstetric management. Guidelines have been developed to support obstetricians in decision-making. However, it is unknown to what extent in the clinical situation guidelines are actually supportive.

\section{Objectives}

We aimed at: i) determining whether obstetricians in the presence of a fetal abnormality are able to classify fetal prognosis according to guidelines; ii) establishing inter- and intra-observer agreement regarding fetal prognosis.
\end{abstract}

Methods

We used three categories of fetal prognosis: category 1: the infant has no chance of survival and the abnormalities cannot be treated (1.1); or the infant has a chance of extra-uterine survival but post-natal use of life-prolonging medical treatment is considered futile (1.2); category 2: the infant has a chance of extra-uterine survival and post-natal use of life-prolonging medical treatment, if necessary, is considered beneficiary. Five senior obstetricians categorized 100 case descriptions of severe fetal abnormalities, which were classified again after five months.

\title{
Results
}

Four obstetricians were able to classify $98 \%$ or more of cases. In $67 \%$ of cases, four or all obstetricians agreed on fetal prognosis. Overall kappa-coefficient was 0.48 (moderate agreement). The differences between obstetricians represented systematic differences in opinions on how to classify cases. Intra-observer agreement was $82-97 \%$.

\section{Conclusion}

Obstetricians were usually able to classify fetal prognosis according to guidelines, but in a substantial number of cases there was disagreement, reflecting systematic differences between obstetricians. 


\section{Introduction}

Whenever an ultrasound diagnosis of a severe fetal abnormality is made, difficult decisions may arise regarding obstetric management. In general, obstetric management involves applying all means to deliver the infant in the best possible condition. However, a 'non-aggressive' policy may be adopted when the prognosis is extremely poor. In that case all interventions that involve a risk for the mother and serve no benefit to the infant will be avoided. In exceptional cases termination of pregnancy may be considered because of parental wish in the case that prolongation of the pregnancy is considered not to be in the interest of the child. In many countries, the conditions under which termination of pregnancy is allowed are legally regulated. In the Netherlands, termination of pregnancy is permitted until 24 weeks of gestation. Termination beyond this gestational age has nevertheless been shown to occur, in the Netherlands as well as in other countries. ${ }^{1-4}$

Decisions about unborn infants with severe abnormalities have far-reaching consequences. They require a careful decision-making process, the quality of which is enhanced by the use of guidelines. ${ }^{5}$ For this purpose, several guidelines have been developed. ${ }^{6,7}$. However, it is unknown to what extent in the clinical situation guidelines are actually supportive. Furthermore, in making an informed decision, parents rely heavily on their obstetricians' views on fetal prognosis. Therefore, accurate and objective information about fetal prognosis and hence on the best obstetric management is of great importance. However, it is unknown whether obstetricians actually share their views on fetal prognosis. Therefore we aimed at: i) determining whether obstetricians in the presence of a fetal abnormality are able to classify fetal prognosis according to guidelines; ii) establishing inter- and intraobserver agreement regarding fetal prognosis.

\section{Methods}

In our Rotterdam tertiary referral centre for fetal abnormality scanning, women with an ultrasound diagnosis of one or several fetal abnormalities are discussed within a multidisciplinary team for several reasons: (i) there is uncertainty about the diagnosis and/or fetal prognosis; (ii) when the infant is expected to be referred to our hospital after birth; (iii) in case the woman requests termination of her pregnancy beyond 24 weeks of gestation. The multidisciplinary team consists of specialists in obstetric, neonatal and paediatric care. A random sample of 100 singleton pregnancies was drawn from all 313 patients with an ultrasound diagnosis of fetal abnormality who were presented to the multidisciplinary team between January 1996 and January 2001. The fetal karyotype was available in 50/100 fetuses, of which 6 were abnormal. $27 / 100$ fetuses displayed multiple structural abnormalities. Gestational age varied between 19.6 and 39.7 weeks (median: 32.5 weeks). Five senior obstetricians from five tertiary prenatal referral centres in the Netherlands were asked to classify these 100 cases. All obstetricians had more than five years of clinical experience in the field of fetal abnormality scanning. Obstetrician 4 classified the cases together with an equally experienced colleague from the same department.

For this study, we used the national guidelines of the Netherlands. In these guidelines a classification of fetal abnormalities is proposed which takes into account both the chance of survival and the chance that an acceptable quality of life will be achieved after birth. This non-standard approach of obstetric management is considered acceptable if there is either no chance of survival and no possibility to treat the abnormality (e.g., in case of anencephaly), or if the quality of life after birth will be unacceptably poor and treatment of the abnormality is either impossible or generally considered to be futile (e.g., in case of severe hydrocephaly). According to the Dutch national guidelines the following two categories could be defined (1.1 and 1.2) (see box 1) [8]: category 1: the infant has no chance of survival and the abnormalities cannot be treated (1.1); or the infant has a chance of extra-uterine survival but post-natal use of life-prolonging medical treatment is considered futile 
(1.2); category 2: the infant has a chance of extra-uterine survival and post-natal use of life-prolonging medical treatment, if necessary, is considered beneficiary. Classification by the five obstetricians was based on the description of the ultrasound findings, the fetal karyotype (if available) and gestational age (see box 2) No information about parental preferences was given. All obstetricians were asked to classify each case again five months later to determine the level of intra-observer agreement after all cases had been arranged in a new order.

Inter- and intra-observer agreement on whether cases were classified in category 1 (1.1 or 1.2 ) or category 2 was established by calculating the number of agreeing obstetricians per case and percentages of agreement between pairs of obstetricians. Kappa coefficients for pairs of obstetricians and an overall kappa coefficient were determined according to Landis and Koch[9]: slight agreement: 00.20 ; fair agreement: $0.21-0.40$, moderate agreement: $0.41-0.60$, substantial agreement: $0.61-0.80$ and almost perfect agreement: $0.81-1.0$. The Wilcoxon ranking test was used to establish whether variability in categorization resulted from random or systematic differences between obstetricians. Both kappa coefficients between pairs of obstetricians and the Wilcoxon ranking test were calculated using the Statistical Package for the Social Sciences, version 10.0. The overall kappa coefficient was calculated using Stata, version 7.0.

Box 1. Examples of the case descriptions as provided to the obstetricians. In the instruction it was explained that all structures that were not mentioned in the case description had a normal appearance on ultrasound.

\section{Case 33}

Lumbosacral spina bifida of 7-8 vertebrae. Club feet. Ventriculomegaly. Arnold-Chiari-malformation.

Gestational age $211 / 7$ weeks. Karyotype: unknown.

\section{Case 56}

Intra-uterine growth retardation, holoprosencephaly, micrognathy, hypotelorism, cleft lip. Heart: ventricular septal defect, overriding aorta. Gestational age 28 1/7 weeks. Karyotype: trisomy 13.

\section{Case 77}

Double bubble. Polyhydramnion. Gestational age $321 / 7$ weeks. Karyotype: normal.

Box 2. Definitions of the categories of classification of fetal prognosis.

\section{Category 1.1}

No chance of survival, the abnormalities can not be treated

This category includes fetal abnormalities, which are expected to inevitably lead to death during or immediately after delivery. In most cases, death will occur during or immediately after delivery, but exceptionally survival is somewhat longer.

Examples: severe lung hypoplasia, some severe and non-operable cardiac abnormalities, some skeletal dysplasias, bilateral renal agenesis, trisomy 13 , trisomy 18 , anencephaly.

Category 12

Chance of survival after delivery, but post-natal life-prolonging treatment is considered futile.

This category includes fetal abnormalities in the fetus, which lead to severe and non-treatable functional impairments. There is a (often limited) chance of survival. According to current medical opinion life-sustaining treatment after delivery will only prolong an existing situation, which is considered hopeless for the infant. Regarding the dismal prognosis, life-sustaining treatment can even be considered harmful.

Examples: very severe spina bifida, very severe hydrocephalus.

Category 2

Chance of survival after delivery and post-natal life-prolonging treatment after birth, if necessary is considered beneficiary.

This category includes abnormalities, which have a good chance of survival after birth. Neonatal life-sustaining treatment is either not necessary or, if necessary, is regarding the chance of survival and prognosis, considered beneficiary according to current medical opinion

Examples: isolated intra-abdominal cyst, unilateral hydronephrosis. 
prognosis was impossible $(n=4)$, or a combination of these reasons $(n=2)$. The number of cases that was classified as category 1 (no chance of survival or postnatal treatment is considered futile) ranged from 17 to 50 . Obstetricians 1,2 and 3 systematically classified cases more often as category 1 than obstetricians 4 and 5 (table 1).

Table 1. Categorization by the obstetricians

\begin{tabular}{|c|c|c|c|c|c|c|c|}
\hline & \multicolumn{5}{|c|}{ Obstetrician } & \multirow[b]{2}{*}{ Total } & \\
\hline & 1 & 2 & 3 & 4 & 5 & & \\
\hline & $n$ & $n$ & $\mathrm{n}$ & $n$ & $\mathrm{n}$ & & \\
\hline Category 1 & 50 & 43 & 33 & 17 & 28 & 171 & $34 \%$ \\
\hline Category 2 & 49 & 54 & 42 & 83 & 70 & 298 & $60 \%$ \\
\hline Could not be classified & 1 & 1 & 24 & & 2 & 2 & $6 \%$ \\
\hline Missing values & & 2 & 1 & & & 3 & \\
\hline
\end{tabular}

Wilcoxon ranking test comparing the classifications of the obstetricians: obstetricians tand $2: p=0.09$,

1 and $3: p=0.5,1$ and $4: p=0.00,1$ and $5: p=0.00,2$ and $3: 0.2,2$ and $4: p=0.00,2$ and $5: p=0.01$,

3 and $4: p=0.00,3$ and $5: p=0.02,4$ and $5: p=0.01$

Table 2 shows that the median percentage of cases for which pairs of obstetricians were in agreement was $76 \%$ (range $67 \%-93 \%$ ). The overall kappa coefficient was 0.48 (moderate agreement), while the kappa coefficients for pairs of obstetricians varied between 0.31 and 0.86 .

In $67 / 100(67 \%)$ cases there was agreement on the classification between four or all obstetricians (table 3 ). If a single structural abnormality was present $(n=73)$, in $51 / 73(69 \%)$ cases four or all obstetricians agreed on the fetal prognosis. In this subset, fetal prognosis was classified as category 1 in $13 / 51(25 \%)$ cases. This included five out of six cases of spina bifida and three out of six cases of hydrocephaly. In the cases representing an intra-abdominal cyst $(n=7)$, double bubble $(n=5)$, echodense kidneys $(n=2)$, gastroschizis $(n=2)$ or intestinal dilatation $(n=2)$, four or all obstetricians agreed that the fetal prognosis should be classified as category 2 (table 3 ). In the presence of multiple structural abnormalities $(n=27)$, in $16(59 \%)$ cases four or all obstetricians agreed on the fetal prognosis. In this subset, in $9 / 16(56 \%)$ cases fetal prognosis was classified as category 1 . In the four cases with multiple structural abnormalities associated with an abnormal karyotype (i.e. trisomy 13 or trisomy 18 ) four or all obstetricians agreed that fetal prognosis should be classified as category 1 .

In $82-97 \%$ of cases, the repeat classification was similar to the first classification (table 4). The median kappa coefficient between the first and repeat classification was 0.65 (range $0.64-0.93$ ).

\section{Discussion}

The sample of 100 cases, which was used to evaluate a classification schedule for fetal prognosis, was drawn from a population of complicated cases for which discussion within a multidisciplinary team of a tertiary referral centre was considered necessary. Nevertheless, information about ultrasound findings, gestational age and karyotype (if available) was in the majority of cases sufficient for four out of five senior obstetricians to classify them into one of two main prognostic categories. One obstetrician was not sure about the fetal prognosis in a significant number of cases. On average, the obstetricians classified $34 \%$ of the cases in category 1 , i.e. cases with abnormalities that are incompatible with life or for which the use of post-natal life-prolonging treatment is considered futile. This percentage is rather high due to the selection of cases. Since in the Netherlands no routine ultrasound is offered, ultrasound abnormalities are often not discovered until late in pregnancy or even after birth. ${ }^{10-12}$

In two thirds of the cases, most or all obstetricians were in agreement on the classification of fetal prognosis. On an individual level, the obstetricians were 
Table 2. Obstetricians' inter-observer agreement.

\begin{tabular}{|c|c|cc|}
\hline Obstetricians & $n$ & $p_{0}$ & Kappa \\
\hline $1-2$ & 96 & $82 \%$ & 0.65 \\
$1-3$ & 75 & $86 \%$ & 0.73 \\
$1-4$ & 99 & $67 \%$ & 0.34 \\
$1-5$ & 97 & $74 \%$ & 0.48 \\
$2-3$ & 73 & $93 \%$ & 0.86 \\
$2-4$ & 97 & $71 \%$ & 0.38 \\
$2-5$ & 95 & $72 \%$ & 0.40 \\
$3-4$ & 75 & $72 \%$ & 0.39 \\
$3-5$ & 73 & $75 \%$ & 0.47 \\
$4-5$ & 98 & $76 \%$ & 0.31 \\
\hline Median & & $76 \%$ & \\
\hline Overall kappa & & & 0.48 \\
\hline
\end{tabular}

$p_{0}$ :percentage of observed agreement

Table 3. Degree of agreement for the different abnormalities.

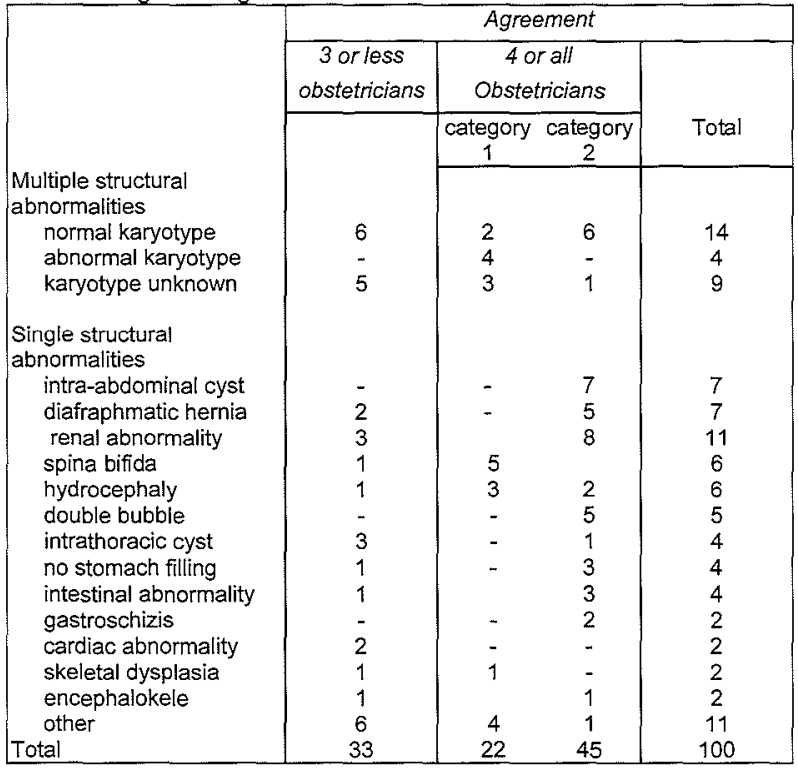

Table 4. Obstetricians' intra-observer agreement

\begin{tabular}{|l|c|cc|}
\hline Obstetrician & $n$ & $p_{0}$ & kappa \\
\hline 1 & 99 & $82 \%$ & 0.64 \\
2 & 97 & $91 \%$ & 0.81 \\
3 & 67 & $97 \%$ & 0.93 \\
4 & 99 & $89 \%$ & 0.65 \\
5 & 97 & $87 \%$ & 0.65 \\
\hline median & & $89 \%$ & 0.65 \\
\hline
\end{tabular}

po:percentage of observed agreement 
consistent in assessing fetal prognosis based on the information provided. The substantial intra-observer agreement that was found in this study indicates that the case descriptions were adequate and that the differences between obstetricians represented systematic differences in opinions on how to classify cases. Some obstetricians appeared to be more inclined to consider an extremely poor prognosis than others.

Several factors may account for these systematically disparate opinions on fetal prognosis. First of all, obstetricians may have interpreted some case descriptions, in particular the sonographic information, differently and may therefore have come to different conclusions about the diagnosis. Secondly, the distinction in two prognostic categories, as proposed in the Dutch national guidelines, is based upon the diagnosis and the possibility to treat abnormalities after birth. It may not be obvious in all cases whether or not post-natal treatment for a specific diagnosis is possible. ${ }^{13}$ For example, opinions may differ as to whether a hypoplastic left heart or a major spina bifida can be treated. Thirdly, the classification system used in this study relates to national guidelines for end-of-life-decisions in neonates, for which treatment is considered futile in case of no chance of survival or when the expected quality of life is extremely poor. ${ }^{14-16}$ Examples of poor quality of life are life-long dependency on intensive medical treatment, physical suffering (pain and dyspnoea) and lack of ability to communication with the environment. However, judgments of what quality of life is unacceptably poor may vary between obstetricians. Moreover, whereas any prognosis involves a degree of uncertainty, the level of uncertainty that is accepted with regard to classifying abnormalities as incompatible with life or for which the use of postnatal life-prolonging treatment is considered futile may differ amongst obstetricians. The finding that obstetricians especially disagreed on the fetal prognosis in the presence of multiple congenital abnormalities with a normal or unknown karyotype supports this. Obstetrician four remarked that in case of prognostic uncertainty, even in case of severe abnormalities, he/she would give the fetus the benefit of the doubt by classifying the prognosis as category 2 . The classification of obstetrician four may have been influenced by the fact that classification of all cases took place with another colleague.

It is not unlikely, that the obstetricians based their classification not only on the prognosis they thought to be most likely, but also on the type of obstetric management they thought was indicated. ${ }^{17}$ Our comments concerning the factors underlying differences in opinion concerning the appropriateness of neonatal treatment also hold for obstetric management. Rational decision-making and prevention of undesirable variability could be improved by aiming at an evidencebased evaluation of fetal diagnosis and prognosis, using data, which are as objective as possible. Furthermore, medical and moral factors should be clearly distinguished in the assessment of prognosis and in the choice of obstetric management. ${ }^{13,18-20}$

A number of other issues have to be taken into account when evaluating the results of this study. Firstly, this study was carried out in the Netherlands, where there is a rather open societal and professional debate about end-of-life decision making. ${ }^{21}$ As a result, Dutch obstetricians may be more familiar with the concept of futility of medical treatment and quality of life than most of their colleagues in other countries. Secondly, in clinical practice, the opinion of paediatric specialists is important in evaluating fetal prognosis as well. ${ }^{22-24}$ Finally, the views of parents are obviously very important in end-of-life decision-making.

In conclusion, our study shows that obstetricians are usually able to classify fetal abnormalities into prognostic categories. However, we found systematic differences between the obstetricians' classifications, which may be explained by different interpretations of the ultrasound findings, different attitudes towards the acceptability of poor levels of quality of life, and different attitudes towards diagnostic uncertainty. Differences in the classification of fetal prognosis between obstetricians may result in differences in obstetric management between obstetric centres. 
Rational decision-making and prevention of undesirable variability could be improved by aiming at an evidence-based evaluation of fetal diagnosis and prognosis, using data, which are as objective as possible. Furthermore, medical and moral factors should be clearly distinguished in the assessment of prognosis and in the choice of obstetric management. Finally, possibilities of neonatal treatment and its consequences for survival and quality of life should be taken into account before deciding on obstetric management.

\section{Acknowledgement}

The authors would like to thank P.P. van den Berg (UMC St Radboud, University Hospital Nijmegen), C.M.. Bilardo (AMC, University Hospital Amsterdam), G.C.M.L.Christiaens (UMC, University Hospital Utrecht), P. Stoutenbeek (UMC, University Hospital Utrecht) E.A.P. Steegers (Erasmus MC, University Hospital Rotterdam) and F.P.H.A. Vandenbussche (LUMC, University Hospital Leiden) for their valuable contribution to this study. 


\section{References}

1. Brahams, D., Judicial warning on very late abortions. Lancet, 1990. 335:464.

2. Gagin, R., et al., The decision-making process for requests for late termination of pregnancy in Israel. Health Soc Work, 2001. 26:98-104.

3. Gevers, S., Late termination of pregnancy in cases of severe abnormalities in the fetus. Med Law, 1998. 17:83-92.

4. Guillem, P., et al., Trends in elective terminations of pregnancy between 1989 and 2000 in a French county (the Isere). Prenat Diagn, 2003. 23:877-83.

5. Woolf, S.H., et al., Clinical guidelines: potential benefits, limitations, and harms of clinical guidelines. Bmj, 1999. 318:527-30.

6. Chervenak, F.A., et al., Ethical issues in the management of pregnancies complicated by fetal anomalies. Obstet Gynecol Surv, 2003. 58:473-83.

7. Wladimiroff, J., Nota Late Zwangerschapsafbreking; Report on Late termination of Pregnancy (official views and guidelines of the Dutch Association of Gynecology and Obstetrics). 1994: Utrecht.

8. Ministry, H., Late termination of pregnancy: care and assessment [Late zwangerschapsafbreking: zorgvuldigheid en toetsing]. 1998, Ministry of Health, Ministry of Justice: Rijswijk, The Netherlands.

9. Landis, J.R. and G.G. Koch, The measurement of observer agreement for categorical data. Biometrics, 1977. 33:159-74.

10. Stoll, C., R. Tenconi, and M. Clementi, Detection of Congenital Anomalies by Fetal Ultrasonographic Examination across Europe. Community Genet, 2001. 4:225-232.

11. Stoll, C., E. Garne, and M. Clementi, Evaluation of prenatal diagnosis of associated congenital heart diseases by fetal ultrasonographic examination in Europe. Prenat Diagn, 2001. 21:24352.

12. Olde Scholtenhuis, M.A., et al., Audit of prenatal and postnatal diagnosis of isolated open spina bifida in three university hospitals in The Netherlands. Ultrasound Obstet Gynecol, 2003. 21:48-52.

13. Lofmark, R. and T. Nilstun, Conditions and consequences of medical futility--from a literature review to a clinical model. J Med Ethics, 2002. 28:115-9.

14. Dutch Paediatric Society, To do or not to do? Boundaries of Medical Action in Neonatology [Doen of laten. Grenzen van het medisch handelen in de neonatologie]. 1992, Nederlandse Vereniging voor Kindergeneeskunde: Utrecht.

15. Versluys, $Z$. and $R$. de Leeuw, A Dutch report on the ethics of neonatal care, J Med Ethics. 1995. 14-6.

16. Dutch, S.P., To do or not to do? Boundaries of Medical Action in Neonatology [Doen of laten. Grenzen van het medisch handelen in de neonatologie]. 1992, Nederlandse Vereniging voor Kindergeneeskunde: Utrecht.

17. Molewijk, A.C., et al., Implicit normativity in evidence-based medicine: a plea for integrated empirical ethics research. Health Care Anal. 2003. 69-92.

18. Pellegrino, E.D., The anatomy of clinical-ethical judgments in perinatology and neonatology: a substantive and procedural framework. Semin Perinatol, 1987. 11:202-9.

19. Chervenak, F.A. and L.B. McCullough, An ethically justified, clinically comprehensive management strategy for third-trimester pregnancies complicated by fetal anomalies. Obstet Gynecol, 1990. 75: 311-6.

20. Grundstein-Amado, R., An integrative model of clinical-ethical decision making. Theoretical Medicine, 1991. 12:157-70.

21. Onwuteaka-Philipsen, B.D., et al., Euthanasia and other end-of-life decisions in the Netherlands in 1990,1995, and 2001. Lancet, 2003. 362:395-9.

22. Mirlesse, $V_{\text {. }}$ et al., Perinatal management of fetal cardiac anomalies in a specialized obstetricpediatrics center. Am J Perinatol, 2001. 18:363-71.

23. Caniano, D.A. and F. Baylis, Ethical considerations in prenatal surgical consultation. Pediatr Surg Int, 1999. 15:303-9.

24. Dibbins, A.W., M.R. Curci, and D.J. McCrann, Jr., Prenatal diagnosis of congenital anomalies requiring surgical correction. Implications for the future. Am J Surg, 1985. 149:528-33. 



\section{Chapter 4}

\section{Survival after non-aggressive obstetric management in cases of severe fetal abnormalities}

H.H.Bijma, A.van der Heide, H.I.J. Wildschut, S.van de Vathorst,

D.Tibboel, J.W.Wladimiroff, P.J. van der Maas.

British Journal Obstetrics Gynaecology 2005;112:1630-5. 


\begin{abstract}
Objective

Obstetricians may choose to refrain from interventions aimed at sustaining fetal life, (i.e., non-aggressive obstetric management) in some cases of extremely poor fetal prognosis. But as this approach does not always result in the death of the infant during delivery, neonatal management must now be considered.

We sought to provide empiric data concerning such perinatal end-of-life decisions. Firstly, to describe survival during delivery and after birth following nonaggressive obstetric management in pregnancies complicated by severe fetal anomalies. Secondly, to describe neonatal management in the live-born infants with severe anomalies.
\end{abstract}

Design

Retrospective descriptive study.

Setting

Tertiary centre.

Population

Eighty consecutive cases that were managed non-aggressively after the diagnosis of a severe fetal anomaly.

Methods

Data were collected from obstetric and neonatal records, as well as ultrasound reports.

Main outcome measures

Survival, neonatal management and health status after birth.

Results

Relevant data were available for $78 / 80(98 \%)$ infants. Six ( $8 \%)$ infants died in utero, $16(21 \%)$ died during delivery (11 from cephalocentesis), and $56(72 \%)$ were born alive. In $29(52 \%)$ of the live-born infants, life-sustaining neonatal treatment was initiated. Twenty three of $29(79 \%)$ infants died within 6 months of birth in case neonatal life-sustaining treatment was initiated, compared with $25 / 27(93 \%$ ) who did not receive neonatal life-sustaining treatment. Eight infants survived; each was profoundly handicapped.

Conclusion

Life sustaining neonatal support after non-aggressive obstetric management in case of severe fetal malformations has little to no beneficial impact on survival. 


\section{Introduction}

The ultrasound diagnosis of a fetal anomaly with a poor prognosis provokes questions about future obstetric management. For example, caesarean delivery seems inappropriate for a lethal anomaly since it does not convey any benefit to the fetus whilst it is associated with iatrogenic maternal morbidity ${ }^{1}$. Here, the obstetrician may refrain from obstetric interventions. Such management, referred to as nonaggressive obstetric management, may result in the birth of a live infant. In this situation, prenatal management may have impaired the child's condition at birth. Furthermore, the birth of a live infant mandates a decision as to whether or not initiate life-sustaining neonatal treatment.

The debate on non-aggressive obstetric management so far has has centred around the ethical aspects. ${ }^{1-3}$ Chervenak argued that non-aggressive obstetric management is acceptable when there is (1) a very high probability of the diagnosis and either (2a) a very high probability of death or (2b) survival with a very high probability of severe and irreversible deficit of cognitive developmental

Capacity. ${ }^{4}$ However, clinical information about the sequelae of non-aggressive obstetric management is scarce. It is reported that some infants are born alive after non-aggressive obstetric management, but information on outcome is lacking ${ }^{2,3}$. The objective of the present study is to provide such information as a guide to the validity of this practice.

\section{Methods}

The Erasmus $M C$ is the largest tertiary referral centre for fetal anomaly scanning in the Netherlands, serving 3.5 million inhabitants and 35000 newborns/year. Between December 1995 and January 2003 consecutive women receiving nonaggressive obstetric management after the diagnosis of a severe fetal malformation were included. Cases are typically discussed after the ultrasound diagnosis by a multidisciplinary perinatal team consisting of obstetricians, neonatologists, paediatric surgeons and organ specialists, such as paediatric neurosurgeons, paediatric neurologists, paediatrics cardiologists and paediatric urologists. The multidisciplinary perinatal team, meeting weekly, decides as a team on obstetric and neonatal management. Non-aggressive obstetric management is defined as management in which obstetric interventions aimed at sustaining fetal life are partially or completely refrained from. Generally, such management is adopted when: i) the fetus has no chance of survival (i.e. certain death, mostly perinatal but in exceptional cases the child may reach the age of one year) or ii) the anomaly has some chance of survival, but health status is expected to be so severely affected that neonatal treatment is considered futile and in some cases even harmful. Families were counselled, and standard obstetric management adopted if the parents objected to a non-aggressive obstetric management. We obtained permission from the Ethics Committee of our hospital for this study.

Infants were included if: i) a fetal anomaly was diagnosed by ultrasound and ii) nonaggressive obstetric management was adopted. The minutes of the multidisciplinary perinatal team were used to establish which fetuses were selected for nonaggressive obstetric management. A physician (HB) experienced in prenatal diagnosis, but not involved in the clinical management collected the data retrospectively from obstetric and neonatal records, as well as ultrasound reports. In case the woman delivered in another hospital, relevant data were requested from the obstetric, neonatal and paediatric departments of the delivering hospital. Data points included survival in utero, during delivery, and during the neonatal and post-neonatal period. Furthermore, we evaluated whether or not neonatal life-sustaining treatment was initiated for live-born infants, as well as the perinatal characteristics. Finally, we 

six months.

Table 1. Diagnostic characteristics in fetuses for whom a non-aggresive obstetric management was adopted.

\begin{tabular}{|c|c|c|c|}
\hline \multirow[t]{2}{*}{ Fetal abnormality } & $\begin{array}{l}\text { No chance of } \\
\text { survival }\end{array}$ & $\begin{array}{l}\text { Some chance of } \\
\text { survival, but with } \\
\text { severely affected } \\
\text { health status }\end{array}$ & \multirow[t]{2}{*}{ Total } \\
\hline & $n=14$ & $n=64$ & \\
\hline Intracranial abnormalities & 1 & 24 & $25(32 \%)$ \\
\hline Hydrocephaly & - & 15 & \\
\hline Encephalocele & - & 2 & \\
\hline Vein of Galen malformation & - & 1 & \\
\hline Hydranencephaly & 1 & - & \\
\hline Arterio-venous malformation & - & 1 & \\
\hline Holoprosencephaly & - & 2 & \\
\hline Multiple intracranial abnormalities & - & 3 & \\
\hline Multiple structural abnormalities(1) & - & 15 & $15(19 \%)$ \\
\hline 2 abnormalities & - & 4 & \\
\hline 3 abnormalities & - & 8 & \\
\hline 4 abnormalities & - & 2 & \\
\hline 5 abnormalities & $=$ & 1 & \\
\hline Chromosomal abnormalities & 8 & - & $8(10 \%)$ \\
\hline Trisomy 18 & 4 & - & \\
\hline Trisomy 13 & 1 & - & \\
\hline Trisomy 21 thydrops fetalis & 1 & - & \\
\hline Trisomy 22 & 1 & - & \\
\hline Monosomy 7 trisomy 10 & 1 & - & \\
\hline Spina bifida & - & 6 & $6 \quad(8 \%)$ \\
\hline Bilateral kidney abnormality & - & 6 & $6 \quad(8 \%)$ \\
\hline Cardiac abnormality & - & 6 & $6 \quad(8 \%)$ \\
\hline Skeletal dysplasia & 2 & 2 & $4(5 \%)$ \\
\hline $\begin{array}{l}\text { Osteogenesis imperfecta type /I } \\
\text { Jeune syndrome }\end{array}$ & $\begin{array}{l}2 \\
- \\
\end{array}$ & $\overline{2}$ & \\
\hline Fetal akinesia syndrome & 3 & - & $3 \quad(4 \%)$ \\
\hline Other & - & 5 & $5 \quad(6 \%)$ \\
\hline CCAML & - & 2 & \\
\hline Fetal hypokinesiathydrops fetalis & - & 1 & \\
\hline Congenital rubella infection & - & 1 & \\
\hline Diaphragmatic hemia & - & 1 & \\
\hline
\end{tabular}

Table 2. Survival in utero, during delivery and after birth of infants with sonographically diagnosed severe fetal abnormalities in case of a non-aggressive obstetric management with and without neonatal life-sustaining treatment

\begin{tabular}{l} 
Survival \\
\hline $\mathrm{n}=78$ \\
\hline Stillbirth \\
Death during delivery \\
Death within 24 hours after birth \\
Death within first week after birth \\
Death within six months after birth \\
Alive after six months after birth \\
\hline NA:
\end{tabular}

\begin{tabular}{|c|c|c|}
\hline & \multicolumn{2}{|c|}{$\begin{array}{c}\text { Neonatal treatment } \\
\text { initiated }\end{array}$} \\
\hline & withdrawn & continued \\
\hline$n=22$ & $n=21$ & $n=8$ \\
\hline 6 & NA & NA \\
\hline \multirow[t]{5}{*}{16} & NA & NA \\
\hline & 4 & 1 \\
\hline & 11 & 2 \\
\hline & 5 & 0 \\
\hline & 1 & 5 \\
\hline
\end{tabular}

\begin{tabular}{c}
$\begin{array}{c}\text { Neonatal } \\
\text { not initiated }\end{array}$ \\
\hline $\mathrm{n}=27$ \\
\hline NA \\
NA \\
19 \\
4 \\
2 \\
2 \\
\hline
\end{tabular}

Total

\begin{tabular}{rr}
\hline \multicolumn{2}{c}{$n=78$} \\
\hline 6 & $(8 \%)$ \\
16 & $(21 \%)$ \\
24 & $(31 \%)$ \\
17 & $(22 \%)$ \\
7 & $(9 \%)$ \\
8 & $(12 \%)$
\end{tabular}
NA: not applicable 
Figure 1. Survival of infants with sonographically diagnosed severe fetal abnormalities in case of a nonaggressive obstetric management.

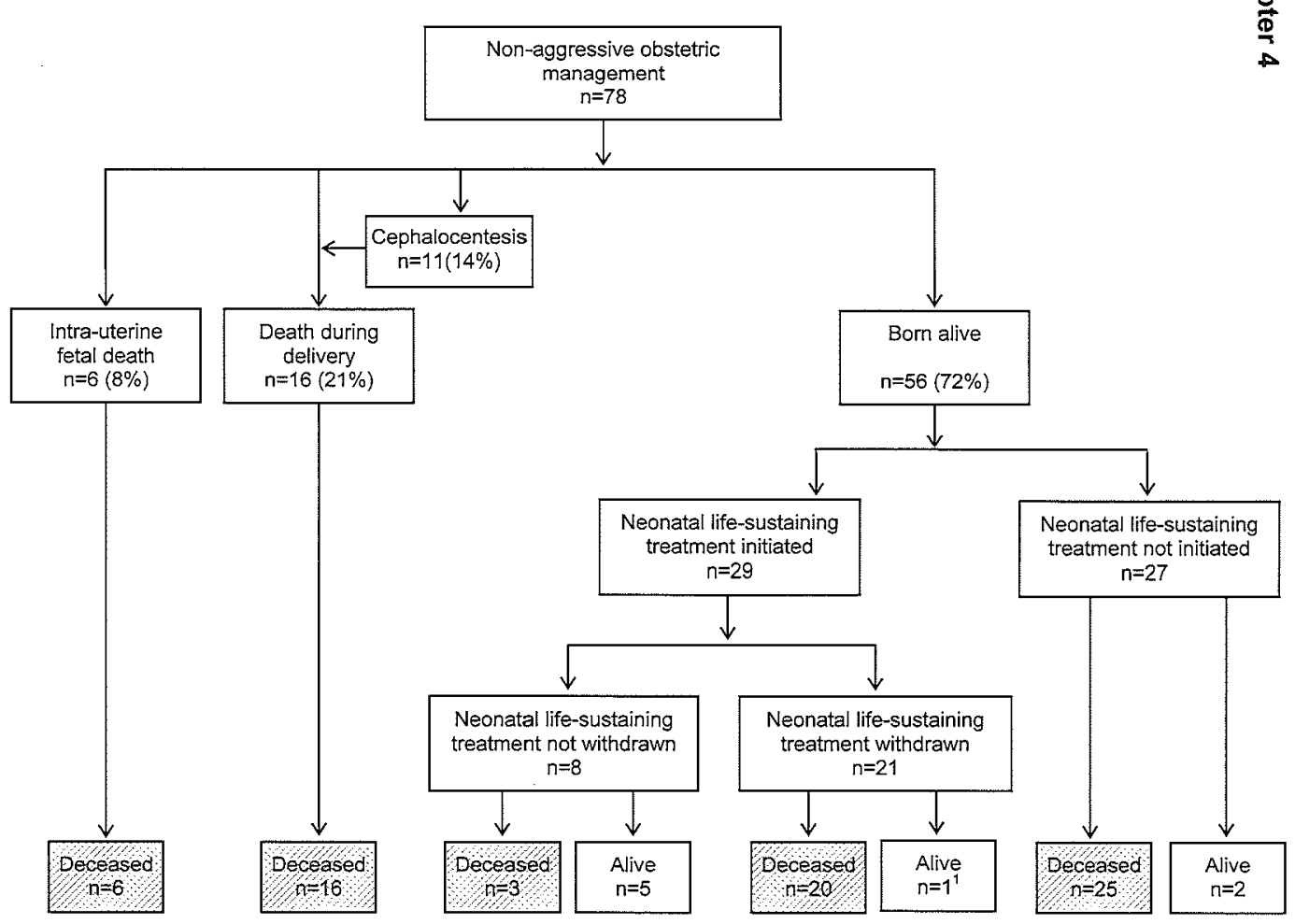

${ }^{1}$ withdrawal of neonatal life-sustaining treatment in this case consisted of an advance directive for DNR-management

\section{Results}

Non-aggressive obstetric management was adopted in 80 pregnancies with a severe fetal anomaly (table 1). Two pregnancies were excluded because follow-up data were not retrievable.

The median maternal age was 29.4 years (range $17.6-43.0$ years) and the median gestational age at diagnosis was 30.6 weeks (range $12.6-38.0$ weeks). Diagnostic characteristics are provided in table 1. In $14 / 78(18 \%)$, the fetus was considered to have no chance of survival, and in $64 / 78(82 \%)$, the fetus was thought to have some chance of survival but with an extremely poor prognosis (table 1). In three instances, non-aggressive obstetric management consisted of refraining from a caesarean section (on fetal indication). In the remaining 75 pregnancies, the recommendation was to refrain from all obstetric interventions to sustain fetal life. In total, $16 / 78(21 \%)$ infants were born before 34 weeks of gestation; $49 / 78(63 \%)$ infants were delivered in the tertiary centre; in $6 / 78(7 \%)$ cases, the delivery was assisted for maternal reasons.

Figure 1 and table 2 illustrate the survival of the fetuses for whom nonaggressive obstetric management was adopted. Six of $78(8 \%)$ infants died in utero and $16 / 78(21 \%)$ died during delivery, 11 of which as result of cephalocentesis. 
Fiftysix of $78(72 \%)$ infants were born alive. In $29(52 \%)$ of the live-born infants, one or more life sustaining neonatal treatments were initiated including artificial ventilation $(n=21)$, invasive procedures $(n=11)$ and resuscitation $(n=3)$ (table2). Twelve of $14(86 \%)$ infants diagnosed prenatally as having no chance of survival were born alive; in one, life-sustaining treatment was initiated. Fortyfour of $64(69 \%)$ who were diagnosed as having some chance of survival were born alive. In 28/44 (64\%), life-sustaining neonatal treatment was initiated. Infants subjected to life-sustaining treatment had a higher median gestational age, birth weight and umbilical cord arterial $\mathrm{pH}$ compared with infants for whom no such treatment was initiated (table 3).

Table 3. Perinatal characteristics of fetuses in case of a non-aggressive obstetric management with or without initation of neonatal life-sustaining treatment

\begin{tabular}{|c|c|c|}
\hline Perinatal characteristics & $\begin{array}{c}\text { Neonatal treatment } \\
\text { initiated }\end{array}$ & $\begin{array}{c}\text { Neonatal treatment } \\
\text { not initiated }\end{array}$ \\
\hline & $n=29$ & $\mathrm{n}=27$ \\
\hline Gestational age (weeks;median range) & $38.4(28.9-43.6)$ & $35.4(29.3-42.9)$ \\
\hline Birth weight (grams; median, range) & $2975(1415-4620)$ & $1990(1010-3380)^{*}$ \\
\hline $\mathrm{pH}$ (median, range) & $7.27(7.08-7.37)^{\dagger}$ & $7.11(6.90-7.30)^{\ddagger}$ \\
\hline Apgar-score 1 minute (median, range) & $5(1-10)^{\S}$ & $3(1-9)^{\pi}$ \\
\hline Delivery in tertairy centre (number, \%) & $20 / 29(69 \%)$ & $18 / 27(67 \%)$ \\
\hline
\end{tabular}

Of 29 infants receiving neonatal life-sustaining treatment, $22(76 \%)$ died within six months (table 2). Of the 27 infants for whom no neonatal life-sustaining treatment was initiated, $25(93 \%)$ died within six months. Life-sustaining treatment was withdrawn in $21 / 29(72 \%)$ infants at a later stage. The stated reasons for withdrawal included: a poor prognosis of the congenital anomaly as already recorded before birth $(n=8)$, maximum life-sustaining treatment had failed to be beneficial $(n=7)$, postnatal diagnostic results confirmed a poor prognosis $(n=3)$, neonatal complications $(n=2)$ or unknown $(n=1)$.

Table 4 describes the infants who survived. Long-term follow-up was missing for one child. The median follow-up time was 5.0 years (range 2.3-7.6 years). Five children were diagnosed with hydrocephaly, with or without spina bifida or multiple intracranial anomalies. Five children had a limited life expectancy and were dependent on medical care for daily activities. Six children had a developmental delay, five children will never live independently and two children had severely impaired ability to communicate. None of the children suffered from major hypoxic consequences, and none were considered to have cerebral palsy.

\section{Discussion}

We describe 78 fetuses with severe structural anomalies for whom non-aggressive obstetric management was adopted. About one quarter of these fetuses died in utero or during delivery, thus the majority was born alive. Lifesustaining neonatal treatment was initiated in about half. But whether or not neonatal life-sustaining treatment was initiated, most infants died soon after birth. Whilst $8 / 78$ infants survived for at least six months, all had severe health problems. An earlier study noted that neonatal management is often not planned prenatally. ${ }^{5}$ And when it was planned prenatally, in only $11 \%$ of the cases it was decided to refrain from lifesustaining neonatal treatment. ${ }^{5}$. We describe a substantial number of cases of nonaggressive obstetric management, and in doing so confirm the reasonableness of the approach. ${ }^{3,6}$ 
Table 4. Diagnosis, condition and follow-up period of children with sonographically diagnosed severe abnormalities born after a non-aggressive obstetric management

\begin{tabular}{|c|c|c|c|}
\hline 1. & $\begin{array}{l}\text { Spina bifida (Th8-L4), severe } \\
\text { hydrocephaly }\end{array}$ & $\begin{array}{l}\text { Paralysis from Th7, wheelchair-dependent, difficulties with } \\
\text { sitting, urinary and fecal incontinence, special education }\end{array}$ & 7.6 \\
\hline 2. & $\begin{array}{l}\text { Spina bifida (thoracolumbar), } \\
\text { syringomyely, hydrocephaly }\end{array}$ & $\begin{array}{l}\text { Paralysis from Th8, wheelchair-dependent, urinary } \\
\text { incontinence, special care, normal psychomotoric development }\end{array}$ & 6.3 \\
\hline 3. & Severe hydrocephaly & Special education, developmental delay & 6.8 \\
\hline $4 .^{1}$ & $\begin{array}{l}\text { Severe hydrocephaly, corpus } \\
\text { callosum agenesia, } \\
\text { atrophy occipital brain }\end{array}$ & $\begin{array}{l}\text { Hemiparesis, impaired sight, impaired hearing, developmental } \\
\text { delay of one year }\end{array}$ & 4.3 \\
\hline 5. & $\begin{array}{l}\text { Multiple intracranial abnormalities, } \\
\text { bilateral cataract }\end{array}$ & $\begin{array}{l}\text { Tetraplegy, epilepsy, impaired swallowing, severe } \\
\text { developmental delay, special nursing care }\end{array}$ & 4.1 \\
\hline 6. & $\begin{array}{l}\text { Spina bifida (Th12-L5), } \\
\text { hydrocephaly }\end{array}$ & $\begin{array}{l}\text { Walks with support, urinary and fecal incontinence, some } \\
\text { developmental delay }\end{array}$ & 5.7 \\
\hline 7. & Multiple structural abnormalities & Long-term follow-up missing. & \\
\hline 8. & Hypoplastic left heart syndrome & $\begin{array}{l}\text { Norwood-I surgery, further surgery not possible. Severely } \\
\text { impaired physical endurance }\end{array}$ & 2.3 \\
\hline
\end{tabular}

The management of pregnancies complicated by severe fetal anomalies can either be standard, that is, all interventions necessary to keep the fetus in an optimal condition until birth are applied, or non-aggressive, that is, interventions that may harm the pregnant woman are avoided. The upper legal limit for termination of pregnancy in the Netherlands is 24 weeks of gestation. ${ }^{7,8}$ After that, termination of pregnancy is only allowed when the fetus has no chance of survival. ${ }^{7,8}$ Therefore, the options for obstetric management in case of a diagnosis of severe fetal anomaly after 24 weeks of gestation are often limited to either standard or non-aggressive management.

Only 12 live-born infants in our sample were considered to have no chance of survival. Non-aggressive obstetric management was associated with death in all cases, usually soon after birth. Life-sustaining neonatal treatment was initiated for only one of these infants.

Unfortunately, the majority of cases involved infants with anomalies that did not preclude survival, but were expected to convey severe health problems. Such problems may include the absence of cognitive development, daily dependence on medical care, lack of communicative possibilities, and physical suffering, such as pain or dyspnoea. ${ }^{8-11}$ The prognosis of these infants was so poor, that obstetric interventions aimed at sustaining the life of the fetus were considered not to be in its best interest. Most of these infants were born alive, and birth leads to the initiation of life-sustaining neonatal treatment in a substantial number of cases. In accordance with previous findings, neonatologists tended to initiate life-sustaining treatment especially when the infants seemed vital, as reflected by good Apgar scores, normal birth weight and maturity. ${ }^{12}$

Thus, postnatal management seeking to sustain life may follow prenatal management that avoids life-sustaining interventions. There are several explanations for this. Firstly, interventions aimed at sustaining life after birth may be applied while the diagnosis made before birth is confirmed. Sustaining the life of the newborn infant makes diagnostic testing possible and allows follow-up of the newborn's vital condition and disease course. Whereas, any intervention before birth carries risks for the pregnant woman, the desire to confirm the diagnosis postnatally does not negate the decision to avoid life-sustaining interventions before birth. Secondly, the newborn infant may be (or seem to be) more vital than expected before birth. Thirdly, neonatologists rather than the multidisciplinary perinatal team decide the medical treatment after birth, and their view concerning the appropriate management may be 
different from what they agreed upon before birth. To what extent neonatal interventions have prolonged futile suffering in these cases cannot be concluded from our study. Neither can we be sure either that non-aggressive obstetric management resulted in a less than optimal condition of the infant at birth and to a less than optimal health status after birth. Whether or not standard obstetric management would have improved the health status of the eight long-term surviving children is unclear, but seems unlikely considering the individual circumstances.

This study was carried out in the Netherlands where the societal and professional debate about end-of-life decision making is rather open, thus facilitating research and debate about decisions to limit life-sustaining obstetric interventions. However, we used a retrospective approach to collect cases, because nonaggressive obstetric management is quite rare. This resulted in limited data about the dynamics of the decision-making process or the role of the parents.

\section{Conclusion}

Most anomalous infants are born alive after non-aggressive obstetric management, stressing the need to consider the neonatal approach in advance. In half the live-borns, life-sustaining treatment is initiated, reflecting differences between the prenatal and postnatal perspective. Life sustaining neonatal support after nonaggressive obstetric management for severe fetal malformations has little to no beneficial impact on survival. Only $10 \%$ of the infants for whom a non-aggressive obstetric management was adopted survived, and all have severe health problems.

\section{Acknowledgement}

We thank B. Dreischor for her assistance in data collection. 


\section{References}

1. Kirkinen $P$, Jouppila $P$, Herva R. Fatal fetal abnormalities. Route of delivery and effect of the development of antepartum diagnostics in the last 13 years. J Reprod Med 1992;37:645-8.

2. Chervenak FA, McCullough LB. Nonaggressive obstetric management. An option for some fetal anomalies during the third trimester. Jama 1989;261:3439-40.

3. Spinnato JA, Cook VD, Cook CR, Voss DH. Aggressive intrapartum management of lethal fetal anomalies: beyond fetal beneficence. Obstet Gynecol 1995;85:89-92.

4. Chervenak FA, McCullough LB, Skupski D, Chasen ST. Ethical issues in the management of pregnancies complicated by fetal anomalies. Obstet Gynecol Surv 2003;58:473-83.

5. Bijma HH, Schoonderwaldt EM, van der Heide A, Wildschut $\mathrm{HI}$, van der Maas PJ, Wladimiroff JW. Uttrasound diagnosis of fetal anomalies: an analysis of perinatal management of 318 consecutive pregnancies in a multidisciplinary setting. Prenat Diagn 2004;24:890-5.

6. Chervenak FA, McCullough LB. An ethically justified, clinically comprehensive management strategy for third-trimester pregnancies complicated by fetal anomalies. Obstet Gynecol 1990;75:311-6.

7. Dutch Society Obstetricians and Gynaecologists. [Model Reglement Medisch Handelen Late Zwangerschapsafbreking bij niet met het leven verenigbare afwijkingen vallend onder categorie 1; versie dd 221003]. Utrecht: Nederlandse Vereniging Obstetrie en Gynaecologie, 2003.

8. Wladimiroff J. Nota Late Zwangerschapsafbreking; Report on Late termination of Pregnancy (official views and guidelines of the Dutch Association of Gynecology and Obstetrics). Utrecht, 1994.

9. Dutch Paediatric Society. To do or not to do? Boundaries of Medical Action in Neonatology [Doen of laten. Grenzen van het medisch handelen in de neonatologie]. Utrecht: Nederlandse Vereniging voor Kindergeneeskunde, 1992.

10. Sauer PJ. Ethical dilemmas in neonatology: recommendations of the Ethics Working Group of the CESP (Confederation of European Specialists in Paediatrics). Eur J Pediatr 2001;160:3648.

11. Hazebroek FW, Bouman NH, Tibboel D. The neonate with major malformations: experiences in a university children's hospital in the Netherlands. Semin Pediatr Surg 2001;10:222-9.

12. Brinchmann BS, Nortvedt $P$. Ethical decision making in neonatal units--the normative significance of vitality. Med Health Care Philos 2001;4(2):193-200.

13. Onwuteaka-Philipsen BD, van der Heide A, Koper D, et al. Euthanasia and other end-of-life decisions in the Netherlands in 1990, 1995, and 2001. Lancet 2003;362:395-9. 



\section{Chapter 5}

\section{Impact of decision-making in a multidisciplinary perinatal team}

H.H.Bijma, A.van der Heide, H.I.J.Wildschut, P.J.van der Maas, J.W.Wladimiroff.

Prenatal Diagnosis 2007;27:97-103 


\section{Abstract}

\section{Objectives}

1. To describe the characteristics of decision-making about management of unborn infants with serious abnormalities by a multidisciplinary perinatal team

2. To evaluate the impact of multidisciplinary team discussions on the degree to which decisions about the management of unborn infants with serious abnormalities are supported.

3. To evaluate the impact of the team discussions on the arguments used by physicians for their preferences concerning management.

\section{Methods}

Prospective analysis of 78 cases discussed within the multidisciplinary perinatal team of a tertiary centre by means of an anonymous one-page questionnaire with structured questions pertaining to the opinion of the responder on medical management of each case.

\section{Results}

We did not find systematic differences in between specialties prior to the discussion of cases. However, discussion with the multidisciplinary perinatal team improved decision-making about management of unborn infants with serious abnormalities by enhancing the degree of support for the decisions taken. The team discussions did not change the arguments physicians mentioned for their preferences.

\section{Conclusion}

Multidisciplinary team discussions improve decision-making about management of unborn infants with serious congenital abnormalities 


\section{Introduction}

The diagnosis of serious fetal abnormality can raise difficult questions about perinatal management. In case of a poor fetal prognosis, the appropriateness of interventions aimed at sustaining life can be questioned. ${ }^{1-4}$ Ethical aspects, diagnostic uncertainty, limited time and the involvement of parents whose future will be deeply affected by the decisions taken, complicate planning of perinatal management. ${ }^{5-7}$ As both obstetric and neonatal interventions affect outcome, a multidisciplinary approach is widely adopted. ${ }^{6,8-13}$ Different team members can analyse the case from different perspectives and add their own expertise. So far, little is known about the role of multidisciplinary team discussions in this field. Crombleholme, evaluating 221 cases of fetal abnormality in which prenatal surgical consultation was sought, found that the decision to terminate pregnancy was changed in $3.4 \%$. ${ }^{9}$ Regarding intellective decisions in health care, multidisciplinary team discussions generally are thought to lead to better decisions than those made by a single individual. ${ }^{14}$ However, group discussions tend to focus on shared rather than unshared information. ${ }^{15,16}$ Furthermore, group interaction is shown to suppress rather than enhance the expression of disparate opinions, thus impeding the possible beneficial influence of new views. ${ }^{17}$ Finally, groups have been shown to make riskier decisions than do their individual members alone. ${ }^{18}$ The aims of this study were 1) To describe the characteristics of decision-making about management of unborn infants with serious abnormalities by a multidisciplinary perinatal team 2) To evaluate the impact of multidisciplinary team discussions on the degree to which decisions about the management of unborn infants with serious abnormalities are supported, and 3) To evaluate the impact of the multidisciplinary team discussions on the arguments used by physicians for their preferences concerning management.

\section{Materials and methods}

The Erasmus MC University Hospital Rotterdam is a regional tertiary referral centre for the southwest of the Netherlands, encompassing 3.5 million inhabitants and 35,000 newborns per year. The perinatal team of our hospital consists of a variable group of physicians, including physician-sonographers, obstetricians, neonatologists, paediatric surgeons, and other paediatric specialists, in the fields of neurosurgery, neurology, cardiology and urology. Midwives, general practitioners and nurses do not participate in the multidisciplinary perinatal team. Pregnancies complicated by fetal abnormalities are discussed by the perinatal team in case there is uncertainty about the diagnosis and/or foetal prognosis, in case the infant is expected to be referred for paediatric care after birth, or to discuss a request of parents to terminate a pregnancy that is already beyond 24 weeks of gestation, which is the upper legal limit for pregnancy termination in the Netherlands.

The multidisciplinary perinatal team (or 'the team') meets weekly and makes decisions on obstetric and neonatal management as well as on the intended place of delivery (i.e., whether or not the delivery should take place in a tertiary centre). Options for obstetric management include standard management, non-aggressive management and termination of pregnancy. Options for neonatal management include standard management or refraining from life-sustaining treatment. During the team's meeting, each case is presented by a physiciansonographer. Subsequently, the team discusses the case and makes decisions.

In our study, we prospectively included 78 consecutive cases, which were discussed by the team in a period of 17 months. For each case, we used a systematic checklist to register characteristics of the foetus, mother and pregnancy as presented, and characteristics of the discussion and decision-making. Further, the physicians participating in the meeting were requested to fill in anonymously a one-page questionnaire with multiple choice questions pertaining to their opinion about the most appropriate type of obstetric management (standard, non-aggressive, termination of pregnancy, no opinion (as yet), other), neonatal management (standard, no neonatal life-sustaining treatment, no opinion (as yet), other), their arguments for their preferences for both obstetric and neonatal management, and their opinion on where delivery 
should take place (home/hospital with midwife/general practitioner, non-tertiary hospital with obstetrician, tertiary hospital with obstetrician, no opinion (as yet)). The questionnaire was filled in twice for each case: firstly, immediately after the presentation of the case (i.e. before the team discussion) and, subsequently, after the team discussion. The physicians also filled in their specialty, their position, and whether or not they had participated actively in the discussion, i.e. raised a question or expressed a view.

As no golden standard for a good standard decision exists for for decision-making in this field, we used the degree of support (consensus) for the decision as outcome measure. This is based both on the assumption that high degree of physician support reflects good quality of the decision and the fact that in clinical practice maximum support for the final decision is necessary for pragmatic reasons. The degree to which different specialists tend to have disparate opinions was measured by comparing percentages of physicians within each group that supported either of the management options, both before and after the team discussion. We also evaluated the percentage of physicians of the different specialties supporting the various options by means of correlation coefficients. We evaluated the impact of the team discussions in several ways. Firstly, we calculated the differences in mean percentages of physicians supporting the final decisions in the three areas of decision-making before and after the team discussions. Secondly, we assessed the number of cases in which consensus increased, decreased of stayed the same. Thirdly, we calculated the mean percentage of phycisians changing their opinion. Finally, we looked if characteristics of the discussions during meetings with a large increase in the degree of support, arbitrarily defined as an increase of $25 \%$ or more, differed from those during meetings with a lesser increase in the degree of support. Finally, we compared the arguments used within the specialties to support specific types of management, both before and after the discussions.

All analyses were done using the Statistical Package for the Social Sciences, version

11.0.

\section{Results}

Characteristics of cases and of the decision-making were registered during 36 meetings, during which the team discussed 78 cases. On average, 17 physicians attended these meetings. They received in total 1432 questionnaires, of which $1328(93 \%)$ were completed and returned.

Table 1 shows the characteristics of the team meetings. Most discussions concerned third trimester pregnancies (mean gestational age 32.3 weeks (sd 4 weeks)). On average, $74 \%$ of the participants were senior medical specialists; a mean of $33 \%$ of all participants actively took part in the discussion. The presentation, discussion, and the final decision-making took, on average, 10 minutes per case (sd 6 minutes). The physician-sonographer usually presented information about the ultrasound findings, gestational age, and obstetric history, and showed the ultrasound findings on videotape. The cases discussed concerned multiple congenital abnormalities in $22 / 78(28 \%)$ cases and single abnormalities in 56/78 (72\%) cases. Three fetuses with multiple congenital abnormalities had chromosomal abnormalities (trisomy 13 (2) and marker chromosome (1)). In the remaining 19 fetuses chromosomes were normal (6) or unknown (13), because the results weren't known at the time of the meeting or because the parents did not want chromosome analysis to be done. A wide variety of single abnormalities was discussed: cardiac abnormality (9), double bubble (7), diaphragmatic hernia (6), gastroschizis (4), hydrocephaly/ventriculomegaly (4), intra-abdominal cyst (4), CCAML/lung sequester (3), bilateral renal abnormality (3), spina bifida (2), skeletal dysplasia (2), encephalocele/skull abnormality (2), sacrococcygeal teratoma (2), and other (8). Foetal prognosis was mentioned explicitly in the presentation of 51 cases $(65 \%)$; uncertainty about the diagnosis or prognosis was mentioned in about half of the cases. Parental preference was mentioned explicitly in $30(39 \%)$ cases. The team discussed specific alternatives for management in 33 cases $(42 \%)$. Non-aggressive obstetric management or termination of pregnancy after 24 weeks were discussed in 34 cases (44\%). The team most often decided upon standard obstetric management (60 cases, $77 \%$ ) and standard neonatal management (52 cases, $67 \%$ ). In 10 cases (13\%) the team chose for non-aggressive obstetric management and in 8 cases 
Table 1. Characteristics of participants, information provided at presentation, discussion and decisions of a multidisciplinary perinatal team of a tertiary centre.

\begin{tabular}{|c|c|c|}
\hline $\begin{array}{l}\text { Participants } \\
\text { mean number of participants per perinatal meeting }\end{array}$ & $\begin{array}{c}\text { mean } \\
17\end{array}$ & $\begin{array}{l}(\mathrm{sd}) \\
(6)\end{array}$ \\
\hline $\begin{array}{l}\text { Specialty } \\
\text { mean } \% \text { participants of neonatalogy/paediatrics } \\
\text { mean } \% \text { participants of obstetrics } \\
\text { mean } \% \text { participants of paediatric surgery } \\
\text { mean } \% \text { of particpants of other specialties }\end{array}$ & $\begin{array}{l}30 \% \\
32 \% \\
35 \%\end{array}$ & $\begin{array}{l}(16 \%) \\
(15 \%) \\
(16 \%)\end{array}$ \\
\hline $\begin{array}{l}\text { Position } \\
\text { mean } \% \text { medical specialists } \\
\text { mean } \% \text { residents }\end{array}$ & $\begin{array}{l}74 \% \\
26 \%\end{array}$ & $\begin{array}{l}(16 \%) \\
(16 \%)\end{array}$ \\
\hline $\begin{array}{l}\text { Active participation } \\
\text { mean } \% \text { participants taking an active part } \\
\text { mean } \% \text { participants not taking an active part }\end{array}$ & $\begin{array}{l}33 \% \\
67 \% \\
\end{array}$ & $\begin{array}{l}(18 \%) \\
(18 \%)\end{array}$ \\
\hline $\begin{array}{l}\text { Information provided at presentation } \\
\text { cases in which was/were mentioned: } \\
\text { ultrasound findings } \\
\text { gestational age } \\
\text { obstetric history } \\
\text { whether or not obstetric complications other than fetal abnormality were present } \\
\text { videotape images of ultrasound findings } \\
\text { fetal growth } \\
\text { indication for fetal abnormality scannning } \\
\text { (explicite) fetal prognosis } \\
\text { uncertainty of fetal prognosis } \\
\text { differential diagnosis of the fetal abnormality (e.g.genetic syndrome) } \\
\text { uncertainty of diagnosis } \\
\text { parental preferences for management } \\
\text { prior discussion of management between parents and gynaecologist } \\
\text { prior consultation of paediatric specialist }\end{array}$ & $\begin{array}{l}n \\
78 \\
78 \\
72 \\
68 \\
68 \\
55 \\
53 \\
51 \\
43 \\
36 \\
35 \\
30 \\
23 \\
25 \\
\end{array}$ & $\begin{array}{c}\% \\
(100 \%) \\
(100 \% \\
(92 \%) \\
(87 \%) \\
(87 \%) \\
(71 \%) \\
(68 \%) \\
(65 \%) \\
(55 \%) \\
(46 \%) \\
(45 \%) \\
(39 \%) \\
(30 \%) \\
(32 \%)\end{array}$ \\
\hline $\begin{array}{l}\text { Discussion } \\
\text { cases in which: } \\
\text { consensus about obstetric management was reached } \\
\text { several management alternatives were considered explicitly } \\
\text { the consequences of the alternative options were discussed } \\
\text { a non-aggressive obstetric management was considered } \\
\text { termination of pregnancy }>24 \text { wks gestational age was considered } \\
\text { ethical issues were mentioned explicitly }(1) \\
\end{array}$ & $\begin{array}{l}78 \\
78 \\
33 \\
25 \\
20 \\
14 \\
2\end{array}$ & $\begin{array}{l}\% \\
(100 \% \\
(42 \%) \\
(32 \%) \\
(26 \%) \\
(18 \%) \\
(3 \%) \\
\end{array}$ \\
\hline Decision & & \\
\hline $\begin{array}{l}\text { Obstetric management } \\
\text { standard obstetric management } \\
\text { non-aggressive obstetric management } \\
\text { termination of pregnancy } \\
\text { no decision }\end{array}$ & $\begin{array}{c}60 \\
10 \\
8\end{array}$ & $\begin{array}{l}(77 \%) \\
(13 \%) \\
(10 \%)\end{array}$ \\
\hline $\begin{array}{l}\text { Neonatal management } \\
\text { standard neonatal management } \\
\text { no initiation of life-sustaining treatment } \\
\text { decision on management after evaluation of postnatal situation } \\
\text { no explicit decision (2) }\end{array}$ & $\begin{array}{c}52 \\
4 \\
4 \\
18 \\
\end{array}$ & $\begin{array}{l}(67 \%) \\
(5 \%) \\
(5 \%) \\
(23 \%) \\
\end{array}$ \\
\hline $\begin{array}{l}\text { Place of delivery } \\
\text { tertiary centre } \\
\text { non-tertiary centre } \\
\text { no explicit decision }\end{array}$ & $\begin{array}{c}49 \\
26 \\
3\end{array}$ & $\begin{array}{l}(63 \%) \\
(33 \%) \\
(4 \%)\end{array}$ \\
\hline
\end{tabular}

Management in 6 cases, non-aggressive obstetric management in 4 cases 
Table 2. Percentage of participants of each specialty that supported the different management modalities

\begin{tabular}{|c|c|c|c|c|c|c|c|c|c|c|c|c|}
\hline & \multicolumn{4}{|c|}{ Obstetricians } & \multicolumn{4}{|c|}{ Paediatricians/neonatologists } & \multicolumn{4}{|c|}{ Paediatric surgeons } \\
\hline & \multirow{2}{*}{\multicolumn{2}{|c|}{$\begin{array}{l}\text { before } \\
n=398\end{array}$}} & \multirow{2}{*}{\multicolumn{2}{|c|}{$\frac{\text { after }}{n=395}$}} & \multirow{2}{*}{\multicolumn{2}{|c|}{$\begin{array}{l}\text { before } \\
n=370\end{array}$}} & \multirow{2}{*}{\multicolumn{2}{|c|}{$\frac{\text { after }}{n=360}$}} & \multirow{2}{*}{\multicolumn{2}{|c|}{$\begin{array}{l}\text { before } \\
n=437\end{array}$}} & \multirow{2}{*}{\multicolumn{2}{|c|}{$\begin{array}{c}\text { after } \\
n=450\end{array}$}} \\
\hline & & & & & & & & & & & & \\
\hline & mean & sd & mean & sd & mean & sod & mean & $s d$ & mean & $s d$ & mean & $s d$ \\
\hline \multicolumn{13}{|l|}{ Obstetric management } \\
\hline Standard & 67 & 41 & 72 & 42 & 74 & 38 & 75 & 40 & 73 & 38 & 73 & 40 \\
\hline Non-aggressive & 20 & 35 & 16 & 32 & 14 & 29 & 15 & 32 & 10 & 22 & 12 & 29 \\
\hline Termination of pregnancy & 6 & 22 & 6 & 22 & 5 & 19 & 6 & 22 & 7 & 22 & 7 & 25 \\
\hline No opinion (yet)/other & 8 & 18 & 6 & 13 & 12 & 18 & 4 & 13 & 10 & 17 & 6 & 16 \\
\hline \multicolumn{13}{|l|}{ Neonatal management } \\
\hline Standard & 64 & 41 & 72 & 40 & 71 & 38 & 72 & 40 & 71 & 38 & 72 & 38 \\
\hline No life-sustaining treatment & 23 & 36 & 20 & 36 & 18 & 32 & 22 & 37 & 15 & 28 & 18 & 33 \\
\hline No opinion (yet)/other & 13 & 32 & 9 & 19 & 12 & 18 & 6 & 13 & 13 & 19 & 11 & 18 \\
\hline \multicolumn{13}{|l|}{ Place of delivery } \\
\hline No tertiary center & 37 & 38 & 35 & 41 & 39 & 39 & 36 & 42 & 32 & 33 & 32 & 38 \\
\hline Tertiary center & 59 & 39 & 63 & 41 & 56 & 38 & 62 & 43 & 63 & 33 & 66 & 39 \\
\hline No opinion (yet)/ other & 5 & 11 & 3 & 8 & 5 & 12 & 1 & 6 & 6 & 13 & 2 & 8 \\
\hline
\end{tabular}

Table 3. Mean percentage of consensus before and after discussion for each management modality

\begin{tabular}{lllll}
\hline Final management decision & \multicolumn{4}{l}{ Maximum support } \\
\hline & $\begin{array}{l}\text { Before } \\
\text { discussion } \\
\text { mean }\end{array}$ & $\begin{array}{l}\text { After } \\
\text { discussion } \\
\text { mean sd }\end{array}$ \\
Obstetric management (1) & & & & \\
standard $(n=60)$ & $87 \%$ & $20 \%$ & $94 \%$ & $14 \%$ \\
non-aggressive $(n=11)$ & $71 \%$ & $26 \%$ & $85 \%$ & $20 \%$ \\
TOP $(n=5)$ & $80 \%$ & $17 \%$ & $90 \%$ & $10 \%$
\end{tabular}

Neonatal management (2)

$\begin{array}{lllll}\text { standard }(n=61) & 84 \% & 21 \% & 90 \% & 17 \% \\ \text { no LST }(n=16) & 72 \% & 19 \% & 83 \% & 18 \%\end{array}$

Place of delivery 93)

no tertiary center $(\mathrm{n}=25) \quad 68 \% \quad 20 \% \quad 83 \% \quad 15 \%$

\begin{tabular}{llllll} 
tertiary center $(\mathrm{n}=50)$ & $78 \%$ & $19 \%$ & $89 \%$ & $13 \%$ \\
\hline
\end{tabular}

(1) additionally, in one case the consensus concerned 'other management', and in one case the consensus for 'standard obstetric management' was equal to the consensus for 'non-aggressive obstetric management'.

(2) additionally, in one case the majority stated they had not yet an opinion on neonatal management

(3) additionally, in 3 cases, the consensus for 'tertiary center' was equal to the consensus for 'no tertiary center' 
(10\%) for the termination of pregnancy beyond 24 weeks gestational age. In four cases (5\%), the team decided prenatally to refrain from life-sustaining treatment after birth.

Table 2 shows the mean percentage of obstetricians, paediatricians/neonatologists and paediatric surgeons supporting each management option, before and after discussion of the case. The degree of support for the different options was comparable between the different specialties, both before and after discussion. The percentage of physicians supporting a specific management option highly correlated between the different specialties, both before (Pearson correlation-coefficients, range 0.65-0.93) and after (Pearson correlation-coefficients, range $0.87-0.92$ ) the discussion.

The mean percentage of physicians changing their opinion on obstetric management after discussion of the case was $16 \%$ (sd 20\%) while the mean percentage of those changing their opinion on neonatal management and on the place of delivery was $15 \%$ (sd 17\%) and $19 \%$ (sd 19\%) respectively.

Table 3 shows the mean percentage of physicians supporting a decision, before and after the team discussion. Before the discussion, the degree of support varied between $68 \%$ and $87 \%$, and after the discussion it varied between $83 \%$ and $94 \%$.

Overall, support for decisions on obstetric management increased with $6 \%$ (sd 15\%). The degree of support for obstetric decisions increased in $34(45 \%)$ cases (mean increase $18 \%$, sd $14 \%$ ), decreased in 13 cases (mean decrease $12 \%$, sd $8 \%$ ) and remained similar in 28 cases (37\%): in 26 of the latter, the decision was already supported by the whole team before the discussion (figure 1).

In 10 cases $(13 \%)$, the degree of support increased more than $25 \%$. This relatively large increase often occurred after team discussions of the appropriateness of non-aggressive obstetric management (discussed in 9/10 (90\%) of the cases for which the degree of support increased with more than $25 \%$, versus $11 / 68(16 \%)$ of remaining cases), of specific alternative management options $(10 / 10(100 \%)$ versus $23 / 68(34 \%))$ and of the preferences of the parents $(8 / 10(80 \%)$ versus $22 / 68(32 \%))$.

Overall, support for decisions on neonatal management increased with $5 \%$ (sd $16 \%$ ). The degree of support for neonatal management increased in 32 cases (43\%), decreased in 16 cases $(21 \%)$ and remained similar in 27 cases (36\%): in 23 of the latter, the decision was already supported by the whole team before the discussion. In 6 cases (8\%), the degree of support for decisions on neonatal management increased with more than $25 \%$ : In these cases, the degree of support for decisions on obstetric management also increased with more than $25 \%$.

Finally, overall, support for decisions on place of delivery increased with $11 \%$ (sd15\%) . The degree of support for decisions on the place of delivery increased in 56 cases (75\%) (Figure 1). In 8 cases $(10 \%)$, the degree of support for the place of delivery increased with more than $25 \%$.

The arguments for supporting one of the obstetric and neonatal management modalities as reported by each of the physicians before the team discussions did not differ from those given after the team discussions (table 4). However, there were considerable differences between the different management options (Chi-square: $p<0.00$ for all arguments, both before and after the discussions). 'There is no reason to depart from standard management' was the most frequently mentioned argument to support standard obstetric management, whereas physicians who preferred non-aggressive obstetric management most often marked 'poor prognosis in terms of quality of life'. For pregnancy termination, 'limited life-expectancy' and 'parental preference' prevailed. The most frequently mentioned argument to prefer standard neonatal management was that 'there is no reason to depart from standard management'. The most frequently mentioned argument to prefer refraining from neonatal life-sustaining treatment was 'poor prognosis in terms of quality of life', followed by 'limited life-expectancy'.

\section{Discussion}

This empirical study shows that discussion in a multidisciplinary perinatal team results in an increase of consensus about management of unborn infants with serious abnormalities, ranging from $6 \%$ to $15 \%$. The increase in the degree of support was most prominent when regarding of end-of-life decisions, such as non-aggressive management and termination of 
pregnancy. Hence, discussion in a multidisciplinary perinatal team results in better decisions about the management of unborn infants with serious abnormalities, thereby assuming that a decision based on a high degree of support is better than one based on less degree. ${ }^{19,20}$

This study was not designed for in-depth analysis of the psychological mechanisms influencing the group process in decision-making about the management of unborn infants with serious abnormalities. Hence, phenomena influencing group decision-making, such as suboptimal sharing of information and the tendency to make riskier decisions as a member of the team than as an individual, were not taken into account. The study rather focused on describing whether team discussion was beneficial, despite the possible occurrence of these phenomena and confirmed the value of team discussion for clinical consensus. For clinical practice, it is advised to collect factual information as well as participants' opinions systematically in order to avoid bias resulting from overrelying on shared information and generally accepted opinions. An impartial chairman may be needed to secure this process. ${ }^{21,22}$ Furthermore, confusing moral matters with medical ones should not obscure the discussion. It has been shown that perception of medical facts, such as fetal prognosis, may be influenced by personal and institutional moral values. ${ }^{23,24}$ However, moral matters should be discussed as such and not be disguised in discussion about medical facts. ${ }^{25,26}$

Interestingly, we did not find systematic differences of preferences between specialties prior to the team discussions (table 2). It can be questioned, therefore, to what extent the multidisciplinary team serves to attune disparate views between the different specialties. ${ }^{27-29}$ In our study, most physicians attending the meetings were senior medical specialists who had already been involved with the perinatal team and its goal of multidisciplinary decision-making for several years. Possibly, these physicians were already used to consider perspectives from the viewpoints of other specialties due to long-term learning experiences. Hence the value of discussion in a multidisciplinary team may be by finding a common language for the team's participants rather than by attuning individual participants' opinions in specific cases. Furthermore, the perinatal team does not only contribute to the aim of making joint decisions, but also to the education of both novel apprentices and colleagues from different specialties, who have to get acquainted with the vocabulary, common knowledge and specific reasoning within different specialties. ${ }^{14}$ In most cases, the team decided to apply standard obstetric and neonatal management. These decisions were typically motivated by the 'negative' argument that there was no reason to deviate from standard treatment, that is, treatment aimed at keeping the foetus alive and in the most optimal condition. Decisions to apply non-aggressive obstetric management or even to terminate a pregnancy, and decisions not to apply lifesustaining treatment for the newborn infant were less common. These decisions were usually taken because of an extremely poor prognosis in terms of quality of life, a limited life expectancy even if treatment would be applied, or because of the parents' wish to adopt such management.

Parental preference was mentioned explicitly in $30(39 \%)$ of the cases. In general, parents are asked their preference for obstetric management at the time of diagnosis, especially when end-of-life decisions could be at stake. Termination of pregnancy after 24 weeks gestational age is only considered at explicit parental request. After the multidisciplinary perinatal team has made a decision about perinatal management, this decision will be discussed with the parents. In case parents object to a non-aggressive obstetric management, this will generally be converted to a standard obstetric management.

Few empirical studies have been done on the process and impact of medical decisionmaking in a multidisciplinary team and the most appropriate methodology for such studies has not clearly been established. Our study has to be considered as an attempt to contribute to the development of such methodology and our findings therefore have to be interpreted with caution.

Further, in a clinical setting, the characteristics of the decision-makers, the cases and the decision-making process are highly variable, and cannot be controlled for. This may explain that 
Table 4. Arguments given for each obstetric and neonatal management modality. The participants could choose multiple arguments

\begin{tabular}{|c|c|c|c|c|c|c|c|c|c|c|}
\hline & \multicolumn{6}{|c|}{ Obstetric management } & \multicolumn{4}{|c|}{ Neonatal management } \\
\hline & \multicolumn{2}{|c|}{ Standard } & \multicolumn{2}{|c|}{ Non-aggressive } & \multicolumn{2}{|c|}{$\begin{array}{l}\text { Termination of } \\
\text { pregnancy }\end{array}$} & \multicolumn{2}{|c|}{ Standard } & \multicolumn{2}{|c|}{ No LST } \\
\hline & Before & After & Before & After & Before & After & Before & After & Before & After \\
\hline & $n=910$ & $\mathrm{n}=922$ & $n=202$ & $n=207$ & $n=85$ & $n=85$ & $n=875$ & $n=883$ & $n=255$ & $n=270$ \\
\hline Life expectancy & $190(21 \%)$ & $200(21 \%)$ & $116(57 \%)$ & $120(58 \%)$ & $58(68 \%)$ & $62(73 \%)$ & $192(22 \%)$ & $194(22 \%)$ & $153(60 \%)$ & $175(64 \%)$ \\
\hline Quality of life & $215(23 \%)$ & $199(21 \%)$ & $150(74 \%)$ & $150(72 \%)$ & $52(61 \%)$ & $44(52 \%)$ & $213(24 \%)$ & $209(23 \%)$ & $184(72 \%)$ & $185(68 \%)$ \\
\hline Parental preference & $100(11 \%)$ & $129(14 \%)$ & $50(25 \%)$ & $57(27 \%)$ & $42(49 \%)$ & $49(58 \%)$ & $87(10 \%)$ & $114(13 \%)$ & $64(25 \%)$ & $78(29 \%)$ \\
\hline $\begin{array}{l}\text { No reason to depart from } \\
\text { standard management }\end{array}$ & $581(63 \%)$ & $587(63 \%)$ & $7(4 \%)$ & $2(1 \%)$ & - & - & $568(64 \%)$ & $567(63 \%)$ & - & $3(1 \%)$ \\
\hline No opinion (yet) & $17(2 \%)$ & $5(1 \%)$ & - & - & - & $1(1 \%)$ & $6(1 \%)$ & $5(1 \%)$ & $3(1 \%)$ & $1(0 \%)$ \\
\hline Other & $46(5 \%)$ & $53(6 \%)$ & $3(2 \%)$ & $3(1 \%)$ & $5(5 \%)$ & $2(2 \%)$ & $30(4 \%)$ & $36(4 \%)$ & $3(1 \%)$ & $4(2 \%)$ \\
\hline
\end{tabular}




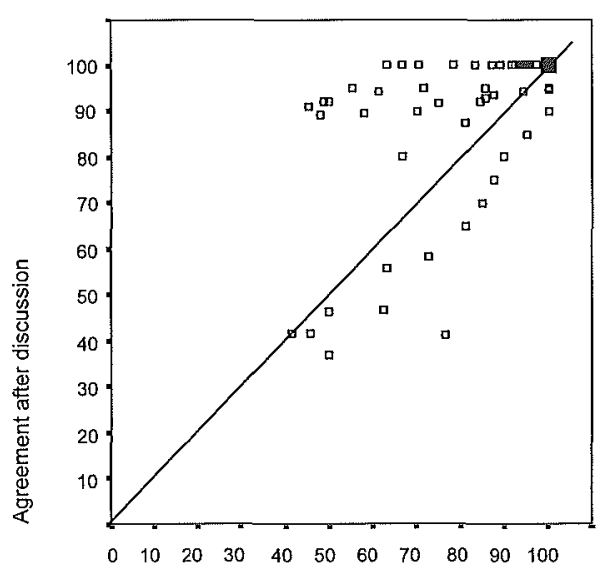

Agreement before discussion (\%)

Obstetric management

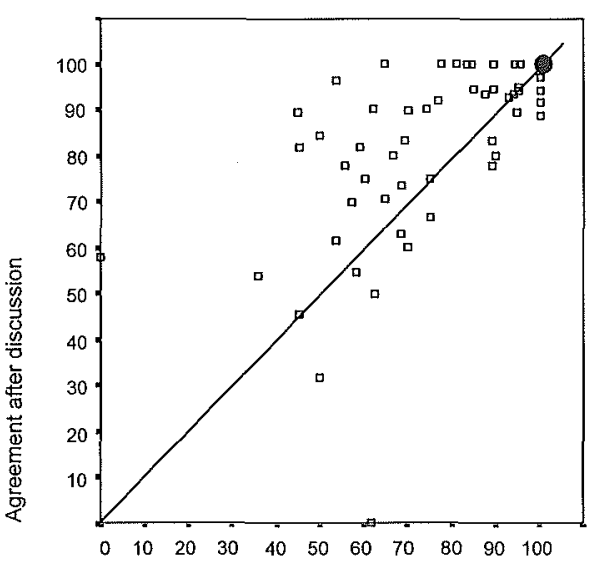

Agreement before discussion (\%)

Neonatal management

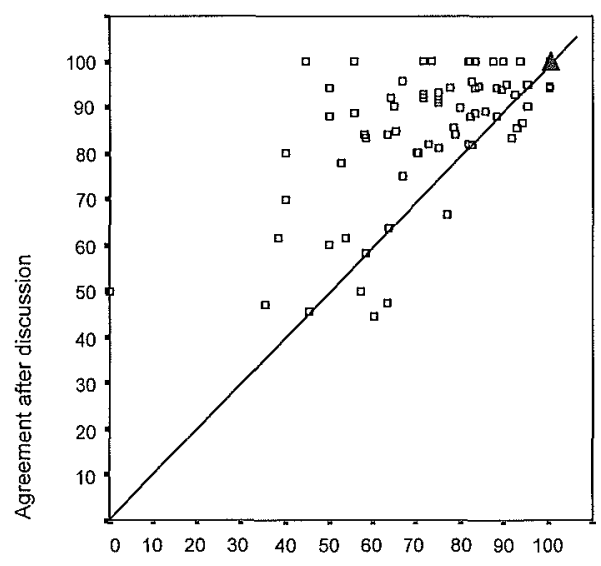

Agreement before discussion (\%)

Place of delivery

Figure 1. Agreement before and after discussion for obstetric management, neonatal management and hospital of delivery. Each square represents a case discussed by the multidisciplinary team. cases (hospital of delivery). The black line indicates equal agreement before and after discussion. In the cases to the left of the black line, agreement has increased after discussing the case. In cases to the right of the black line, agreement has decreased after discussing the case. 
we have not identified group characteristics contributing significantly to large increases in the degree of support for decisions within the team.

The team that was studied here shares many characteristics with perinatal teams in other tertiary centres: task-oriented, including obstetric and paediatric specialties and a variable number of physicians with variable levels of expertise and experience. Differences may exist in the participation of other health care professionals, such as social workers, midwives, nurses and general practitioners, the openness of the debate on end-of-life decisions and the legal regulations. These factors may influence the process of decision-making in other centres.

In conclusion, our study has shown that multidisciplinary team discussions about perinatal decisions have a considerable effect on the degree to which decisions are supported. Multidisciplinary decision-making appears to enhance the inclination of physicians to a priori consider perspectives from other specialties. 


\section{References}

1. Chervenak, F.A. and L.B. McCullough, An ethically justified, clinically comprehensive management strategy for third-trimester pregnancies complicated by fetal anomalies. Obstet Gynecol, 1990. 75: 311-6.

2. Caniano, D.A. and F. Baylis, Ethical considerations in prenatal surgical consultation. Pediatr Surg Int, 1999. 15:303-9.

3. Gross, M.L., Avoiding anomalous newborns: preemptive abortion, treatment thresholds and the case of baby Messenger. J Med Ethics, 2000. 26:242-8.

4. Spinnato, J.A., et al., Aggressive intrapartum management of lethal fetal anomalies: beyond fetal beneficence. Obstet Gynecol, 1995. 85:89-92.

5. Hunfeld, J.A., et al., Emotional reactions in women in late pregnancy (24 weeks or longer) following the ultrasound diagnosis of a severe or lethal fetal malformation. Prenat Diagn, 1993. 13:603-12.

6. Hoeldtke, N.J., Calhoun, B.C., Perinatal hospice. American Journal of Obstetrics and Gynecology, 2001. 185:525-529.

7. Britt, D.W., et al., Devastation and relief: conflicting meanings of detected fetal anomalies. Uitrasound Obstet Gynecol, 2002. 20:1-5.

8. Porter, K.B., P.C. Wagner, and M.L. Cabaniss, Fetal Board: a multidisciplinary approach to management of the abnormal fetus. Obstet Gynecol, 1988. 72:275-8.

9. Crombleholme, T.M., et al., Prenatal diagnosis and the pediatric surgeon: the impact of prenatal consultation on perinatal management. J Pediatr Surg, 1996. 31:156-62

10. Heling, K.S., et al., Fetal ovarian cysts: prenatal diagnosis, management and postnatal outcome. Ultrasound Obstet Gynecol, 2002. 20:47-50.

11. Hedrick, H.L., et al., History of fetal diagnosis and therapy: Children's Hospital of Philadelphia experience. Fetal Diagn Ther, 2003. 18:65-82.

12. Mirlesse, V., et al., Perinatal management of fetal cardiac anomalies in a specialized obstetricpediatrics center. Am J Perinatol, 2001. 18:363-71.

13. Carpenter, M.W., F. Corrado, and J. Sung, Lethal fetal renal anomalies and obstetric outcome. Eur J Obstet Gynecol Reprod Biol, 2000. 89:149-52.

14. Christensen, C. and A.S. Abbott, Team medical decision making, in Decision making in health care: Theory, psychology, and applications. Cambridge series on judgment and decision making, G.B. Chapman and F.A. Sonnenberg, Editors. 2000, Cambridge University Press: New York, NY. p. 267-285.

15. Larson, J.R., Jr., et al., Diagnosing groups: The pooling, management, and impact of shared and unshared case information in team-based medical decision making. Journal of Personality and Social Psychology, 1998. 75:93-108.

16. Stasser, G.T., W., Pooling of unshared information in group decision making; biased information sampling during discussion. Journal of Personality and Social Psychology, 1985:1467-1478.

17. Blumberg, H.H., Group decision making and choice shift, in Small group research: A handbook, A.P. Hare, H.H. Blumberg, and et al., Editors. 1994, Ablex Publishing: Westport, CT. p. 195210.

18. Fisher, B.E., DG, Dimensions of the group process, in Small Group Decision-making: communication in the group process. 1990, McGraw-Hill: New York.

19. Fink, A., et al., Consensus methods: characteristics and guidelines for use. Am J Public Health, 1984. 74:979-83.

20. Jones, J. and D. Hunter, Consensus methods for medical and health services research. Bmj, 1995. 311:376-80.

21. Hall, P. and L. Weaver, Interdisciplinary education and teamwork: a long and winding road. Med Educ, 2001:867-875.

22. Hare, A., Roles, relationships, and groups in organisations:some conclusions and recommendations. Small group research, 2003. 2:123-154.

23. Molewijk, A.C., et al., Implicit normativity in evidence-based medicine: a plea for integrated empirical ethics research. Health Care Anal, 2003. 11:69-92.

24. Bijma, H.H., et al., Obstetricians' agreement on fetal prognosis after ultrasound diagnosis of fetal anomalies. Prenat Diagn, 2004. 24:713-8.

25. Grundstein-Amado, R., An integrative model of clinical-ethical decision making. Theoretical Medicine, 1991. 12:157-70.

26. Pellegrino, E.D., The anatomy of clinical-ethical judgments in perinatology and neonatology: a substantive and procedural framework. Semin Perinatol, 1987. 11:202-9.

27. Lenard, G., Ethical problems in prenatal diagnosis: pediatric considerations. Brain Dev, 1995. 17 Suppl:44-7.

28. Luks, F.I., et al., Experience with a multidisciplinary antenatal diagnosis and management model in fetal medicine. J Matern Fetal Neonatal Med, 2003. 14:333-7.

29. Baldwin, L.M., et al., Access to multidisciplinary cancer care: is it linked to the use of breastconserving surgery with radiation for early-stage breast carcinoma? Cancer, 2004. 100:701-9. 


\section{Decision-making by \\ pregnant women}





\section{Chapter 6}

\section{Parental decision-making after ultrasound diagnosis of a serious fetal abnormality, a review of literature}

H.H. Bijma, H.I.J. Wildschut, A. van der Heide, J.Passchier, J.W. Wladimiroff, P.J. van der Maas.

Fetal Diagnosis and Therapy. 2005;20:321-7. 


\section{Abstract \\ Objective}

The purpose of this article is to provide obstetricians, who are often not familiar with decision making theories, with a comprehensive overview of theories that are relevant for the parental decision-making process after ultrasound diagnosis of a serious fetal abnormality.

\section{Methods}

As little data are available about the specific situation of parental decision-making after ultrasound diagnosis of a fetal abnormality, we turned towards literature about parental decision-making after diagnosis of chromosomal abnormalities as well as general decision-making theories. These were related to parental decision-making after an ultrasound diagnosis of fetal abnormality.

\section{Results}

General decision-making theories often focus on rationality and coherence of the decision-making process. However, studies of both the influence of framing and the influence of stress indicate that emotional mechanisms may have an important and beneficial function in the decision-making process in case of ultrasound diagnosis of a fetal abnormality.

\section{Conclusion}

Cognitive mechanisms that are often elicited by emotions and that are not necessarily rational may have an important and beneficial function in parental decision-making after ultrasound diagnosis of a fetal abnormality. Consequently, the process of parental decision-making should not solely be assessed on the basis of its rationality, but on the basis of the parental emotional outcome. 


\section{Introduction}

After the ultrasound diagnosis of serious fetal abnormality is established, parents and physicians must come to a joint decision about how to manage the pregnancy and delivery. Options include standard obstetric policy, a non-aggressive obstetric policy or termination of pregnancy. ${ }^{1}$ At the empirical level, little is known about the dynamics of the process by which parents reach their decision. Parental decision-making is complicated by several factors. ${ }^{2-4}$

First, the fetal ultrasound abnormality is often complex obscuring some essential structural information that prohibits a definitive diagnosis. Further, the fact that ultrasound provides a structural assessment means that functional aspects are often unknown resulting in prognostic uncertainty. It may be very difficult for the expectant parents to understand the nature of the condition and its possible consequences for future daily life, for themselves, their child and their family. Second, serious fetal ultrasound abnormalities involve decisions about whether to give the unborn child a chance to live and possibly suffer, or to prevent suffering by taking end-of-life-decisions. Such decisions make a long-lasting impact on the lives of the parents and families. Furthermore, parents may cope differently with decisionmaking. Third, emotions play an important role. Most abnormalities are detected unexpectedly during a pregnancy, which, until then, was uneventful. Most expectant parents do not seriously consider the possibility of fetal abnormality. The diagnosis of an abnormality often evokes strong emotions about the well-being of their unborn child, forcing the future parents to confront the harsh reality that an intrinsically positive event as a desired pregnancy can end with disease and suffering. It is under these circumstances, when all social values and meanings seem to lose their usual sense, that parents must make important and far-reaching decisions. Fourth, the decision must consider not only the well-being of the unborn child, but also the wellbeing of the pregnant woman. Though intertwined, they can conflict. How do the parents decide whose best interest should prevail? Finally, the time for making a decision is limited, and the advance of pregnancy means no decision is indeed a decision in itself. In many countries like the Netherlands, termination of pregnancy is legally possible only prior to 24 weeks gestational age. The purpose of this article is to provide physicians who generally are not familiar with decision making theories with a comprehensive overview of theories that are relevant for the parental decisionmaking process after an ultrasound diagnosis of a serious fetal abnormality. An improved understanding of how parents make choices will facilitate the counselling process. We will begin by reviewing empirical literature, and then proceed into general decision-making theories, and then conclude by relating them to parental decision-making after an ultrasound diagnosis.

\section{The process of parental decision-making after ultrasound diagnosis of fetal abnormalities.}

Maternal age, maternal educational level, former uncompleted pregnancies as well as factors related to counselling have been suggested as determinants of parental decision-making. ${ }^{5-8}$ However, so far little attention has been paid to the process of parental decision-making. Further, most authors focus on the decision whether or not to terminate pregnancy not take into account other options. ${ }^{9-11}$ Sandelowski and Jones conducted a qualitative study on the process of parental decision-making. ${ }^{12}$ They interviewed 15 women and 12 of their partners to elucidate the process of decision-making after the detection of serious fetal abnormality. They concluded that an important analytical tool was the extent the parents saw themselves as holding moral agency for the outcome of the pregnancy. They identified five scenarios of choice that varied according to where participants located the moral agency: nature's choice, disowned choice, lost choice, close choice and 
found choice. In nature's choice, the couple feels as if nature has already determined the outcome and, by terminating pregnancy, they are simply acting in line with what nature intends. In disowned choice, the couple recognises and even considers pregnancy termination as an option, but ultimately rejects it as not their decision to make. As a result, they continue the pregnancy. In the scenario of lost choice, the abnormalities are discovered too late in pregnancy for termination, or at a time when the fetus has already become a child to them. These couples feel they have lost the possibility to choose. A close choice occurs when the decision is not clear and could go one way or another. Expectant parents in this group look at their situation from the vantage points of the unborn child, themselves and their families. The final category is found choice. Here, parents construe themselves, sometimes against great odds, as making a choice. Differences in scenarios of choice can have important implications for emotional well-being and clinical intervention. Sandelowski and Jones concluded that those who locate moral agency in something or someone other than themselves avoid some of the pain of bearing responsibility for the choice. ${ }^{12}$

\section{The process of parental decision-making in genetic counselling about future pregnancy}

Most empirical research into the process of parental decision-making focuses on a decision for a future pregnancy in instances of a known genetic risk. Based on these studies, several emotional mechanisms play a role. Parents often have a binary perception of risk. Probabilistic information is translated into two options: the child will or will not be affected. The graduality of chance seems to be of little importance in this process. Instead, the focus shifts to the possible consequences for future family life. ${ }^{13-15}$ Clearly, physicians and parents often look the same problem from a very different perspective. Physicians tend to approach the decision-making process from a rather detached and rational point of view. An unlikely outcome should not weigh heavily on the decision. Parents often give more weight to a possibility than its probability would suggest. This is necessary no doubt because that particular outcome is so undesirable to the parents. Thus, even a very unlikely outcome can predominate the decision-making.

The wording used by health professionals to communicate risks also influences the way the parents perceive the risks. Parents may attach different meanings to verbal expressions of risk when translating verbal to numerical expressions and vice versa. ${ }^{16,17}$ Moreover, the way in which numerical expressions are communicated is of influence on the perception of risk. ${ }^{16}$

The influence of uncertainty has also been studied. The availability of prenatal diagnosis had no influence on reproductive behaviour in couples with a recurrence risk of mental retardation. ${ }^{20}$ However, Frets observed that couples that have prenatal testing available have more difficulty with reproductive decision-making than couples without this option. ${ }^{19}$ This indicates that uncertainty might provide certain emotional advantages by relieving the parents from the burden of decision-making and enabling them to 'hope' for the best. ${ }^{18,19}$

\section{General models of decision-making \\ Subjective Expected Utility}

Most general decision-making theories regard decision-making as a relatively rational process of first weighing and then ranking alternatives, after which the best option is chosen. Perhaps the most relevant theory for our purposes is the Subjective Expected Utility theory, which was originally developed to explain human behaviour during gambling. ${ }^{20}$ The theory assumes a person will select the alternative with the highest utility. It is the product of the likelihood of an outcome occurring if a certain alternative is chosen and the desirability of this outcome..$^{20-24}$ 
According to this theory, parents evaluate the outcome of the several choices they can make and estimate the chance of these outcomes occurring. Their final choice is then based on the product of the desirability of the outcome and the chance of the outcome occurring.

However, many examples from a range of sources, including politics and medicine, clearly demonstrate that emotional mechanisms not accounted for in the Subjective Expected Utility theory play an important role in decision-making. ${ }^{15,25-27}$

\section{Framing and decision-making}

Tversky and Kahnemann criticised the Subjective Expected Utility theory because the concept of framing is not taken into account. ${ }^{23}$ Framing refers to the phenomenon that the context or frame in which a certain risk or outcome is communicated influences the way they are perceived. For instance, a healthy woman whose sister has trisomy 21 will perceive the risk of Down syndrome differently than a woman of similar age who does not have a sibling with trisomy 21 , although the magnitude of risk is the same for both women. Tversky and Kahnemann theorised the decision-making process consisted of two phases. Risks are first framed before being evaluated as indicated by the Subjective Expected Utility theory. The decision frame refers to the decision-makers perception of the acts, outcomes, and contingencies associated with a particular choice. The frame of a decision-maker is controlled by the formulation of the problem and by norms, habits and personal characteristics of the decision-maker. A specific problem can be framed in different ways, leading to different outcomes of the decision-making process. Several of the emotional mechanisms known to play a role in parental decision-making, such as binary perception of risk and the way probabilities are communicated, are perhaps best understood according to the concept of framing described by Tversky and Kahnemann. ${ }^{23}$

The first mode is framing the outcome. Outcomes are perceived as positive or negative in relationship to an outcome judged neutral. Thus, what is expected influences the way a certain outcome is perceived. This means that not only objective data are important in the decision-making, but also the reference point against which they are being weighed. Whether parents judge a certain abnormality to be acceptable depends on their reference point. For some parents this reference point might be the expectation their child is completely healthy; for others, it might be the fear their child has a lethal problem. Parents may attach different meanings to the same biomedical abnormality. For example, the finding of an isolated cleft lip might be viewed in one fashion by parents with all healthy children, and in a completely different fashion by parents who have lost a child and are childless.

A second important mode of framing is aversion of loss: the response to loss is more extreme than the response to gain. This means that in the case of fetal abnormality with the possibility of either a positive or negative outcome, the negative outcome will be a more prominent factor in decision-making even when the likelihood of an adverse outcome is smaller than that of a favourable outcome. For example, in the counselling of a double bubble sign on ultrasound, parents sometimes weigh the possibility of the child having Down syndrome heavier than the possibility of the child having no chromosome abnormality, even though the probability of the last scenario is much higher $(70 \%){ }^{28}$

The third mode of framing is exaggeration of the aversiveness of certain losses (in contrast to losses that are uncertain). People typically prefer a 'probable' to a certain but less worse negative event. They focus on the situation that gives them a chance of hope.

Finally, Tversky and Kahnemann observed that people generally evaluate acts in terms of minimal account, that is, they consider only the direct consequences 
of the act. ${ }^{23}$ Parents sometimes wish to terminate pregnancy immediately after the diagnosis of a lethal malformation. In doing so, parents evaluate only the direct consequences of their decision. They deny themselves the possibility of considering all alternatives (for example continuing pregnancy). The direct consequence of entering this mode might be relief brought on by denying the situation. By getting the affected child 'out of their system', parents believe they can evade the grief generated by bonding with the child they are to loose. But in doing so, they fail to consider the long-term consequences. For example, they may regret not having made a 'real' decision in which all options were given a fair chance. They may have discovered they would have preferred to continue the pregnancy even knowing they child would die at or shortly after birth because they had doubts about accuracy of the diagnosis, regrets of not having 'known' their child longer, feelings of guilt about having actively denied their child any chance to live and delayed mourning because of denial. Another example is the decision of parents not to consent to necropsy, a decision that might be influenced by the short-term impact of the negative emotions associated with this examination. Only in hindsight they recognise that the necropsy might have revealed important information easing their grief and providing insight into the risk of recurrence for future pregnancies.

\section{Stress and decision-making}

Stress plays a role in decision-making. ${ }^{26,27}$ Janis and Mann describe the optimal decision-making process as the thorough canvassing of alternatives and objectives, evaluation of consequences of current and new policies, search for information, unbiased assimilation of new information, evaluation of consequences and planning for implementation and contingencies. ${ }^{26}$ Stress is not all bad. Some stress is indeed necessary. Too little emotional involvement might cause the decision-maker to pay too little attention. Parents, who are not aware of the possible severity of fetal abnormality are not inclined to discuss several options for management of the pregnancy. In hindsight they might regret not to have made clear decisions about the pregnancy when they were in a situation they still could. Too much stress might make the decision-maker "frantically search for a way out of the dilemma and impulsively seize upon a hastily contrived solution that seems to promise immediate relief, overlooking the full range of consequences of his choice" (1). Therefore, in counselling about termination of pregnancy counsellors have to be aware that requesting termination of pregnancy might be a way for the parents to cope with the extremely high levels of stress.

Janis and Mann recognise three conditions that improve the quality of decision-making: (1) moderate, but not excessive awareness of the risks of each alternative, (2) hope of finding a better alternative than the ones already known (3) belief that there is sufficient time to consider alternatives. ${ }^{26}$ In the scenario of decision-making after ultrasound diagnosis of a fetal abnormality, the perceived stress might be so extreme that it endangers the rationality and coherence of the decision-making process. Pregnant women and their partners are often well aware of the risks of each alternative. In our experience, they are usually conscious of the fact that they are deciding the future of their unborn child, their family and themselves. Any hope of finding a better alternative is lost because all possible outcomes of the decision-making process are negative. In some cases, parents try to relieve stress by searching for more alternatives, for example on the Internet, or to find similar cases with a more positive outcome than the norm relayed to them during counselling. Finally, stress is induced because parents often rightly feel that there is inadequately time to consider their decision. This might be due to time limitations for pregnancy termination, advancing maternal disease, or simply feeling the baby growing and kicking while knowing that the child is not healthy or even is going to die. 
There is little empirical research about the role of stress in parental decisionmaking. In a study describing problems in reproductive decision-making, $43 \%$ of the couples described the process of decision-making after genetic counselling as difficult. Of these couples, $28 \%$ could not reach a decision. ${ }^{19}$ Further, decisionmaking was generally unstructured and emotions played an important role. ${ }^{19}$

\section{Naturalistic decision-making theories}

In response to criticism on rational, prescriptive decision-making theories, naturalistic decision-making theories have emerged. ${ }^{29}$ These theories see decisionmaking as context-specific and dynamic, whereby complexity is rather accepted than reduced. ${ }^{29}$ Naturalistic decision-making theories distinguish two phases of decisionmaking: a selection phase and an evaluation phase. In the selection phase, the situation is assessed and matched with a course of action. Matching is under influence of things such as personal experience, morals and goals aspired to. In the evaluation phase, the problem can be seen as being structured after the fact, to justify the decisions already made. So, according to the naturalistic decision-making theories, parents first make a choice, that is consistent with their personal beliefs and then construct reasons for this choice. ${ }^{29}$ For example we all know cases of anencephaly wherein parents immediately request for a termination of pregnancy after hearing that the infant will die after birth. These parents seem to have decided by intuition what, given the situation, for them is the best option. In a later stage they often structure their decision by arguments like 'there was no point in continuing pregnancy" or even state 'there was no real choice'.

\section{Perceived control}

An important issue of parental coping with the decision taken is perceived control. Perceived control is the feeling of control people experience. Perceived control is beneficial in coping with difficult health situations. ${ }^{30-33}$ The role of perceived control is unclear in the case of decision-making after ultrasound diagnosis of an abnormality. ${ }^{34}$ On the one hand, it might be expected that, as in other health situations, perceived control will aid future parents in coping with a very difficult situation. On the other hand, couples confronted with an extremely burdensome situation, one that evokes strong emotions and possibly emotional instability may be relieved to shed the burden of choice. 9,12,13,35-39 "Doctor, what would you do if this was you?" is a familiar refrain. Though we are trained to follow a non-directive attitude in counselling, perhaps there are situations where this is suboptimal. ${ }^{11,40-43}$ More research is needed to establish the role of perceived control and perinatal grief.

\section{Discussion}

The implications of the various mechanisms underlying the quality of the decision-making process depend on the perspective from which they are viewed. Decision-making theories often focus on rationality and coherence of the decisionmaking process to avoid the problem of normative judgement about what is a good decision. ${ }^{23}$ However, the studies of both the influence of framing and the influence of stress indicate that cognitive mechanisms, such as matching, hoping and framing may have an important and beneficial function in the decision-making process. $23,26,44,45$ They may protect basic personal stability from the emotional and cognitive strains caused by the complexity and emotionally disintegrating effect of having to make choices about a loved child. From this viewpoint, these phenomena are not disturbing, but rather facilitate the decision-making process. This observation has important implications for the evaluation of the quality of the decision-making process. It should not be assessed on the basis of its rationality, but on the basis of the parental emotional outcome. In the end, it is about how do parents, faced with a 
potentially life or death decision about a serious fetal abnormality, cope with the outcome of the decision-making process. Whether parents perceive themselves as having a choice at all and what impact this has on the way parents deal with the outcome is another important issue. It suggests the need for a new approach to understanding the process of parental decision-making. Further research is needed to come to improve the model, bridging the gap between rational decision-making theories and clinical reality. Such a model will help us developing guidelines on how to help parents reach their decision in a way that they can best live with the consequences, both for the short and the long term.

\section{Conclusion}

Cognitive mechanisms that are often elicited by emotions and that are not necessarily rational may have an important and beneficial function in parental decision-making after ultrasound diagnosis of fetal abnormality. Consequently, the process of parental decision-making should not be assessed on the basis of its rationality, but on the basis of the parental emotional outcome.

\section{Acknowledgements}

The authors would like to thank the Sophia Foundation for Medical Research for financial support and C.Weiner for his critical comments on earlier drafts of this paper. 


\section{References}

1. Chervenak FA, McCullough LB: An ethically justified, clinically comprehensive management strategy for third-trimester pregnancies complicated by fetal abnormalities. Obstet Gynecol 1990;75:311-6

2. Marteau TM, Dormandy E: Facilitating informed choice in prenatal testing: how well are we doing? Am J Med Genet 2001;106:185-90.

3. Thomassen-Brepols LJ. Psychological implications of fetal diagnosis and therapy. Fetal Ther 1987;2:169-174

4. Verjaal M, Leschot NJ, Treffers PE: Women's experiences with second trimester prenatal diagnosis. Prenat Diagn 1982;2:195-209.

5. Carnevale A, Lisker R, Villa AR, Casanueva E, Alonso E: Counselling following diagnosis of a fetal abnormality: comparison of different clinical specialists in Mexico. Am J Med Genet 1997;69:23-8.

6. Geller G, Tambor ES, Papiernik E: Attitudes toward abortion for fetal abnormality in the second versus the third trimester: a survey of Parisian obstetricians. Prenat Diagn 1993;13:707-722.

7. Schechtman KB, Gray DL, Baty JD, Rothman SM: Decision-making for termination of pregnancies with fetal abnormalities: analysis of 53,000 pregnancies. Obstet Gynecol 2002;99:216-22.

8. Sheiner E, Shoham-Vardi I, Weitzman D, Gohar J, Carmi R. Decisions regarding pregnancy termination among Bedouin couples referred to third level ultrasound clinic. Eur $\mathrm{J}$ Obstet Gynecol Reprod Biol 1998;76:141-146.

9. Chitty L, Barnes C, Berry C: Continuing with pregnancy after a diagnosis of lethal abnormality: experience of five couples and recommendations for management. BMJ 1996;313:478-80.

10. Van 't Hof D, Ebans-Leijdekker $M$, Wiesenhaan $P$, Edelbroek $S$, Exalto $N$. [Request for late pregnancy interruption in severe fetalm anomalies]Verzoek tot late zwangerschapsafbreking bij ernstige aangeboren afwijkingen. Ned Tijdschr Geneeskd 1996;140:585-587.

11. Fertel P, Reiss R. Counseling prenatal diagnosis patients:the role of the social worker. Soc Work Health Care 1997;24:47-63.

12. Sandelowski M. Jones LC. 'Healing fictions'. Stories of choosing in the aftermath of the detection of fetal anomalies Soc Sci Med 1996;42:353-361

13. Beeson D, Golbus M. Decision making: whether or not to have prenatal diagnosis and abortion for x-linked conditions. Am J Med Gen 1985;20:107-14.

14. Lippmann-Hand A, Fraser $C$. Genetic counseling:provision and reception of information. Am $J$ Med Gen 1979;4:113-27.

15. Redelmeier D, Rozin P, Kahneman D. Understanding patients' decisions. JAMA 1993;270:7276.

16. Shiloh S, Sagi M. Effect of framing on the perception of genetic recurrence risks. Am J Med Gen 1989;33:130-5.

17. Shaw NJ, Dear PR: How do parents of babies interpret qualitative expression of probability? Arch Dis Child 1990;65:520-3.

18. Black R: Risk taking behavior:decision making in the face of genetic uncertainty. Soc Work Health Care 1981;7:11-25.

19. Frets $\mathrm{P}$, Duivenvoorden H, Verhage F, Peters-Romeyn B, Niermeijer M: Analysis of problems in making the reproductive decision after genetic counselling. J Med Gen 1991;28:194-200.

20. Von Neumann $J$, Morgenstern O. Theory of games and economic behavior. Princeton: Princeton University Press; 1947

21. Lippman-Hand. Prenatal genetic testing and geneticization: mother matters for all. Fetal Diagn Ther 1993;8(suppl1):175-188

22. Rachlin H. Judgment, decision and choice, a cognitive/ behavioral synthesis. New York: W.H. Freeman and Company; 1989.

23. Tversky A, Kahneman D: The framing of decisions and the psychology of choice. Science 1981;211:453-458.

24. Ridderikhoff. Decision-making strategies in the general practice. Rotterdam: Erasmus University; 1986.

25. Allison GT. Essence of decision:explaining the Cuban missile crisis. London: Glenview; 1971.

26. Janis I, Mann L: Coping with decisional conflict, an analysis of how stress affects decisionmaking suggests interventions to improve the process. Am Sci 1976;64:657-67.

27. Noorderhaven N. Strategic decision making. Workingham etc: Addison-Wesley; 1995.

28. Murshed R, Nicholls $G$, Spitz L: Intrinsic duodenal obstruction: trends in management and outcome over 45 years (1951-1995) with relevance to prenatal counselling. $\mathrm{Br} \mathrm{J}$ Obstet Gynaecol 1999;106:1197-9.

29. Broadstock M, Michie S: Processes of patient decision making: Theoretical and methodological issues. Psychol Health 2000;15:191-204

30. Adler N, David H, Major B, TRoth S, Russo N, Wyatt G: Psychological factors in abortion. Am Psychol 1992:1194-1204. 
31. Suls J, Mullen B. Life events, perceived control and illness: the role of uncertainty; J Human Stress 1981;7:30-34.

32. Shiloh S, Berkenstadt M, Meiran N, Bat-Miriram-Katznelson M, Goldman B: Mediating effects of perceived control in coping with a health threat: the case of genetic counseling. J Appl Soc Psych 1997;27:1146-74.

33. Perlmuter L, Monty R: The importance of perceived controlffact or fantasy? Am Sc $1977 ; 65 ; 759-765$.

34. Hunfeld J, Wladimiroff J, Passchier J: Pregnancy termination, perceived control, and perinatal grief. Psychol Rep 1994;74:217-218.

35. Lub A, Schuitemaker NW, van Roosmalen J, Klumper FJ, Vandenbussche FP: [Continuation of pregnancy in infaust fetal prognosis] Uitdragen van een zwangerschap bij een foetale prognose 'infaust'. Ned Tijdschr Geneeskd 1997;141:2273-6.

36. Hunfeld J, Wladimiroff J, Passchier J, Venema-van Uden M, Frets P, Verhage F: Emotional reactions in women in late pregnancy (24 weeks of longer) following the ultrasound diagnosis of a severe or lethal fetal malformation. Pren Diagn 1993;13:603-12.

37. Muller P, Ryser L. Pregnancy termination in fetal abnormalities (in German). Schweiz Med Wochenschr 1997;127:73-78.

38. Gotzmann L, Schonholzer SM, Kolkle N, Klaghofer R, Scheuer E, Huch R, et al:: Uitrasound examinations in the context of suspected fetal malformations: satisfaction of concerned women and their appraisals. Ultraschall Medizin 2002;23:27-32.

39. Langer $M$, Ringler $M$ : Prospective counselling after prenatal diagnosis of fetal malformations: interventions and parental reactions. Acta Obstet Gynecol Scand 1989;68:323-9.

40. Adler B, Kuchnick $T$ : Genetic counseling in prenatally diagnosed trisomy 13 and 18:psychosocial aspects. Pediatrics 1982;69:94-99.

41. Langer $M$, Ringler $M$ : Management of couples following prenatal diagnosis of fetal abnormalities. Geburtshilfe und Frauenheilkunde 1987;47:186-9.

42. Saal HM: Prenatal Diagnosis: when the clinician disagrees with the patient's decision. Cleft Palate Craniofac J 2002;39:174-79.

43. Perrotte F, Mirlesse V, De Vigan C, Kieffer F, Meunier E, Daffos F: Medical t ermination of pregnancy for fetal abnormality: the patient's point of view. J Gynecol Obstet Biol Reprod (Paris) 2000;29:185-91.

44. Loewenstein GF, Weber EU, Hsee CK, Welch N: Risk as feelings. Psychol Bull 2001;127:267286.

45. Frisch D, Clemen R: Beyond expected utility: rethinking behavioral decision research. Psychol Bull 1994;116:46-54. 


\section{Chapter 7}

\section{Women's views on decision-making about their unborn child with congenital abnormality: a qualitative study.}

H.H.Bijma, H.I.J.Wildschut, A.van der Heide, J.Passchier, P.J.van der Maas, J.W.Wladimiroff (submitted for publication) 


\begin{abstract}
Objectives

To explore pregnant women's reactions after ultrasound diagnosis of fetal abnormality and their perceptions of choice in making decisions about whether or not to terminate pregnancy, and to describe the considerations that play a role in such decisions.
\end{abstract}

\title{
Design
}

Qualitative analysis of prospective semi-structured telephone interviews with women within 1-3 weeks after ultrasound diagnosis of fetal abnormality.

\section{Setting}

Women who were diagnosed with fetal abnormality by ultrasound in a tertiary referral centre.

\section{Population}

30 pregnant women with ultrasound diagnosis of fetal abnormality

Methods

Qualitative analysis

Main outcome measures

Themes arising in women's reactions after diagnosis, perceptions of choice, considerations in decision-making

\section{Results}

Women's reactions after ultrasound diagnosis of fetal abnormality include a wide range of themes, such as grasping the facts, emotions, decision-making, and identity as a parent.

Perceptions of having a choice about whether there was a choice to be discussed varied widely in women, even in medically comparable situations. The rational decision-making, typically aimed for by doctors, is at times troubled by the more naturalistic, intuitive way of decision-making of the women.

In the deliberation of pregnancy termination, women considered the wellbeing of the unborn child, as well as their own well-being and that of the other children and their partner. The benefits of continuing versus terminating pregnancy were appreciated differently. Moral values about whether or not termination of pregnancy is allowed also played a role in the decision making.

\section{Conclusion}

The ambiguity of fetal ultrasound, being on the one hand a technical tool that may providing diagnostic information leading to the discontinuation of pregnancy, while on the other hand it is a bonding ritual personifying the fetus and affirming the reality of the baby to be born. In case of an ultrasound diagnosis of fetal abnormality, the ultrasound examination typically evokes complex reactions. In this situation, perceptions of choice vary widely between women, challenging the possibilities of shared decision-making. In making decisions about termination of pregnancy, women consider its consequences for both the unborn infant and the family as well as moral values. 


\section{Introduction}

Since the first ultrasound image of a fetus in 1963, ultrasound has evolved into the most important diagnostic tool in fetal medicine. "Nowadays, ultrasound examination during pregnancy is routine practice in industrialised countries, diagnosing more than half of all congenital abnormalities before birth. ${ }^{1-3}$ Socially, ultrasound has been widely accepted and has become an integral part of pregnant women's embodied experience of pregnancy. ${ }^{4}$ For most women, however, ultrasound is a way of 'meeting the baby' rather than a diagnostic tool, which could reveal fetal abnormality. ${ }^{5-7}$ Kohut et al, evaluating the knowledge of 113 Canadian women about fetal abnormality scan, showed that about half of the women did not view this scan as a screen for fetal abnormalities. ${ }^{7}$ Usually, ultrasound examination reveals no fetal abnormality, thereby reassuring the pregnant woman and enhancing maternal-fetal attachement. 8

In the case of fetal abnormality, however, women are frequently not prepared for such finding, which could alter the future of their unborn child as well as their own. ${ }^{6}$ Furthermore, women may need to make choices about whether or not to continue pregnancy. Little is known about how decision-making in this context takes place. Currently, shared decision-making is seen as the best way to make medical decisions. ${ }^{9-12}$ Charles described its four necessary characteristics as follows: 1 . both the physician and patient are involved in the decision-making process, 2 . both the physician and patient share information with each other, 3 . both the physician and patient take steps to participate in the decision-making process by expressing treatment preferences, and 4 . a treatment decision is made, and both the physician and patient agree on the treatment to implement. ${ }^{9}$ This model is in accordance with non-directiveness that is currently a valued approach of genetic counsellors. ${ }^{10}$

However, some characteristics of decision-making after ultrasound diagnosis of fetal abnormality may limit the possibilities for shared decision-making and nondirective counselling. Firstly, the diagnosis of fetal abnormality evokes a strong emotional reaction, which may limit the woman's capabilities for decision-making. Indeed, previous research showed that women preferred a self-confident, decisive physician. ${ }^{11}$ Secondly, choices about prenatal diagnosis are frequently experienced as burdening. ${ }^{12}$ It may be that the burden of the long-lasting implications of the women's choice is so large that one may wonder whether women should be made (partially) responsible. Finally, to date little is known about how women perceive choice after ultrasound diagnosis of fetal abnormality. Sandelowski studied parental perception of choice after prenatal diagnosis', including invasive testing as well as ultrasound. She described that even in pregnancy termination, parents sometimes experienced that they had no choice. ${ }^{13}$ In this situation, doubts about the applicability of the shared decision-making model arise. The moral burden associated with pregnancy termination may further limit the applicability of shared decision-making in this situation. Some women may experience mentioning the option of termination of pregnancy as an undesirable statement against their unborn child's right to live.

To date, the research on the decision-making process after ultrasound diagnosis of fetal abnormality has focused on the determinants of termination of pregnancy. Lower gestational age, a more severe abnormality, involvement of the central nervous system, previous uncompleted pregnancies, lower maternal educational level, and the presence of chromosomal abnormalities have been related with a higher rate of women deciding upon termination of pregnancy. ${ }^{14-17}$ However, these data are not conclusive and do not reflect why and in what way some factors are important for the parents. Little is known about the considerations that play a role in deciding about whether or not to terminate pregnancy.

In this study we aimed at gaining insight in the process of pregnant women's decision-making by describing pregnant women's thoughts after ultrasound diagnosis of fetal abnormality, their perceptions of choice and the considerations that were important in decision-making. 


\section{Methods}

The 30 interviewed women were all diagnosed with a fetal abnormality of various severity. They took part in a larger ongoing study in our tertiary centre, which describes the decision-making process of women after ultrasound diagnosis of fetal abnormality quantitatively. They were only included if they spoke Dutch or English fluently and could be interviewed by phone. Women from the larger study were selected in such way to reach a wide variation in severity of the fetal abnormality and gestational age. At the time of the diagnosis, women gave permission to be approached by a physician-researcher (HB), who called a few days later for an interview by phone.

The interviews were semi-structured, the general issue being all considerations regarding decision-making about the course of action regarding their pregnancy. Firstly, we asked participants to describe their predominant thoughts after the ultrasound examination. Secondly, we asked whether they felt they were facing choices about the course of action regarding their pregnancy. Finally, we asked women who felt they were facing choices about the pregnancy, what obstetric management they preferred and what considerations were important to them. The interview strategy aimed at encouraging women to give their full personal account, thereby telling them that information would be shared with their physician at their explicit request only. We obtained ethical approval for this study from the regional ethics review board. All eligible women had given oral and written consent.

All interviews were recorded, typed out verbatim and coded line by line. To test the reliability of the analysis, a second researcher (HW) reanalysed $25 \%$ randomly selected verbatim reports. No substantial differences were found at this analysis.

\section{Results}

Thirty women participated in this study. Median gestational age at the time of the diagnosis was 22 weeks (range 12-37 weeks). Fetal prognosis was considered lethal in $6(20 \%)$, poor in $9(30 \%)$, good in $9(30 \%)$, and uncertain in $6(20 \%)$ women. Nine women opted for termination of pregnancy at the time of the interview; $16(53 \%)$ women continued their pregnancies, while $5(17 \%)$ women did not know yet what course to follow.

Median maternal age was 30 years (range19-42 years). Four women (13\%) had low-level education, 15 women $(50 \%)$ had middle level education, and 11 women $(37 \%)$ had high-level education; fifteen women $(50 \%)$ had paid occupation. Eight (27\%) women considered themselves religious. 16 women $(53 \%)$ had one or more living children.

Median time between the ultrasound and diagnosis was 7 days (range 1-21 days). Median duration of the interviews was 17 minutes (range 9-46 minutes).

\section{Issues and concerns after the diagnosis}

The participants reported a wide variety of thoughts during the days after the ultrasound diagnosis. Box 1 shows the themes that emerged. At the moment of the interview, some women were in the process of grasping the facts. This was reflected in: 1) describing that they were getting used to the situation, 2) transforming the diagnosis and prognosis into concrete implications, e.g. what does the diagnosis mean, what to expect for the future, what treatment will be necessary after birth, 3) experiencing an urge for information and certainties, 4) thinking about why this is happening to them, and 5) feeling as if the situation was unreal. For some women, religious faith made it easier to deal with the new situation. Some women were completely bewildered by the diagnosis of fetal abnormality, not knowing what to think or feel.

Furthermore the women experienced a wide range of emotions. Some women described negative emotions, such as fear, anger, guilt, and sadness, while others experienced positive emotions, such as hope, resignation, and relief, e.g. 
about a prognosis that was better than anticipated or about knowing about the abnormality before giving birth.

Some women reported they were predominantly occupied with the choices they felt they had to make. These women usually were in the process of weighing the different scenarios.

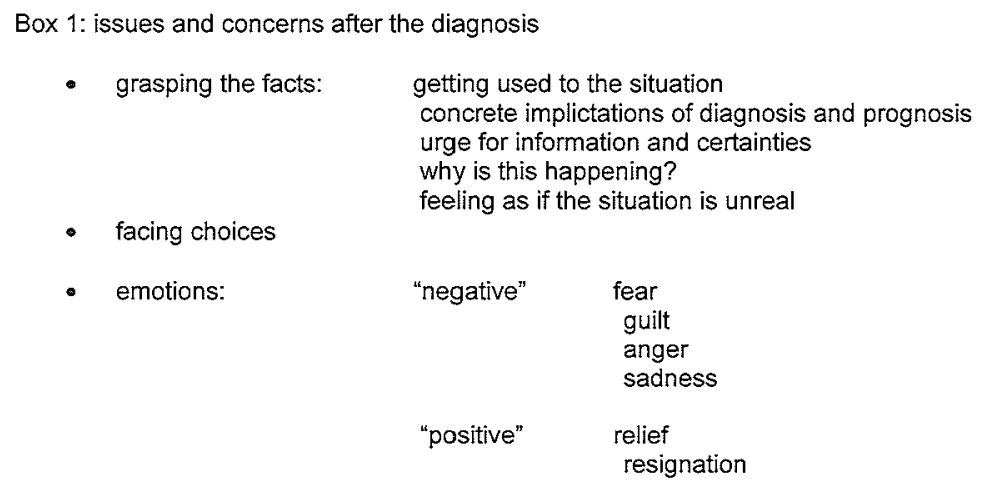

- identity as a parent

Finally, identity as a parent emerged as a theme. Women were in the process of defining themselves as parent, as reflected in parental bonding to the unborn infant and thinking about becoming a parent.

\section{Women's perceptions of choice}

Women's perceptions of whether or not they had to make choices about continuing pregnancy varied widely. Some women felt they clearly had a choice, some women felt they had clearly no choice, and some women were ambiguous about whether or not they were having choices.

For women who clearly felt they had no choice to make the prognosis of the fetal abnormalities could be uncertain, good, poor or lethal. Experiencing having no choice could be based on several grounds (box 2). Firstly, some women felt that taking a decision was beyond their competence, either because they felt it was not up to them to end a life or because it was too burdensome to make a choice. Secondly, some women felt that fetal prognosis was so poor, that this left them no choice. This concerned fetuses that were deemed to die anyhow. These women felt that nature had taken action already and that a choice to continue or terminate pregnancy had no influence on the fatal outcome. Thirdly, some women felt there was no choice because the pregnancy was too advanced (either because the fetus had already become too much of a person to them, or because of legal restraints), or because they judged the prognosis of the abnormality to be relatively good. Finally, some women felt they had no choice because they did not want to think about choices.

Some women, with either an uncertain, good, poor or lethal prognosis clearly felt there was indeed a choice to make about whether or not to continue pregnancy (box 3). In these women, two patterns of decision-making occurred. The first consisted of weighing the benefits and drawbacks of the different options. Women made scenarios and evaluated the outcome of these scenarios, resulting in a weighted choice. The second pattern of decision-making concerns an intuitive choice. The women making an intuitive choice felt rather than reasoned what was the right choice for them. 
Some women reported ambiguity in their views on choice (box 4). These women had a choice, i.e. they mentioned several possible courses of action. However, it was so clear to them what was the right course that they felt there was no choice to make.

Medically comparable situations yielded very different perceptions of choice. This can be illustrated by comparing five women who were pregnant of a child with a lethal prognosis. Two women felt there were no choices to make (woman 3 and woman 7 (box 2)), one woman felt there was a choice to make (woman 27 (box 3)), and two women were ambiguous about whether or not there were choices to make (woman 4 and woman 16 (box 4)). Furthermore, two women, even though agreeing that there were no choices to make, opted for opposite courses of action (woman Box 2. Views of women, who experienced no choice about continuing pregnancy after ultrasound diagnosis of fetal abnormality.

\section{No choice}

1. Making a choice is beyond my competencies

It is not up to me to end a life

'No, there's no doubt in my mind, that whatever may be wrong, especially because of our religious beliefs I don't believe that it's up to us to end a life.' (woman 1, fetus with abnormality with good prognosis)

Too burdensome a choice

'No, I could never bring myself to do that, because that would make me feel that I would truly be taking the baby's life.' (woman 3, fetus with abnormality with lethal prognosis)

\section{Nature has already decided}

At that moment, you're simply told there is really no chance of survival, uh, and I guess, however awful the situation is, we're glad with this result. We're glad that we haven't been forced to choose(...) However strange it may sound, we were glad with the result that meant we didn't have to choose whether or not to let the baby be born (..) To put it bluntly: there was nothing to consider. If you ask some one, I very explicitly asked the person who did the ultrasound whether there was any chance of survival and you're told there's not, then you know the baby will die, whether in 40 weeks from now or the moment it's born, and five days later or not, you just know there's nothing to consider, you haven't got a choice' (woman 27 , fetus with abnormality with lethal prognosis)

\section{In this situation I have no choice}

Too advanced pregnancy

'Well I didn't really have the chance to choose, as my pregnancy was already too advanced, so uh, well you don't actually get to make a choice, you just choose to go on and accept that, well, the baby will be born, it will be given help and wait' (woman 13 , fetus with abnormality with uncertain prognosis)

There would only be a choice in case of an extremely poor prognosis

'No, no, at the worst only if it should turn out to have all kinds of really awful things, like there would be reason to suspect, say, a trisomy 13 or whatever, well, that would be different, but if it's only the schisis, no, absolutely not' (woman 14 , fetus with abnormality with good prognosis)

\section{I don't want to think about choices}

'No, we just want to wait the two weeks, and then we'll hear whether or not it's a choice we'll have to face. Obviously, the choice is something you can already talk about. How far we'll go. But it's something we prefer not to think about too much.' (woman 28 , fetus with abnormality with uncertain prognosis)

3 and woman 7 (box 2)): one to continue pregnancy (woman 3) and one to terminate pregnancy (woman 7). Women with a good fetal prognosis had different perceptions of choice as well. Compare for example, two women who were both pregnant of a child with a cleft lip/palate. For one woman this did not result in the perception of having to choose (woman 14 (box2)), whereas another woman was struggling with making a choice (woman 8 (box3)). She was angry that doctors had not discussed the possibility of pregnancy termination with her after this diagnosis and felt it was her right to be fully informed about all options 


\section{Considerations}

A wide range of considerations was important for women who decided to terminate their pregnancy (box 5). When the child had no chance of survival, some women felt that continuing pregnancy would impose either physical risks or an emotional burden upon themselves, while it would not benefit the fetus. Some women opted for termination of pregnancy in case of fetal prognosis that was poor, but not precluding survival. These women mentioned poor quality of life for the child as a reason to terminate their pregnancy. Another consideration was the well-being of other children in the family. Women feared that the attention and care that would be needed for a handicapped sibling would have a negative effect on the well-being of other children of the family. Finally, a partner favouring termination of pregnancy was mentioned as playing a role.

Box 3. Views of women, who reported experiencing there were choices to make about continuing pregnancy after ultrasound diagnosis of fetal abnormality.

\section{Choice}

\section{Weighted choice}

'Oh, yes. Yeah, because they said that if 1 then wanted to have it removed that we could discuss it then, and that uh, then I could still have it removed. But then I think, like, should I let them remove it now, because I. like, don't know whether it can feel any pain or not and if I don't have it removed now, on the other hand I do want to know how long it will survive... will it make it up to forty weeks, I mean these are the kind of questions you're constantly wrestling with, because if you decide one way, what are the consequences and what if I decide the other way. '(woman 7, fetus with abnormality with lethal prognosis)

'Hmm, I guess just the decision you have to take is, 1 think, very hard and particularly so because you can already feel that it's alive, you see. And, yeah, on the one hand you think, what are you putting a baby like that through by letting it be born. On the other hand, it's also just extremely difficult, I mean you yourself are taking the decision to end someone's life.' (woman 9, fetus with abnormality with poor prognosis)

'The thought that on the one hand I had the feeling I had to decide within a week to uh end the pregnancy or not, because I was almost at 23 weeks when the ultrasound showed well you know and, yeah then they start in about the 24-week limit and then it's really down to, well, what to decide and that is so hard, as a parent, to have to face a choice about deciding about your child's life (...) it is so hard to be faced with this choice and it is so tough and I know that everybody has a different way of looking at it, some would say I can't handle it and I don't want to have the baby in my body any more, but I just feel as if I would be tearing it from the place where it's safe and that I would be playing God. '(woman 2, fetus with abnormality with poor fetal prognosis)

'Pregnancy termination did come into it for a while and the consequences this could have on your emotional life and everything else. At a certain moment, I really felt that I had my back up against a wall and was being forced to choose between two evil, two inhuman things (...) I had various reactions (from doctors - HB), like a schisis is no reason to terminate a pregnancy and it made me very angry, as if they were forcing me into a particular corner, and even if you'd want to, it's not like it's all of a sudden, by then there've also been so many discussions and tears already, and at a certain moment I really felt like who is this guy in a white coat to tell me that they don't do that, as far as that goes it was very unfair was my experience, first that they didn't suggest that option themselves, okay, option sounds terribly businesslike because you're talking about a baby's life. I just think people deserve to know what's what and what's possible, I just think it's your right.' (woman 8 , fetus with abnormality with good prognosis)

\section{Intuitive choice}

'My choice was very definite and nothing about that is going to change, I want it out, and that was the first thing I said, and there was absolutely no other possible way to think about it. ' (woman 22, fetus with abnormality with lethal prognosis) 
Box 4. Views of women, who reported ambiguity in their views on choice about continuing pregnancy after ultrasound diagnosis of fetal abnormality.

Ambiguous choice

'Of course we think we have to make a choice, but for us, it wasn't a choice.'

(woman 4, fetus with abnormality with lethal prognosis)

'No, it wasn't that, they were very clear about that, that there was simply no chance of survival, so then you can choose whether to go on carrying, but that's hardly sensible and not really advisable, according to the doctors, so as far as that goes you have no choice.' (woman 16, fetus with abnormality with lethal prognosis)

Some women who decided to continue pregnancy that was complicated by a fatal fetal abnormality felt that carrying their pregnancy to term would be beneficial for the infant, for example because this provided the child with a comfortable environment (box 5). Some women felt their own well-being benefited from carrying their pregnancy to term, for example because they would have the possibility to hold the living child in their arms for a while, or because this would enable them to bury their child. Other considerations were their emotional attachment or that they felt the child's movements, which made it impossible for them to take matters in their own hand. Finally, moral reasons played a role in choosing to continue pregnancy. Some women felt that it was not up to them to end a life or were convinced that they had to accept their fate.

Box 5. Pregnant women's considerations for terminating or continuing pregnancy after ultrasound diagnosis of fetal abnormality.

Considerations for termination of pregnancy

- The child has no chance of survival

- There is no benefit in carrying pregnancy to term

- Maternal physical risk of carrying pregnancy to term

- Emotional burden of carrying pregnancy to term

- Being able to start mourning

- Suffering of the child (pain, quality of life)

- Well-being of other children in the family

- Preference of partner

Considerations for continuing pregnancy

- Being able to hold a living child

- Being able to bury the child

- Fear of regretting a termination of pregnancy

- Keeping the child in a safe environment

- Giving the child the opportunity to bond

- Having an emotional attachment to the child

- Feeling the child

- Wanting to accept the fate of life

- Not having the right to end a life

\section{Discussion}

The double standard of fetal ultrasound

As is illustrated by the findings of this study, a variety of reactions emerged among pregnant women after the diagnosis of fetal structural abnormality. The women in our study tried in several ways to grasp the facts, by exposing a need for ample and concrete information and an urge for certainties, as well as by 
experiencing the situation as unreal. Furthermore, they experienced a wide range of emotions and were sometimes struggling with their identity as a parent.

This wide range of reactions reflects the double standards of fetal ultrasound in western society. On the one hand, fetal ultrasound is a technical instrument, aimed at diagnosing fetal abnormality and providing relevant medical information. Such information may have several benefits. Firstly, it enables planning of specialised obstetric and neonatal care, which may improve infant outcome, for example in case of serious cardiac abnormalities and in case of diaphragmatic hernia or lung abnormalities warranting the need of extra-corporeal membrane oxygenation. 18 19 Occasionally, treatment in utero may even be an option, for example in case of twinto-twin transfusion or fetal arrhythmias. Secondly, diagnosis of fetal abnormality could help physicians to avoid futile, but possibly harmful medical interventions. This situation occurs when fetal abnormality with no chance of survival is diagnosed, for example anencephaly, trisomy 13 , trisomy 18 or bilateral renal abnormality. In case of such abnormalities, medical intervention aimed at prolonging fetal life, for example caesarean section on fetal indication, does not improve the infant's outcome. Such intervention, however, may harm the pregnant woman or future infants, for example by surgical complications or by rupture of the uterine scar in subsequent pregnancy. Thirdly, diagnosis of fetal abnormality enables parents to adjust to the new situation before birth, thereby possibly improving attachment after birth, for example in case of cleft lip/palate. ${ }^{20}$ Finally, diagnosis of fetal abnormality informs parents, thereby enabling them to make choices about whether or not to continue pregnancy. In this study, the diagnostic, information-providing side of fetal ultrasound is reflected in the findings that, after diagnosis of fetal abnormality, pregnant women experience a grief reaction on the news, and feel they are facing choices.

In western culture fetal ultrasound has a different, more ritual role as well. It is baby's first picture. ${ }^{5}$ That is, for many women and their partners fetal ultrasound is the hallmark in acknowledging the reality of the unborn infants existence. ${ }^{21} 22$ Fetal ultrasound changes the pregnancy from an extension of the woman's body into a fetus with it's own personhood. ${ }^{523-25}$ Hence, most women having fetal ultrasound, expect a bonding experience rather than a diagnostic test. ${ }^{7}$ When fetal ultrasound is reassuring, the notion is that no problems will arise; fetal ultrasound is unequivocally a bonding experience. ${ }^{8}$ However, when fetal ultrasound shows fetal abnormality, a double problem arises. Firstly, ultrasound fails to be the unburdened bonding ritual it was expected to be. Secondly, parents are 'brutally" confronted with the diagnostic capacity of ultrasound. The diagnosis of serious fetal abnormality may evoke choices about whether or not to continue pregnancy. These choices demand pregnant women and their partners to take up their parental role, while the ritual establishing such attachment has just been severed. Hence, ultrasound diagnosis of fetal abnormality on the one hand disturbs the western ritual of becoming a parent, while on the other hand such diagnosis demands taking up such role. The double standard of ultrasound is illustrated by the findings of this study, e.g., women having trouble to grasp the facts, at times even experiencing depersonalisation and derealisation and struggling with their identity as a parent. This becomes painfully apparent when the findings are not reassuring.

\section{Choice and decision-making}

Women had highly variable perceptions of choice, which can be referred to as having 'no choice', 'a choice' and 'ambiguous choice'. Women could experience no choice for several reasons. Firstly, some women showed a rejected choice: they acknowledged that several courses of action existed but they did not want to decide about such choice, because they felt it is morally not up to them to make such choice, because they found such choice too burdensome or because they just avoided thinking about such choices. Sandelowksi, interviewing 12 women and their 
partners about their perceptions of choice after prenatal diagnosis showing fetal abnormality, found similar perceptions (referring to them as disowned choice) ${ }^{13}$. Secondly, in accordance with Sandelowski's study some women showed a perception of choice referred to as nature's choice, that is they felt they had no choice because the real choice had already be made by nature. Whatever they would do, it would not affect the long-term future of their child. Hence, whether they would terminate their pregnancy or not, there was no real choice to be made. Finally, women could experience no choice in this specific situation, i.e. they acknowledged that general decisions could be made, but found this was not justified in this specific situation, because of the duration of gestation or the good prognosis of the child being affected. Two patterns emerged in women, who did perceive a choice. Firstly, some women showed a weighted choice. They made different scenarios and weighted the pros and cons of these scenarios. Other women showed an intuitive choice, i.e. they felt rather than reasoned what was the right choice for them. Unexpectedly, another pattern of choice emerged in this study, namely that of ambiguous choice. Women showing ambiguous choice were aware that several courses of action existed, but felt they had no choice. For them the right course of action to pursue was so evident, that they felt there was no choice to make. This way of decision-making can be understood from the perspective of naturalistic decisionmaking theories. These distinguish two phases of decision-making: a selection phase and an evaluation phase. In the selection phase, the situation is assessed and matched with a course of action. Matching is under influence of factors such as personal experience and morals. In the evaluation phase, the problem can be seen as being structured after the action to justify the decisions already made intuitively. So, according to the naturalistic decision-making theories, women first make a choice, that is consistent with their personal beliefs and then construct reasons for this choice. ${ }^{26} 27$

Remarkably, women had very different perceptions of choice in medically comparable situations, i.e. in case of similar fetal prognosis. For example in case of lethal fetal prognosis, women could experience a choice, no choice or an ambiguous choice. Furthermore, women could experience no choice, implying that no deliberating needs to take place, while opting for opposite courses of action, i.e. continuing pregnancy or terminating pregnancy. These findings can, once again, be explained from the perspective of naturalistic decision-making theories. From this perspective, women had already made an intuitive decision, that was so evident to them, that decision-making was not an issue for discussion. Thus, personal beliefs and considerations were

so important, that they even impeded women from considering several choices, as described before. ${ }^{132}$ For the individual level, this implicates tailored counselling, that is sensitive for the wide range of perceptions of choice.

At a broader level, however, the findings of this study evoke questions about how decision-making should take place. Medical decision-making usually aims for rational decision-making, that can be described as the "thorough canvassing of alternatives and objectives, evaluation of consequences of current and new policies, search for information, unbiased assimilation of new information, evaluation of consequences and planning for implementation and contingencies" ${ }^{29}$ So, on the one hand women make decisions in a way that can be best described by naturalistic decision-making theories, whereas on the other hand doctors aim at making decisions according to rational decision-making theories. This finding can be viewed from different perspectives. From the perspective that rational decision-making is the best way to make decisions, this notion implies that women should be encouraged to make their decisions in a more rational way. From a different perspective, however, this study shows that rational decision-making does not suffice as a model for decision-making in health care. In fact, the difference between the commonly adopted ideal of rational decision-making in health care on the one hand and the 
naturalistic decision-making by women on the other hand, poses a challenge for shared decision-making. ${ }^{9}$

Shared decision-making is described as the process of making decisions jointly by doctor and patient, who are both informed by the best information available. ${ }^{30}$ This information includes not only risks and benefits of the different management options, but incorporates patient characteristics and values as well. ${ }^{30}$ Hence, shared decision-making assumes a rational decision-making process, in which the patient's values are weighted as one of a number of factors. ${ }^{30-33}$ However, our data show that, at least in some situations, women make decisions in a naturalistic rather than in a rational way. In clinical practice, this may result in situations in which women feel that they are not facing decisions, whereas doctors think there are decisions to make. Doctors need to appreciate that women may view the decision-making process in their own particular way. This poses specific demands for the counselling process. Doctors must not assume that women' perceptions of choice are the same as theirs, but have to ascertain the women' views of the decision-making process systematically. Only then both parties are equally well informed, which is a prerequisite for shared decision-making.

\section{Considerations in decision-making}

To date, research evaluating considerations for termination of pregnancy has focused on describing determinants of such decision. As described previously, lower gestational age, a more severe abnormality, involvement of the central nervous system, previous uncompleted pregnancies, lower maternal educational level, and the presence of chromosomal abnormalities are related with an increased rate of women deciding upon termination of pregnancy. ${ }^{14-17}$ This study shows that women considered a wide variety of factors in making decisions about whether or not to terminate their pregnancy. Women deciding to terminate pregnancy and women deciding to continue pregnancy show similar patterns of considerations, albeit with different connotations. Firstly, the well-being of the unborn child is an important consideration for women continuing pregnancy with the argument of keeping the child in the safe environment of the womb in its best interest. In this context, women opting for termination of pregnancy use a different argument, i.e. the prevention of suffering of the child. Secondly, well-being of the women self is a consideration. Women deciding to terminate pregnancy fear the maternal physical risk and emotional burden of carrying the pregnancy to term and want to be able to start mourning. Women deciding to continue pregnancy want to be able to hold a living child, to bury their child and fear regretting a decision to terminate pregnancy. Thirdly, the benefit of carrying pregnancy to term is a consideration. Women terminating pregnancy feel there is no benefit in carrying pregnancy to term, while women continuing pregnancy experience benefit in keeping the child in a safe environment and giving it an opportunity to bond. The consideration of well-being of other children in the family and the preference of the partner emerges only in women terminating pregnancy. Moral considerations such as 'wanting to accept the fate of life' and 'not having the right to end a life' emerge only in women continuing pregnancy. Finally, only women continuing pregnancy mention the fact of feeling the child.

Summarising, the ambiguity of fetal ultrasound evokes complex reactions after ultrasound diagnosis of fetal abnormality. On the one hand a tool possibly providing diagnostic information which may question the continuation of pregnancy, and on the other hand it could be considered as a bonding ritual personifying the fetus and affirming the reality of the baby to be born. In case of fetal abnormalities, perceptions of choice vary widely, challenging the possibilities of shared decisionmaking. In making decisions about termination of pregnancy, women consider its consequences for both the unborn infant and the family as well as moral values. 


\section{References}

1. McNay MB, Fleming JE. Forty years of obstetric ultrasound 1957-1997: from A-scope to three dimensions. Ultrasound Med Biol 1999:25:3-56.

2. Romano PS, Waitzman NJ. Can decision analysis help us decide whether ultrasound screening for fetal abnormalities is worth it? Ann N Y Acad Sci 1998;847:154-72.

3. Health Council of the Netherlands. Prenatal Screening: Down's syndrome, neural tube defects, routine-ultrasonography. The Hague: : Health Council of the Netherlands, 2001; publication no. 2001/11., 2001.

4. Harris $G$, Connor L, Bisits A, Higginbotham N. "Seeing the baby": pleasures and dilemmas of ultrasound technologies for primiparous Australian women. Med Anthropol Q 2004;18:23-47.

5. Mitchell L. Baby's first picture: Ultrasound and the politics of fetal subjects. Toronto: University of Toronto Press, 2001.

6. Garcia J, Bricker L, Henderson J, Martin MA, Mugford M, Nielson J, et al. Women's views of pregnancy ultrasound: a systematic review. Bith 2002;29:225-50.

7. Kohut RD, D Love, EJ. Women's knowledge of prenatal ultrasound and informed choice. J Genet Couns 2002;11:265-776.

8. Boukydis CT, MC Delaney-Black, V Boyes, K King, M Robinson, T Sokol, R. Women's responses to ultrasound examinations during routine screens in an obstetricn clinic. $J$ Ultrasound Med 2006;25:721-8.

9. Charles C, Gafni A, Whelan T. Shared decision-making in the medical encounter: what does it mean? (or it takes at least two to tango). Soc Sci Med 1997;44:681-92.

10. Bartels DLB, McCarthy, P Caplan, AL. Nondirectiveness in genetic counselling: a survey of practitioners. Am J Med Genet 1997;72:172-179.

11. Hunfeld JL, A De Jong, M Oberstein, ML Tibben, A Wladimiroff, JW Wildschut, HI Passchier J. Prenatal consultation after a fetal abnormality scan: videotaped exploration of physician's attitude and patient's satisfaction. Prenat Diagn 1999;19:1043-7.

12. Berkel DwW, C van der. Norms and prenorms on prenatal diagnosis: new ways to deal with morality in counseling. Patient Educ Couns 1999;37:153-63.

13. Sandelowski M, Jones LC. Healing fictions': stories of choosing in the aftermath of the detection of fetal abnormalities. Soc Sci Med 1996;42:353-61.

14. Grevengood C, Shulman LP, Dungan JS, Martens P, Phillips OP, Emerson DS, et al. Severity of abnormality influences decision to terminate pregnancies affected with fetal neural tube defects. Fetal Diagn Ther 1994;9:273-7.

15. Pryde $P$, Isada N, Hallak $M$, Johnson $M$, Odgers $A$, Evanns $M$. Determinants of parental decision to abort or continue after non-aneuploid ultrasound-detected fetal abnormalities. Obstetrics \& Gynecology 1992;80:263-273.

16. Sheiner E, Shoham-Vardi I, Weitzman D, Gohar J, Carmi R. Decisions regarding pregnancy termination among Bedouin couples referred to third level ultrasound clinic. Eur J Obstet Gynecol Reprod Biol 1998;76:141-6.

17. Schechtman KB, Gray DL, Baty JD, Rothman SM. Decision-making for termination of pregnancies with fetal abnormalities: analysis of 53,000 pregnancies. Obstet Gynecol 2002;99:216-22.

18. Sklansky M, Tang A, Levy D, Grossfeld P, Kashani I, Shaughnessy R, et al. Maternal psychological impact of fetal echocardiography. J Am Soc Echocardiogr 2002;15:159-66.

19. Rothenbach PL, P Powell,D. The use of extracorporeal membrane oxygenation in infants with congenital diaphragamatic hernia. Semin Perinatol 2005;29(1):40-4.

20. Berk N, Maratzita M, Cooper M. Medical genetics on the cleft palate-craniofacial team:understanding parental preference, 1999

21. Draper J. 'It was a real good show': the ultrasound scan, fathers and the power of visual knowledge. Socioloy of Health \& Illness 2002;24:771-775.

22. Britt DW, Risinger ST, Mans MK, Evans MI. Devastation and relief: conflicting meanings of detected fetal abnormalities. Ultrasound Obstet Gynecol 2002;20(1):1-5.

23. Petchesky R. Fetal images:the power of visual culture in the politics of reproduction. Feminist Studies 1987;13:263-292.

24. Georges E. Fetal ultrasound imaging and the production of authoritative knowledge in Greece. Med Anthropol Q 1996;10:157-75.

25. Casper $M$. The making of the unborn patient, a social anatomy of fetal surgery. New Brunswick, New Jersey, and London: Rutgers University Press, 1998.

26. Broadstock M, Michie S. Processes of patient decision making: Theoretical and methodologica issues. Psychology and Health 2000;15:191-204.

27. Bijma HH, Wildschut HI, van der Heide A, Passchier J, Wladimiroff JW, van der Maas PJ. Parental decision-making after ultrasound diagnosis of a serious foetal abnormality. Fetal Diagn Ther 2005;20:321-7.

28. Snowdon CE, D Garcia,J. 'It was a snap decision':parental and professional perspectives on the speed of decisions about participation in perinatal randomised controlled trials. Soc Sci Med 2006;62:2279-90. 
29. Janis I, Mann L. Coping with decisional conflict, an analysis of how stress affects decisionmaking suggests interventions to improve the process. American Scientist 1976;64:657-67.

30. Towle A, Godolphin W. Framework for teaching and learning informed shared decision making Bmj 1999;319:766-71.

31. Frosch DL, Kaplan RM. Shared decision making in clinical medicine: past research and future directions. Am J Prev Med, 1999:285-94.

32. Whitney SN, McGuire AL, McCullough LB. A typology of shared decision making, informed consent, and simple consent. Ann Intern Med, 2004:54-9.

33. Charles C, Gafni A, Whelan T. Decision-making in the physician-patient encounter: revisiting the shared treatment decision-making model. Soc Sci Med 1999;49:651-61. 



\section{Chapter 8}

\section{Decision-making after ultrasound diagnosis of fetal abnormality, do women feel they have something to choose?}

H.H.Bijma, H.I.J.Wildschut, A.van der Heide, J.Passchier, P.J.van der Maas, J.W.Wladimiroff (submitted for publication) 


\begin{abstract}
Objective

When serious fetal abnormalities are detected, termination of pregnancy may be considered. Little is known about pregnant women's process of decision-making in this situation. This study aims at describing women's perception of whether or not they feel that they have a choice to make and explores to what extent this perception is related to their expectation of the child's prognosis, and to feelings of derealization or depersonalization.
\end{abstract}

Design

Prospective descriptive study.

Setting

Tertiary centre.

Population

Women diagnosed with fetal abnormality by ultrasound.

Methods

Interviews by phone.

Main outcome measures

Women's perception of choice, their perception of fetal prognosis, the presence of feelings of derealization or depersonalization, information-seeking behaviour.

\title{
Results
}

$107 / 160(67 \%)$ women agreed to participate. In $54 \%$ of all cases, women felt that they did not have a choice concerning whether or not to continue pregnancy. In $46 \%$ of the cases, women felt that they had a choice: half of them, however, felt ambiguous about this choice: they knew that a choice was possible without feeling that they actually had to make a choice themselves because it was obvious which course had to be followed. The perception of choice was strongly related to their expectation of the child's prognosis. Of the women who thought that their child's future was not affected, $85 \%$ felt that they did not have choice, whereas this percentage was $10 \%$ for women who felt that their child had no future. Feelings of derealization or depersonalization were present in $50 \%$ of all women, but they were not related to women's perception of choice. $61(57 \%)$ women looked for additional information. Information seeking behaviour was not related to the perception of choice either.

\section{Conclusion}

The current study showed that about half of the women experienced the need of making choices. However, after ultrasound diagnosis of a serious fetal abnormality feelings of derealization and depersonalization complicate adequate counselling. Nonetheless, the option of making choices needs to be addressed, in particular when fetal prognosis is poor. Finally, counselling should offer guidance in the process of information seeking. 


\section{Introduction}

Congenital abnormalities are a major cause of perinatal and infant death in industrialized countries. With the technological innovations of fetal ultrasound many of these abnormalities can now be detected before birth. When serious fetal congenital abnormalities are diagnosed, the majority of women opt for termination of pregnancy. ${ }^{1,2}$ Such a decision, however, is highly burdened, having both moral and emotional important and long-lasting consequences. ${ }^{3,4}$ Furthermore, such decisions need to be made at a time of extreme emotional distress as the result of the unexpected and harsh diagnosis. Up to $45 \%$ of women faced with serious fetal abnormalities show severe psychological instability, deep shock and acute grief with anger, despair, guilt, and feelings of inadequacy. ${ }^{4,5}$ Furthermore, feelings of depersonalization and derealization in reaction to the significance of the diagnosis may coexist. Such conditions complicate the decision-making process about termination of pregnancy.

Little is known about how women make decisions about whether or not to terminate pregnancy after ultrasound diagnosis of a serious fetal abnormality. Previous research has shown that the likelihood of pregnancy termination is associated with gestational age, the severity of the fetal abnormality, involvement of the central nervous system, and the presence of chromosomal abnormalities. ${ }^{6-9}$ A higher maternal educational level and a history of pregnancies, that did not result in the birth of a living child increase the likelihood of pregnancy termination. However, few data are available about women's perception of fetal prognosis, which may differ from the medical point of view. Also, the interference of psychological mechanisms, such as depersonalization and derealization, and the information-seeking behaviour in relation to the decision-making process are fields that have remained largely unexplored. Previous research has shown that choice is a complicated concept, because women opting of termination of pregnancy may not feel that there is a choice at all. ${ }^{10}$

This study aims at describing pregnant women's decision-making process about termination of pregnancy, thereby focusing on women's perception of choice, their perception of fetal prognosis, and the characteristics of the decision-making process in those who perceived a choice. Moreover, this study focuses on the occurrence of depersonalization or derealization, and women's information-seeking behaviour.

\section{Methods}

This study was conducted at the department of Obstetrics and Prenatal diagnosis of the Erasmus University Medical Center in Rotterdam, the Netherlands. Our unit is a large tertiary referral center for fetal abnormality scanning, serving 3.5 million inhabitants. When a fetal abnormality is suspected elsewhere, the woman is normally referred to our department for detailed fetal abnormality scanning. Between 01 July 2001 and 01 June 2003 we invited 160 consecutive women who were referred to our hospital to participate in the study. Eligible women included those who were ultimately diagnosed with a structural fetal abnormality at our department, who were fluent in Dutch, and who could be reached by phone. Eligible women received an information leaflet from the physician-sonographer who had carried out the ultrasound examination and subsequent counselling. Women who provisionally agreed to participate were contacted a few days later by the physician-researcher who would conduct the interviews (HB). All participants gave oral and written informed consent. Apart from general information about the study, each woman was informed that the interview data would be stored and analyzed anonymously. Furthermore, they were told that the information they provided would only be shared with other physicians upon their explicit request. Ethical approval for the study was obtained from the Research Ethics Committee of our hospital.

Women were interviewed by phone at a time that was convenient for them, using a semi-structured interview schedule. Questions pertained to their perception of choice, their ideas about the prognosis of their child, whether or not they had a feeling as if it all were not true, and to their information-seeking behaviour. If the woman felt she had a choice, she was asked about her decision -making process.

The interviews consisted of both closed and open questions. The closed questions covered the presence of variables we were interested in, for example choice: 'Do you feel you 
are facing choices about whether or not to continue your pregnancy?'. The open questions then aimed at exploring in depth pregnant women's perceptions, for example 'Could you tell me a bit more about that?'. Women were given the opportunity to discuss topics other than those mentioned by the interviewer, in order to give them the least discomfort as possible. At the end of the interview each woman was asked if there were additional issues that she felt were important. If the woman had further comments or needed support due to distress related to the interview, she was advised to contact either the researcher who had done the interview or an independent physician. All interviews were conducted by one researcher ( $\mathrm{HB}$ ), a physician experienced in prenatal medicine but not involved in the clinical management of the study patients. The interviews were audiotaped; answers were transcribed literally.

Women's perception of choice was evaluated by asking whether they felt they were faced with choices regarding the continuation of their pregnancy. Women's perception of fetal prognosis was evaluated by asking women whether they felt that the child's chance of survival was limited and whether they felt that the child's chances later in life were reduced. The prognosis was also assessed by the research team, classifying an abnormality with no chance of survival as 'lethal', a non-lethal but severely disabling abnormality as 'poor', a non-lethal and not severely disabling abnormality as 'good', and 'uncertain' in case of uncertainty about the diagnosis. In women who felt they had a choice, we evaluated several characteristics of the decision-making process, such as whether several options were discussed, whether other people who they considered important agreed with their decision, and whether they felt they had an impact on the decision. The presence of derealization was evaluated by asking women whether they had a feeling 'as if it all wasn't true'. The interviewer then invited women to elaborate on their answer. When women answered it was rather like feeling 'as if it is happening to somebody else', this was coded as depersonalization. To evaluate informationseeking behaviour, we asked women 'have you been looking for additional information? If so, we asked how they had searched information and what kind of information they were looking for. analyses.

Statistical Package for Social Sciences (SPSS), version 11.0 was used for statistical

\section{Resuits}

160 women were eligible to take part in the study. Of these women, $23(14 \%)$ women declined participation because of emotional distress $(n=20)$ or other reasons $(n=3)$. Thirty $(19 \%)$ women were excluded because they had already delivered or terminated pregnancy at the time they were reached by phone. Hence, $107 / 160(67 \%)$ women were included in this study. None of the women needed psychological support due to the distress of the interview. The mean maternal age was 29.8 years (sd 5.3 years). The median gestational age at the time of the diagnosis was 22.1 wks (range 11.4.-37.3 weeks). The median number of days between the interview and the ultrasound diagnosis was $8(0-69)$ The median duration of the interview was 17 minutes (range 10-64 minutes).

Table 1 shows that $54 \%$ of all women felt that they did not have a choice concerning the further management of their pregnancy, and that continuation of pregnancy was the only option. In contrast, $22 \%$ of all women felt they had to make a choice: half of them preferred termination of pregnancy and $42 \%$ preferred continuation of their pregnancy. The remaining $22 \%$ of women felt ambiguous about whether or not they had a choice: they said they did not have a choice but they were also aware that different courses of action were possible. In this ambiguous group, $54 \%$ preferred to continue their pregnancy whereas $42 \%$ preferred their pregnancy to be terminated.

Perception of choice bore a significant relationship $(p=0.00)$ with perceived fetal prognosis (table 2): women who perceived their child's prognosis as good mostly felt they had no choice $(85 \%)$, whereas women who thought that their child's future was limited or unclear or who thought that their child had no future more often felt that they had to make a choice. Women who felt that their child had no future rather often (52\%) felt ambiguous. 
Table 1. Pregnant women's perception of choice after ultrasound diagnosis of fetal abnormality

\begin{tabular}{|c|c|c|c|c|}
\hline Choice & Ambiguous choice & No choice & & \\
\hline$(\%)$ & $(\%)$ & $(\%)$ & $\mathrm{n}$ & $(\%)$ \\
\hline
\end{tabular}

\begin{tabular}{lcccccccc}
$\begin{array}{l}\text { Preferred management } \\
\text { Continuing pregnancy }\end{array}$ & 10 & $(42)$ & 14 & $(58)$ & 58 & $(100)$ & 82 & $(77)$ \\
Termination of preanancy & 12 & $(50)$ & 10 & $(40)$ & 0 & & 22 & $(21)$ \\
Other & 2 & $(8)$ & 1 & $(4)$ & 0 & & 3 & $(3)$ \\
$\quad$ Total & 24 & $(22)$ & 25 & $(22)$ & 58 & $(54)$ & 107 & $(100)$ \\
\hline
\end{tabular}

The prognosis as estimated by women may not always coincide with the prognosis as established on medical grounds. Table 3 compares the expectations of pregnant women with the medical prognosis as established by the research team. In case of a lethal or poor medical prognosis, none of the women thought their child had an unlimited future. In case of a good medical prognosis, $43 \%$ thought that their child's future was unlimited whereas $34 \%$ that it was limited and $23 \%$ was unsure. An uncertain medical prognosis yielded different expectations among

Table 2. Pregnant women's perception of choice by perceived fetal prognosis

\begin{tabular}{lccccccccc}
\hline $\begin{array}{l}\text { Prognosis as estimated } \\
\text { by women }\end{array}$ & \multicolumn{2}{c}{ Unlimited future } & \multicolumn{2}{c}{ Unclear future } & \multicolumn{2}{c}{ Limited future } & \multicolumn{2}{c}{ No future } \\
& $\mathrm{n}$ & $(\%)$ & $\mathrm{n}$ & $(\%)$ & $\mathrm{n}$ & $(\%)$ & $\mathrm{n}$ & $(\%)$ \\
\hline & 1 & $(4)$ & 4 & $(25)$ & 11 & $(26)$ & 8 & $(38)$ \\
Choice & 3 & $(11)$ & 3 & $(19)$ & 8 & $(19)$ & 11 & $(52)$ \\
$\begin{array}{l}\text { Ambiquous choice } \\
\text { No choice }\end{array}$ & 23 & $(85)$ & 9 & $(56)$ & 24 & $(56)$ & 2 & $(9)$ \\
& 27 & $(25)^{1}$ & 16 & $(15)^{1}$ & 43 & $(40)^{1}$ & 21 & $(20)^{1}$ \\
\hline
\end{tabular}

${ }^{7}$ Row percentages

women: $13 \%$ of the women in this group thought that their child had no future, $50 \%$ thought that their child's future was limited, $25 \%$ thought that their child's future was not limited and $13 \%$ was unsure.

Table 4 explores the association between the perception of choice and the presence of derealization or depersonalization. In total, $50 \%$ of the women experienced derealization or depersonalization. Of these women, 31 described this experience in quite broad terms, such as 'feeling as if it's not real', 'this is so unexpected, I just can't grasp it' or did not elaborate on their answer. In eleven women derealization emerged as not being able to believe the doctors were right, resulting in intuitive doubts about the diagnosis, even though they rationally thought the doctors were right. Six women described not being able to grasp the facts because they still felt the child kicking. Five women described a feeling as if it was not happening to them, but to someone else. Of all women, $50 \%$ did not experience derealization or depersonalization, seven of whom stating that they just knew it was true because they had seen the abnormality themselves on ultrasound. Perception of choice was not different for women who either did or did not experience derealization or depersonalization.

In total, $57 \%$ of the women searched for additional information. Of all women, $44 \%$ searched the Internet for additional information and $25 \%$ women sought advice from books. Nine women consulted acquaintances with personal experience with the abnormality. Three women sought additional information from their midwife or general physician. Women sought information on a wide range of subjects: $46 \%$ of all women sought general information about the abnormality and $25 \%$ sought information about concrete implications of the abnormality, the most important topics being expected course of treatment, and implications for delivery, breastfeeding, and care. Further, $6 \%$ sought information on grief and/or coping, $5 \%$ sought for stories of people who had experienced the same situation, and $6 \%$ sought for information on 
Table 3. Pregnant women's perception of fetal prognosis by medical prognosis

\begin{tabular}{|c|c|c|c|c|c|c|c|c|c|c|}
\hline \multirow{3}{*}{$\begin{array}{l}\text { Fetal prognosis as estimated } \\
\text { by pregnant woman }\end{array}$} & \multicolumn{10}{|c|}{ Medical prognosis } \\
\hline & \multicolumn{2}{|c|}{ lethal } & \multicolumn{2}{|r|}{ poor ${ }^{2}$} & \multicolumn{2}{|c|}{$g o o d^{3}$} & \multicolumn{2}{|c|}{ uncertain $^{4}$} & total & \\
\hline & $n$ & $\%$ & $n$ & $\%$ & $\mathrm{n}$ & $\%$ & $n$ & $\%$ & $n$ & $\%$ \\
\hline $\begin{array}{l}\text { no future } \\
\text { future limited } \\
\text { future not limited } \\
\text { future unclear }\end{array}$ & $\begin{array}{l}13 \\
2 \\
0 \\
0\end{array}$ & $\begin{array}{l}(87 \%) \\
(13 \%)\end{array}$ & $\begin{array}{l}2 \\
6 \\
0 \\
2\end{array}$ & $\begin{array}{l}(20 \%) \\
(60 \%) \\
(20 \%)\end{array}$ & $\begin{array}{c}0 \\
12 \\
15 \\
8\end{array}$ & $\begin{array}{l}(34 \%) \\
(43 \%) \\
(23 \%)\end{array}$ & $\begin{array}{c}6 \\
24 \\
12 \\
6\end{array}$ & $\begin{array}{l}(13 \%) \\
(50 \%) \\
(26 \%) \\
(13 \%)\end{array}$ & $\begin{array}{l}21 \\
44 \\
27 \\
16\end{array}$ & $\begin{array}{l}(20 \%) \\
(40 \%) \\
(25 \%) \\
(15 \%)\end{array}$ \\
\hline Total & 15 & $(14 \%)^{1}$ & 10 & $(9 \%)^{1}$ & 35 & $(33 \%)^{1}$ & 48 & & 107 & $(100 \%)$ \\
\hline
\end{tabular}

1. anencephaly/exencephaly (3), bilateral renal agenesia (3), lethal skeletal dysplasia (3), trisomy 18 (2), multiple congenital abnormalities including bilateral dysplastic kidneys (1), fetal akinesia (1), bilateral severe obstructive uropathy (1), twin reversed arterial perfusion (1)

2. fetal hydrops (5), hypoplastic left heart (1), extrophia vesicae (1), large omphalocele (1), skull defect (1), alobar holoprosencephaly (1)

3. unilateral obstructive uropathy/kidney abnormality/bilateral mild uropathy (9), cleft lip/palate (8), single limb abnormality/club feet (6), gastroschizis (4), ventriculomegaly (2), intra-abdominal cyst (2), small CCAML/lung sequester (1), double bubble (1), mild Ebstein abnormality (1), polydactyly (1)

4. multiple congenital abnormalities with normal or unknown karyotype (16), diaphragmatic hernia (4), bilateral obstructive uropathy (3), CCAML/lung sequester (3), omphalocele (3), spina bifida (3), encephalokele (2), hysdrocephaly (2), trisomy 21 with multiple congenital abnormalities (2), bilateral echodense/enlarged kidneys (2), atypical intra-abdominal structure (2), tetralogy of Fallot (1), sacrococcygeal teratoma (1), ${ }^{1}$ Row percentages extended gut (1), bilateral edema feet (1), acardiac twin (1)

Table 4. Pregnant women's perception of choice by presence of derealization and depersonalization

\begin{tabular}{lcccc}
$\begin{array}{l}\text { Depersonalization / } \\
\text { derealization }\end{array}$ & \multicolumn{2}{c}{ Present } & \multicolumn{2}{c}{ Not present } \\
& $\mathrm{n}$ & $(\%)$ & $\mathrm{n}$ & $(\%)$ \\
\hline Choice & 14 & $(26)$ & 10 & $(19)$ \\
Ambiguous choice & 12 & $(23)$ & 13 & $(24)$ \\
No choice & 27 & $(56)$ & 31 & $(56)$ \\
Total & 53 & $(50)^{1}$ & & $(54$ \\
\hline
\end{tabular}

${ }^{7}$ Row percentages

Table 5. Number of women searching for additional information after ultrasound diagnosis of structural fetal abnormality by choice

\begin{tabular}{lcccc}
\hline Information seeking behavior & \multicolumn{2}{c}{$\begin{array}{c}\text { Searched for information } \\
n\end{array}$} & $\begin{array}{c}\text { Did not search for information } \\
\text { n }\end{array}$ & $(\%)$ \\
\hline Choice & 9 & $(15)$ & 15 & $(33)$ \\
Ambiquous choice & 16 & $(26)$ & 9 & $(20)$ \\
No choice & 36 & $(59)$ & 22 & $(47)$ \\
Total & 61 & $(57)^{1}$ & $46^{1}$ & $(43)$ \\
\hline
\end{tabular}

${ }^{1}$ Row percentages

diagnostic tests, legal regulation and on whether the child would be born alive in case of termination of pregnancy. Table 5 shows that the perception of choice of women who were looking for additional information did not differ significantly from the perception of women who were not looking for additional information.

Table 6 shows characteristics of the decision-making process in 49 cases where women felt, either ambiguously or not, that they had a choice. Doctors discussed several management options with $47 \%$ of these women. The partner agreed with the decision in $86 \%$, other people that were important to the women agreed in $72 \%$, and women felt that doctors 
agreed with their decision in $57 \%$. Furthermore, $61 \%$ women felt they actually had influence on the decision-making process.

Table 6. Characteristics of the decision-making process for women experiencing a choice (either ambiguous or not)

\begin{tabular}{|c|c|}
\hline \multicolumn{2}{|l|}{ Characteristics of the decision-making process } \\
\hline $\begin{array}{l}\text { Doctor discussed several options } \\
\text { Yes } \\
\text { No } \\
\text { I don't know yet }\end{array}$ & $22(45 \%)$ \\
\hline $\begin{array}{l}\text { Partner agreed with decision? } \\
\text { Yes } \\
\text { No } \\
\text { I don't know yet } \\
\text { no partner }\end{array}$ & $\begin{array}{cc}\mathrm{n}=\mathbf{4 9 ( 1 )} \\
42 & (86 \%) \\
0 & \\
1 & (2 \%) \\
1 & (2 \%)\end{array}$ \\
\hline $\begin{array}{l}\text { Other important people agreed with decision? } \\
\text { Yes } \\
\text { No } \\
\text { not discussed with other people } \\
\text { no clear answer }\end{array}$ & \begin{tabular}{rr}
\multicolumn{2}{c}{$\mathbf{n = 4 9}(2)$} \\
36 & $(73 \%)$ \\
5 & $(10 \%)$ \\
5 & $(10 \%)$ \\
3 & $(6 \%)$
\end{tabular} \\
\hline $\begin{array}{l}\text { Doctor agreed with decision? } \\
\text { Yes } \\
\text { No } \\
\text { I don't know yet/not discussed with doctor }\end{array}$ & \begin{tabular}{rr}
\multicolumn{2}{c}{$n=49(1)$} \\
28 & $(57 \%)$ \\
4 & $(8 \%)$ \\
13 & $(27 \%)$
\end{tabular} \\
\hline $\begin{array}{l}\text { Influence on decision-making? } \\
\text { Yes } \\
\text { No } \\
\text { I don't know yet } \\
\text { sometimes yes, sometimes no }\end{array}$ & \begin{tabular}{cc}
\multicolumn{2}{c}{$\mathrm{n}=49(1)$} \\
30 & $(61 \%)$ \\
10 & $(20 \%)$ \\
4 & $(8 \%)$ \\
1 & $(2 \%)$
\end{tabular} \\
\hline
\end{tabular}

\section{Discussion}

Our study shows that after ultrasound diagnosis of fetal abnormality about half of the women felt they were facing choices, either or not ambiguously. In case a woman felt she has been faced with a choice, she feels the need to make a decision. In case of an ambiguous choice, women are aware that several courses of action are possible, but as the course to follow is so obvious to them they do not feel the need to make decisions. The current study showed that about half of the women who were aware that several courses of action existed, experienced the need of making choices, whereas for the other half the course to follow was obvious. About half of the women experiencing a choice, either or not ambiguously, opted for termination of pregnancy. Conversely, in about half of the women opting for termination for pregnancy, choice was ambiguous. Hence, for these women, even though acknowledging different possible courses of action, the right course of action was clear.

Perceived choice was related to the perceived fetal prognosis. A more severe prognosis was associated with experiencing a choice, either or not ambiguously. In case of a lethal prognosis, however, there were less women feeling the need to make choices than in case of non-lethal prognosis. This can be explained by the fact that, in case of a lethal prognosis, women can only make a decision about the timing of death, but have no influence on the actual outcome in the sense of whether the child will die or not. Thus, in this situation it may rather be losing the child than making decisions about the pregnancy that forms the burden for the pregnant women and their partners.

Many women experienced feelings of derealization or depersonalization at the time of the interview. To them it felt as if it all was not really happening or as if it was happening to someone else. Derealization sometimes took the form of doubting the accuracy of the 
diagnosis. These women described that they knew that the doctor was right, but still felt as if the doctor had made a huge mistake. One woman described feeling 'as if she (i.e., the doctor) was looking at the videotape of the wrong child'. Derealization is described as 'alteration in the perception or experience of the external world so that it seems strange or unreal'; depersonalization is described as ' alteration in the perception or experience of the self so that one feels detached from, and as if one is an outside observer of one's mental process or body'. ${ }^{11}$. The prevalence of these psychiatric symptoms in the general population is $1-2 \%$, but rises to $31-66 \%$ at the time of a traumatic event. ${ }^{12}$. The etiology of derealization and depersonalization remains unknown, but the symptoms may be enhanced by depression, anxiety, and trauma. ${ }^{13}$ The occurrence of derealization or depersonalization after ultrasound diagnosis of fetal abnormality should probably be understood as a reaction to the traumatic event. Furthermore, derealization and depersonalization may be partly attributable to the specific situation. Indeed, a sharp contrast exists between what the pregnant woman observes herself, i.e., feeling well with the child growing and kicking and the message of a serious, maybe even lethal fetal abnormality. In our study, derealization and depersonalization were not related to the perception of choice. The meaning of derealization and depersonalization for the decision-making process is unclear. One may argue, however, that derealization and depersonalization are unwanted phenomena as they may detach women from the reality of the decisions they are making, as these decisions have long-lasting and irreversible consequences. From a different vantage point, it may be argued that derealization and depersonalization are coping mechanisms, ensuring a basic psychological stability necessary for making decisions. It seems wise to at least counsel women about the frequent occurrence of these phenomena. Firstly, this prepares women for experiences that may be alarming to them. Moreover, it may prevent these phenomena of becoming barriers between the pregnant woman and her physician, for example in the case the pregnant woman cannot believe the diagnosis is true or when she feels a wrong diagnosis was made.

Most women in our study looked for additional information. The rationale of information seeking is not restricted to gathering data, either or not in the context of decision-making. Information-seeking also embodies a way of coping with the situation. ${ }^{14-16}$ Previous studies distinguished women who were information-seekers (monitors) and women who were information-avoiders (blunters). ${ }^{17}$ The main source of information was the Internet. Internet provided a wide variation of information: general information about the abnormality, information about bereavement, but also experiences of other parents and contact information of patient support groups. Internet can be accessed at the parents' needs. Even though the Internet can be a great source of information and may provide parents with the possibility to actively cope with the diagnosis, its risks are obvious. There is a potential bias in the patient stories that are published the internet, the information may be incorrect, and inapt comparisons may be made. ${ }^{18}$ Counselling should take into account differences between women in the need for information, and a balance must be sought between providing adequate and abundant information. ${ }^{19}$ Information-seeking behaviour was not related with perceived choice.

When women experienced a choice (either or not ambiguously), their doctor discussed several options in only about half of the cases. Furthermore, $13 \%$ of the women experiencing a choice did not know whether the doctor agreed with their decision. Several explanations may account for this. Firstly, it may be that women themselves were so determined about their choice, that their doctor thought it inappropriate to discuss it with them. Secondly, it may be that for the doctor the course of action was so evident that he/she did not think it necessary or morally right to discuss it with the parents. Finally, it may be that legal regulations prohibited the doctor from discussing termination of pregnancy after 24 weeks of pregnancy. Both the partner and other people who were important for the woman usually agreed with the decision.

The findings of this study allow for some recommendations regarding counselling after ultrasound diagnosis of fetal abnormality. Firstly, the notion of making choices is an important issue after ultrasound diagnosis of fetal abnormality. Hence, the option of making choices needs to be addressed during counselling. However, women show a wide variety in how they perceive choice: this observation warrants prudent enquiring of pregnant women's thoughts of 
making choices. Secondly, this study shows that derealization or depersonalization occur frequently. As such phenomena may interfere with the counselling and decision-making, these need to be addressed specifically, with the objective of ensuring a good patient-physician relationship and minimizing the possible adverse influence of such phenomena on the decisionmaking process. Finally, women show a great need for information seeking. Therefore, counselling should offer guidance of this process, for example by referring to trustworthy websites and books or by warning women for the sometimes-biased information on the internet. 


\section{References}

1. Mansfield, C., S. Hopfer, and T. Marteau, Termination rates after prenatal diagnosis of Down syndrome, spina bifida, anencephaly, and Turner and Klinefelter syndromes. Prenat Diagn, 1999. 19: 808-812.

2. Salvesen, K.O., L Schmidt,N Malt,UF Eik-Nes SH, Comparison of long-term psychological responses of women after termination of pregnancy due to fetal anomamly and after perinatal loss. Ultrasound Obstet Gyn, 1997. 9:80-85.

3. Chervenak, F.A., et al., Ethical issues in the management of pregnancies complicated by fetal anomalies. Obstet Gynecol Surv, 2003. 58:473-83.

4. Statham, H., W. Solomou, and L. Chitty, Prenatal diagnosis of fetal abnormality: psychological effects on women in low-risk pregnancies. Baillieres Best Pract Res Clin Obstet Gynaecol 2000. 14: 731-47.

5. Hunfeld, J.A., et al., Emotional reactions in women in late pregnancy (24 weeks or longer) following the ultrasound diagnosis of a severe or lethal fetal malformation. Prenat Diagn, 1993. 13:603-12.

6. Pryde, P., et al., Determinants of parental decision to abort or continue after non-aneuploid ultrasound-detected fetal abnormalities. Obstet Gynecol, 1992. 80:263-273.

7. Schechtman, K.B., et al., Decision-making for termination of pregnancies with fetal anomalies: analysis of 53,000 pregnancies. Obstet Gynecol, 2002. 99:216-22.

8. Drugan, A., et al., Determinants of parental decisions to abort for chromosome abnormalities. Prenat Diagn, 1990. 10:483-90.

9. Grevengood, C., et al., Severity of abnormality influences decision to terminate pregnancies affected with fetal neural tube defects. Fetal Diagn Ther, 1994. 9:273-7.

10. Sandelowski, M. and L.C. Jones, Healing fictions': stories of choosing in the aftermath of the detection of fetal anomalies. Soc Sci Med, 1996. 42:353-61.

11. American Psychiatric Association, Diagnostic Statistic Manual IV, ed. A.P. Association. 1997: American Psychiatric Association.

12. Hunter, E.C., M. Sierra, and A.S. David, The epidemiology of depersonalisation and derealisation. A systematic review. Soc Psychiatry Psychiatr Epidemiol, 2004. 39:9-18.

13. Baker, D., et al., Depersonalisation disorder: clinical features of 204 cases. Br J Psychiatry, 2003. 182:428-33.

14. Steptoe, A., et al., Satisfaction with communication, medical knowledge, and coping style in patients with metastatic cancer. Soc Sci Med, 1991. 32:627-32.

15. van der Molen, B., Relating information needs to the cancer experience: 1 . Information as a key coping strategy. Eur J Cancer Care, 1999. 8:238-44.

16. Leydon, G.M., et al., Cancer patients' information needs and information seeking behaviour: in depth interview study. Bmj, 2000. 320:909-13.

17. Miller, S.M., Monitoring and blunting: validation of a questionnaire to assess styles of information seeking under threat. J Pers Soc Psychol, 1987. 52:345-53.

18. Cline, R.J. and K.M. Haynes, Consumer health information seeking on the Internet: the state of the art. Health Educ Res, 2001. 16:671-92.

19. Case, D.O., et al., Avoiding versus seeking: the relationship of information seeking to avoidance, blunting, coping, dissonance, and related concepts. J Med Libr Assoc, 2005. 93:353-62. 


\section{Chapter 9}

\section{General discussion}




\subsection{Introduction}

The aim of this thesis is to evaluate decision-making after ultrasound diagnosis of a fetal abnormality. Three aspects of decision-making are studied, i.e., 1. the frequency of end-of-life decisions, that is decisions to refrain from medical intervention aimed at prolonging fetal life (non-aggressive obstetric management) and/or as decisions aimed at ending fetal life (termination of pregnancy) after ultrasound diagnosis of fetal abnormality 2 . decision-making by physicians, and 3 . decision-making by parents. This chapter firstly discusses the findings related to these three aspects of end-of-life decision-making in fetal medicine. Secondly, methodological aspects are discussed. Thirdly, implications for clinical practice and policy are addressed. Finally, suggestions for further research are made.

\subsection{Frequency of end-of-life decisions in fetal medicine}

End-of-life decisions can be described as decisions to refrain from medical intervention aimed at prolonging fetal life (non-aggressive obstetric management) and/or as decisions aimed at ending fetal life (termination of pregnancy). In the ErasmusMC University Hospital Rotterdam, the largest tertiary centre for fetal medicine in the Netherlands, almost all end-of-life decisions are made by a multidisciplinary perinatal team. This team discusses obstetric and neonatal management in case of serious fetal abnormality for either one or more of the following reasons, i.e., (i) when there is uncertainty about the diagnosis and/or prognosis exists, (ii) to discuss parental requests for pregnancy termination beyond 24 weeks of gestation, which is the upper legal limit for pregnancy termination in the Netherlands and iii) the infant is expected to be referred to the paediatric department after birth. When fetal abnormality is diagnosed elsewhere, the woman will typically be referred to our centre. In case of a request for termination of pregnancy before 24 weeks gestational age for reasons of serious fetal abnormality, the request will usually not be discussed in the multidisciplinary perinatal team. Hence, in clinical practice, most pregnancies with a gestational age of 24 weeks or more that are complicated by a fetal abnormality are discussed by the multidisciplinary perinatal team. The multidisciplinary perinatal team of the ErasmusMC University Hospital Rotterdam makes end-of-life decisions in about one-third of the cases being discussed,i.e., on average 19 cases per year. Based on these estimates, we can extrapolate the nation-wide crude figures of endof-life decisions in fetal medicine in the Netherlands thereby assuming that (1) in our referral region every pregnant woman with the ultrasound diagnosis of a serious fetal abnormality was indeed referred to our center and (2) that the frequency of end-of-life decisions in other centers is similar to those in our center. Our tertiary center serves about 35,000 new-borns per year. Between January 1996 and January 2001, on average 197.687 infants were born each year in the Netherlands.1 Extrapolating the data of our center suggests that nationwide an end-of-life decision after 24 weeks gestational age is made in about 106 cases per year. Unfortunately, no other data exist on non-aggressive obstetric management. A study by Bosma et al, however, extrapolating the frequency of late termination of pregnancy reported by non-tertiary and tertiary hospitals in North-Holland (103 cases), reported an estimated frequency of late termination of pregnancy of 150 times per year in the Netherlands. 2 The discrepancy between our estimate and the latter findings may be ascribed to either regional decision-making differences or lack of referral from non-tertiary centres, for example in case of an unequivocal diagnosis, such as anencephaly or when the diagnosis was made just before or during delivery. It may be clear, however, that exact figures for the frequency of end-of-life decisions in fetal medicine in the Netherlands are lacking. It is unlikely that a study of death certificates study will yield more accurate data, as the legal regulations, officially prohibiting termination of pregnancy after 24 weeks gestational age, preclude accurate reporting.

Given the importance of end-of-life decisions, both at the personal and societal level, a high-quality registration of both non- aggressive obstetric management and termination of pregnancy is needed, preferably by means of a nationwide, anonymous register. International comparison can be made for example with France, where law does not prohibit termination of pregnancy after 24 weeks. Guillem et al. reported an annual frequency of 32 pregnancy 
terminations after 24 weeks gestational age/14000 births in a region in France. ${ }^{3}$ Extrapolating these findings to the Netherlands will yield estimate of 451 terminations per 197,687 births which is much higher than those reported in the Netherlands (i.e., 106 end-of-life decisions or 150 terminations of pregnancy beyond 24 weeks/197,687 births), probably reflecting differences in legal regulations.

\subsection{The process of end-of-life decision-making in fetal medicine by physicians \\ 9.3.1 Evaluation of fetal prognosis}

Fetal prognosis is an important factor in physician's end-of-life decision-making. From a study involving five senior obstetricians each working at a distinct tertiary center for fetal medicine in the Netherlands, it was concluded that at an individual level, obstetricians were able to classify fetal prognosis in accordance with the current national guidelines in terms of whether of not a fetal end-of-life decision was justified. Furthermore, these senior obstetricians were consistent in their classification of fetal prognosis at repeated evaluation. However, in one-third of the cases only three or less out of the obstetricians agreed with each other on fetal prognosis, as defined by current national guidelines. Hence, in one-third of the cases senior obstetricians differed in their opinion about whether fetal prognosis was such that it justified an end-of-life decision or not. These differences reflected, at least partly, systematic differences in evaluating fetal prognosis, whereby some obstetricians were more inclined to classify the clinical problem as one with an extremely poor prognosis. In fact, some of the senior obstetricians were more inclined to appraise a fetal prognosis as such that an end-of-life decision was justified. There are several possible explanations for these findings, including different interpretation of ultrasound findings, different perspectives on possibilities for neonatal treatment, different perspectives on quality of life, and different attitudes towards an uncertain prognosis. In clinical practice, fetal prognosis as such is not an objective truth but rather reflects the perception of the physicians involved. This perception is typically based on a mixture of scientific evidence, clinical experience, and personal, institutional and societal perspectives. Others have shown that even facts, that are presented as scientific truths, reflect implicit normativity. ${ }^{4}$ Presumably, the less scientific evidence is available, the more room is left for other influences. It is important for clinicians to be aware of this - unavoidable - subjectivity. This finding implies two important recommendations for improving decision-making in clinical practice. Firstly, it is important to be transparent about the medical factors considered in the perception of fetal prognosis. Medical facts should be presented as objectively as possible while moral values should not be presented as medical facts. Subjective elements of fetal prognosis should be described as concrete as possible. For example, the various domains of 'poor quality of life' should be addressed, each preferably backed up by relevant medical facts. As end-of-life decisions in themselves are already so morally burdened and complex, optimal transparency is required in the discussions, both among physicians and with the parents. Secondly, the unavoidable subjectivity in evaluating fetal prognosis suggests a certain humbleness of the physicians' part in the decision-making process. With regard to adequate decision-making, physicians often have different albeit not necessarily more knowledge than parents. In fact, the role of physicians is to provide objective information and to structure the decision-making process, ensuring that all relevant factors are considered. In some clinical situations, however, our study showed a divergence of opinion among senior obstetricians with regard to the appropriateness of an end-of-life decision. In case of conflict between the obstetrician on the one hand and the woman and her partner on the other hand, referral to another centre for a second opinion should be considered.

\subsubsection{Multidisciplinary team decision-making}

Multidisciplinary team discussion is commonly advised in making management decisions in case of

fetal abnormality. ${ }^{5-7}$ Such multidisciplinary team decision-making serves many goals, such as collecting all relevant information on a case, reaching consensus on management decisions, 
attuning obstetric and neonatal management decisions, and sharing the moral and medical burden of being responsible for such difficult decisions. ${ }^{8,9}$ Furthermore, national guidelines consider discussion in a multidisciplinary team an indicator of good quality decision-making. Consensus of the multidisciplinary team is required prior to termination of pregnancy being performed at 24 weeks or more. ${ }^{8,9}$ Finally, with the ever-increasing differentiation of medical care, multidisciplinary team decision-making is an important topic for medicine in general as well. This thesis describes the impact of multidisciplinary team discussions on (1) management decisions, (2) attuning obstetric and neonatal decisions, (3) reaching consensus, and (4) the degree of implementation of these decisions in clinical practice.

Firstly, as shown in a retrospective study (chapter 3), decision-making in the multidisciplinary team works well in making decisions about obstetric management. That is, the team always reaches a joint decision on obstetric management. However, decision-making on neonatal management is problematic. Frequently no explicit management decision on neonatal management is made, thus leaving room for inconsistencies in management before and after birth. This is in accordance with data of Luks et al, who reported that only $18 \%$ of the 77 caseconferences involving 114 cases resulted in prenatal planning of postnatal care. ${ }^{5}$

Secondly, a prospective study (chapter 5) shows than on average decision-making results in an increase of consensus for obstetric management, neonatal management and hospital of delivery. The increase of consensus is highest in decisions about hospital of delivery. From the scarce International data it is indicated that multidisciplinary team discussion does have an impact on management decisions, mainly in obstetric management and hospital of delivery. A change in obstetric management after multidisciplinary discussion is reported in $3.6 \%$ (only prenatal surgical consultation) up to $42 \%$. 5,7

Finally, chapter 3 shows that the decisions of the multidisciplinary team are implemented in $88-100 \%$ of the cases. This indicates a good agreement between the decisions made in the multidisciplinary perinatal team and subsequent clinical practice. Hence, the multidisciplinary perinatal team is a clinically relevant support for making management decisions on fetuses with serious abnormalities.

In conclusion, multidisciplinary team decision-making does increase consensus, is important for clinical practice and works well in case of obstetric management, but may be improved in case of neonatal management.

\subsubsection{Physicians' considerations for end-of-life decisions}

Physicians of the multidisciplinary perinatal team do not report specific considerations for their decision of 'standard obstetric and neonatal management'. In fact, their commonest consideration is that ' there was no reason to depart from standard management'. So, standard management is by default, not needing to be safe-guarded by specific arguments. In industrialized countries, it seems more acceptable for doctors to intervene with the aim of continuing life than to leave it up to nature. Indeed, life is considered to have a sanctity in it's own. This is reflected in the finding that, after a non-aggressive obstetric management, whereby the obstetrician refrains from interventions aimed at sustaining the life of the unborn child, neonatologists start life-sustaining treatment significantly more often in infants with signs of good vitality than in those not showing such signs, even though both of them have a very poor long-term prognosis. It is important to realise that in case of infants for whom a nonaggressive obstetric management is adopted because of a poor prognosis in terms of quality of life, vitality is not a prognostic indicator, in contrast with the significance of vitality in case of infants being born preterm without congenital abnormality. ${ }^{10,11}$ Evidently, it is very difficult to refrain from interventions aimed at keeping the infant with a poor prognosis alive.

A non-aggressive obstetric management or no life-sustaining neonatal treatment is usually considered because of poor quality of life, and to a lesser extent, life expectancy. Parental preference is mentioned as a consideration in $27-29 \%$ of the cases. This relatively low parental involvement in decision-making may be explained in two ways. Firstly, it may be that parents themselves are not familiar with the concept of a non-aggressive obstetric 
management. Secondly, it may be that the obstetrician does not discuss this option with the parents for several reasons until after such management is considered an option by he multidisciplinary perinatal team. Termination of pregnancy is typically considered because of life expectancy and/or poor quality of life. In this context, parental request plays a role in $58 \%$ of the cases In the context of end-of-life decision-making, life expectancy has two aspects. When life expectancy is certainly very poor, this makes decision-making less complicated from a medical point of view, because irrespective of the parents request, it will not influence the longterm outcome for the child. However, in case parents request a termination of pregnancy in case of some chance of survival but with probably extremely poor prognosis regarding quality of life, decision-making is highly complex. Physicians may feel they cannot comply with the request of termination of pregnancy, because of lack of certainty about the prognosis, although they concur the prognosis to be probably very poor and are equally worried as are the parents.

\subsubsection{Non-aggressive obstetric management}

Non-aggressive obstetric management represents a specific and problematic end-of-life decision. In the Dutch situation, basically three groups of cases for which a non-aggressive obstetric management may be adopted can be distinguished. Firstly, there is a group of infants who are expected to die before, during or within one year after delivery, for example infants with anencephaly, bilateral renal agenesia and trisomy 13 or 18 . For this group of infants, termination of pregnancy at 24 weeks or more, if requested by the parents, generally is condoned (assuming that decision-making has taken place according to national guidelines). Even though such decisions are morally and emotionally burdened, these are not so complicated in a strict decision-making sense, because the medical management has no influence on the long-term outcome of the infant. The infant will die anyway. Hence medical management is aimed at: (1) palliation and not prolonging suffering for the infant and (2) enabling the parents to say goodbye and grief in the way that is best for them. Palliation/no prolonging of suffering is achieved by refraining from unnecessary medical interventions during and after delivery. There is no evidence showing more suffering with either termination of pregnancy or carrying the pregnancy to term, as long as no unnecessary medical interventions are done during and after delivery. As there is no gain for the child by obstetric interventions, the pregnant woman should not be exposed to risks ensuing from such interventions. Hence, in this situation a non-aggressive obstetric management and a no life-sustaining management are clearly delineated.

Secondly, non-aggressive obstetric management may be considered for infants who have a prognosis that is so poor that refraining from neonatal life-sustaining intervention is justified, but that is not poor enough for legal justification of late termination of pregnancy. Generally accepted examples of such cases are hypoplastic left heart syndrome, extreme hydrocephalus and severe spina bifida, but frequently it is not clearly delineated whether a prognosis is so poor that it is justified to refrain from life-sustaining neonatal treatment, especially since the diagnosis may not be as certain both before and after birth. In these cases different perspectives between neonatologists and obstetricians may arise.

Thirdly, non-aggressive obstetric management may be considered for infants who have a prognosis that is so poor that the obstetrician does not want to expose the pregnant woman to the risks of obstetric intervention, but not so poor or not so certain that the neonatologists can decide before birth to refrain from neonatal life-sustaining treatment. This may occur in case of a fetus with several serious abnormalities while an explicit syndromal diagnosis cannot be made. On the basis of the sum of multiple congenital abnormalities the obstetrician may consider the outcome of the fetus to be so poor that life-sustaining intervention that could harm the pregnant woman is not warranted, while the paediatrician find no reason to refrain from lifesustaining treatment after birth. The situation in which non-aggressive obstetric management is followed by neonatal life-sustaining interventions is likely to induce suffering. Firstly, because for parents the different perspectives add to uncertainty in an already very difficult situation and may be difficult to understand. Why are the doctors first giving up on their child and then try to 
salvage it by all means after birth? Doesn't such management hurt the child? Why is a diagnosis certain enough for making end-of-life decisions before birth, but needs confirmation after birth, even if the child needs to be kept alive to do so? Secondly, inconsistencies in management before and after birth may prolong suffering of the child by allowing it to get injured by delivery, but not allowing it to die after birth.

To date, many questions about the best way of decision-making about infants with severe abnormalities remain unresolved. Important features of good quality decision-making include consistency, transparency, discussing medical and ethical aspects separately, and good counseling of the parents, including explanation that a non-aggressive obstetric management does not necessarily mean that the infant will die after birth.

\subsection{Parental decision-making in fetal medicine}

\subsubsection{The process of decision-making by pregnant women}

Both a review of literature (chapter 6) and a prospective study (chapter 7) show that parental decision-making is complicated by several psychological mechanisms. Risk is perceived as a feeling rather than a number and it's perception is influenced by the way it is communicated. Furthermore, parents deal with genetic information by dichotomising risk into the adverse event happening or not happening, thereby translating abstract prognostic information into concrete scenario's. Finally, several ways of decision-making are distinguished. Classical decisionmaking theories describe decision-making as a rational weighing of outcomes and their desirability, after which the decision with the highest likelihood of the most desirable outcome is chosen. Newer theories acknowledge an'intuitive' way of decision-making. According to these theories, parents make a quick intuitive decision, after which arguments are formulated to account for this decision. This thesis found (chapter 7) both ways of decision-making in pregnant women after ultrasound diagnosis of fetal abnormality.

This thesis shows that women may experience very different perceptions of choice, ranging from 'no choice', to 'choice' or 'ambiguous choice' after ultrasound diagnosis of fetal abnormality. In situations with similar fetal prognosis, women may have different perceptions of choice, posing a challenge for the widely accepted model of shared decision-making.

A wide range of considerations is important for women in deciding about whether or not to terminate pregnancy. Not only the well-being of the unborn child, but the well-being of the other children in the family, the well-being of themselves, the benefit of carrying to term and moral issues play a role.

Several psychological phenomena may interfere with decision-making. Firstly, derealisation/depersonalisation occurs in about half of the women. This probably represents a psychological mechanism as a response on an acute trauma, which is often further enhanced by the fact that for both prospective parents the abnormality is clinically not noticeable. About half of the women are seeking additional information. This information-seeking behaviour probably represents not only an actual need for information, but a way of regaining control over the situation. The relationship between these phenomena and decision-making remains unclear. On the one hand they may disrupt the decision-making process. For example derealisation/depersonalisation may disrupt the awareness that truly important decisions are at stake and information-seeking behaviour may be a way to avoid making difficult decisions. On the other hand, it may well be that these mechanisms are necessary to ensure a basic psychological stability, that is necessary to be able to make decisions.

\subsection{Methodological aspects}

The most important methodological limitation in studying decision-making is the lack of a golden standard. Some people judge a decision by it's outcome (for example how a couple feels afterwards about the management decisions they made), some people judge a decision by it's intrinsic value (for example when judging that life or death decisions are not for humans to make) and some people judge a decision by it's procedure (for example whether all relevant considerations were taken into account). Since the evaluation of the quality of a decision is 
intertwined with one's personal moral values, it is unlikely that a universal golden standard for a good decision will become apparent in future, thereby affecting the methodology used and conclusions drawn.

Another important aspect is the exploratory nature of this thesis, resulting from the fact that clinical decision-making in general and decision-making after ultrasound diagnosis of fetal abnormality specifically is largely unknown. Many more aspects of decision-making after ultrasound diagnosis of fetal abnormality remain to be uncovered, characteristics of a good decision need to be defined, instruments need to be refined and validated, new devices need to be developed and more pregnant women, partners and physicians need to be asked about their views.

\subsection{Implications for policy and clinical practice}

9.6.1 Implications for policy

The findings of this thesis suggest several changes in current policy. Firstly, it is worrying that in $70 \%$ of the cases being discussed by the multidisciplinary perinatal team were only diagnosed at 24 weeks or more. At that stage termination of pregnancy is illegal, albeit generally condoned in case the infant has no chance of survival. The delay in diagnosis can probably be explained by the fact that, at the time of this study, in the Netherlands no routine ultrasound is offered at 20 weeks. As ultrasound is widely available, many women do have ultrasound examination later in pregnancy, for example for evaluating growth or fetal position. They are then faced with an unexpected serious abnormality thereby realizing that do not have a choice anymore in terms of pregnancy termination. Clinical practice is gradually changing in the Netherlands in terms of facilitation of ultrasound at 20 weeks gestation. Such policy must, however, be accompanied by good counseling explaining the possibilities and limits of fetal ultrasound creating furthermore awareness that fetal ultrasound is indeed a diagnostic tool, possibly revealing adverse findings. Secondly, evaluation of fetal prognosis according to the national guidelines for termination of pregnancy after 24 weeks is troublesome. On the one hand, individual obstetricians are able to consistently classify fetal prognosis according to these guidelines. However, frequently inter-agreement is lacking. This indicates that the classification of fetal prognosis as recommended by these guidelines, does not discern properly between cases that can be condoned and those that should be prosecuted. This may lead to a defensive attitude of obstetricians even if they feel that late termination of pregnancy is justified.

\subsubsection{Implications for clinical practice}

\subsubsection{Decision-making in a multidisciplinary perinatal team}

Decision-making in a multidisciplinary perinatal team is beneficial, in a sense that it results in more agreement. However, some general points need to be considered, i.e., (1) the decision-making process should be as structured and transparent as possible (2). each specialist who is present at team-meetings should be asked for his/her opinion, (3) in case of an end-of-life decision, the considerations for this decision should be clearly stated and written down and (4) in case quality of life is a consideration, then specific aspects of quality of life should be mentioned.

\subsubsection{Counseling the pregnant woman and her partner}

This thesis yields several data that are of importance in counseling pregnant women and their partners after ultrasound diagnosis of fetal abnormality. Firstly, derealization /depersonalization frequently occur, as well as information-seeking. Counselling should take the occurrence of these phenomena into account. Another important observation made in this thesis is the wide variety in perception of choice, even in medically comparable situations. This raises doubt about the applicability of the model of shared decision-making in the de context of decision-making after ultrasound diagnosis of fetal abnormality. Should pregnant women be made aware of choices they did not perceive themselves before? This issue can only be answered when more data, both short-term and long-term, about women's perceptions of 
decision-making, in relation with emotional outcome, are available. Furthermore, this issue involves moral matters. In-depth ethical analysis is outside the scope of this thesis, but does need attention.

In regard of the way decisions should be taken, this thesis shows that both a more rational and a more intuitive way of decision-making occur. So far, data suggest that both forms are acceptable. Hence decision-making should not necessarily be aimed at maximizing rationality. It may well be that for some women a good decision is a decision that 'feels good' rather than one that can be explained by rational arguments. This does not preclude however, to openly discuss all arguments that may be of importance.

\subsection{Suggestions for further research}

Several suggestions for future research arise from the findings of this study.

Firstly, the mechanisms of group decisions need further study. Subjects of such study should be whether shared medical responsibility in groups leads to riskier decisions, in what way medical teams reach consensus, and how medical teams resolve conflicting views.

Secondly, better guidelines for evaluating fetal prognosis need to be developed. In this respect, the key point is better inter-observer agreement leading to management that is more consistent and that can be better judged by legal standards. An important issue of parental decision-making is what way of counseling elicits the best the decision. In this respect it is important that philosophical and societal notions of what constitutes a good decision are developed and instruments evaluating counseling and decision-making accordingly. Only then, the process of decision-making can be evaluated and subsequently improved.

Finally, longitudinal data, correlating the pregnant women's and their partners experiences of decision-making with long-term emotional outcome, are needed. Only then we can establish what is the best way of making decisions after ultrasound diagnosis of fetal abnormality. 


\section{References}

1. Statistics Netherlands, C.B.R.2007.

2. Bosma, J.M., G. van der Wal, and S.L. Hosman-Benjaminse, Late termination of pregnancy in North Holland. Br J Obstet Gynaecol, 1997. 104:478-87.

3. Guillem, P., et al., Trends in elective terminations of pregnancy between 1989 and 2000 in a French county (the Isere). Prenat Diagn, 2003. 23:877-83.

4. Molewijk, A.C., et al., Implicit normativity in evidence-based medicine: a plea for integrated empirical ethics research. Health Care Anal, 2003, 11:69-92.

5. Luks, F.I., et al., Experience with a multidisciplinary antenatal diagnosis and management model in fetal medicine. J Matern Fetal Neonatal Med, 2003. 14:333-7.

6. Caniano, D.A. and F. Baylis, Ethical considerations in prenatal surgical consultation. Pediatr Surg Int, 1999. 15:303-9.

7. Crombleholme, T.M., et al., Prenatal diagnosis and the pediatric surgeon: the impact of prenatal consultation on perinatal management. J Pediatr Surg, 1996. 31:156-62

8. Gevers, J., Medical decisions made by teams:carefulness and responsability. Nederlands Tijdschrift Voor Geneeskunde, 1998. 142:804-8.

9. Wladimiroff, J., Nota Late Zwangerschapsafbreking; Report on Late termination of Pregnancy (official views and guidelines of the Dutch Association of Gynecology and Obstetrics). 1994: Utrecht.

10. Brinchmann, B.S., 'They have to show that they can make it': vitality as a criterion for the prognosis of premature infants. Nurs Ethics, 2000. 7:141-7.

11. Brinchmann, B.S. and P. Nortvedt, Ethical decision making in neonatal units--the normative significance of vitality. Med Health Care Philos, 2001. 4:193-200.

12. Senat, M.V., et al., The use of lidocaine for fetocide in late termination of pregnancy. Bjog, 2003. 110:296300 . 


\section{Summary}

Chapter 1 is an introduction to the role of ultrasound in prenatal detection of congenital abnormality and to the decision-making resulting from that. Congenital abnormalities are the main cause of infant mortality in industrialized countries. Nowadays the development of ultrasonography enables the majority of these abnormalities to be detected already before birth. Despite discussion about the benefits and drawbacks of routine prenatal ultrasound, in most industrialized countries structural fetal ultrasound assessment of severe congenital abnormalities at gestational age of 20 weeks is offered. In the Netherlands, until recently structural fetal ultrasound assessment was not offered routinely to pregnant women, because government approval was lacking, based on concerns about the position of disabled people in society and concerns about medicalisation of pregnancy, among others. Many pregnant women view structural fetal ultrasound as an integral part of prenatal care, but are usually not prepared for an unfavourable result, which often evokes strong emotional reactions.

Detection of severe abnormality by fetal ultrasound, may evoke questions about obstetric and neonatal management. When the unborn child has a poor chance of survival or a very limited quality of life, one may question whether all medical means aimed at sustaining fetal life should be applied. Such issues have opened a new field of research: end-of-life decisions in fetal medicine. End-of-life decisions are decisions concerning medical interventions around the end of life that may, certainly or probably, hasten death. In fetal medicine, in this context a distinction can be made between a non-aggressive obstetric management and termination of pregnancy. In case of non-aggressive obstetric management medical life-sustaining intervention is deferred from because of a poor prognosis. In case of termination of pregnancy, medical intervention ( at the request of the pregnant woman) is aimed at ending fetal life because of a poor prognosis.

In the Netherlands, termination of pregnancy is prohibited after 24 weeks gestational age. Such policy, however, is condoned if certain conditions are met. These conditions are described in guidelines that are set by the Minister of health, Welfare and Sport and by the Minster of Justice, in collaboration with the Dutch Association for Obstetrics and Gynaecology. According to these guidelines an explicit parental request for termination of pregnancy after 24 weeks gestational age can be complied with if the infant has no chance of survival and the abnormalities cannot be treated or if the child has a chance of extra-uterine survival but post-natal use of lifeprolonging medical treatment is considered futile.

In Chapter 2 the decisions made by the multidisciplinary perinatal team of the ErasmusMC in regard of obstetric and neonatal management after ultrasound diagnosis of fetal abnormality are described, based on the results of a retrospective study of 318 consecutive cases. The multidisciplinary perinatal team makes an endof-life decision in $30 \%$ of the cases; in $20 \%$ of all cases the team decides upon a non-aggressive obstetric management and in $10 \%$ a parental request for termination of pregnancy is consented to. In $36 \%$ of all cases neonatal management is decided upon before delivery; in $89 \%$ of these decisions this concerns a standard neonatal management and in $11 \%$ it is decided to refrain from neonatal life-sustaining treatment. Actual management corresponds with the decision of the multidisciplinary perinatal team in $88-100 \%$ of the cases. The finding that in the majority of the cases neonatal management is not decided upon before delivery and, hence that obstetric and neonatal management are not attuned probably reflects a different attitude towards end-of-life decisions after ultrasound diagnosis of fetal abnormality by neonatologists and obstetricians. The author concludes that attuning obstetric and neonatal management is important for a consistent perinatal management. 
Based on a prospective study Chapter 3 describes the agreement of five expert obstetricians in classifying fetal prognosis according to guidelines that were drawn by the government in collaboration with the Dutch Association of Obstetrics and Gynaecology. Three categories of fetal prognosis are discerned 1: the infant has no chance of survival and the abnormalities cannot be treated (1.1); or the infant has a chance of extra-uterine survival but post-natal use of life-prolonging medical treatment is considered futile (1.2); category 2: the infant has a chance of extrauterine survival and post-natal use of life-prolonging medical treatment, if necessary, is considered beneficiary. The obstetricians classified a random sample of 100 cases that were discussed by the multidisciplinary perinatal team of the ErasmusMC. The cases were classified again after five months. For analysis, category 1.1 and 1.2 are joined. In $67 \%$ of the cases at least four of five obstetricians agree. Total kappacoefficient is 0.48 (moderate agreement). The differences between obstetricians reflect systematic differences in classification, that is some obstetricians tend more to classify a fetal prognosis as poor than do others. Intra-observer agreement is $82-$ $97 \%$.

Chapter 4 focuses on a specific end-of-life decision in fetal medicine: non-aggressive obstetric management. In case of a non-aggressive obstetric management regarding a severe fetal abnormality the obstetrician refrains from medical interventions that aim at sustaining fetal life and may harm the mother. A retrospective study of 78 consecutive cases evaluates survival after non-aggressive obstetric management as well as consequent neonatal management. Six(8\%) infants die in utero, $16(21 \%)$ infants die during delivery (11 resulting from cephalocentesis) $56(72 \%)$ infants are born alive. In $29(52 \%)$ of the life-born infants, neonatal life-sustaining treatment is initiated, which is refrained from later in $21 / 29(72 \%)$ infants. When neonatal lifesustaining treatment is initiated, 23/29(79\%) infants die within 6 months after birth. . WWhen no neonatal life-sustaining treatment is initiated, $25 / 27(93 \%)$ of the infants die within 6 months after birth. Eight children have survived:, they all have severe health problemsly impaired quality of life.

Based on a prospective study of 78 cases Chapter 5 describes the impact of discussion in a multidisciplinary perinatal team on consensus about planned obstetric and neonatal management and the arguments for management preferences. After presentation of the medical facts, both before and after discussion, all physicians participating in the perinatal multidisciplinary team filled in a questionnaire anonymously, in which they indicated their management preferences and the arguments for this preference.

Prior to discussion no systemic differences between the different specialties were present. For all management modalities discussion by the multidisciplinary perinatal team increases consensus. Analysis of the cases in which consensus increased with $25 \%$ or more showed an overrepresentation of obstetric nonaggressive management. The arguments given by the team members do not change after discussion. In case of a standard obstetric and standard neonatal management the most frequently mentioned argument is that there is 'no reason to depart from standard management : The most frequently mentioned argument for a nonaggressive obstetric management and a neonatal management in which is refrained from neonatal life-sustaining treatment is 'expected quality of life', whereas the most frequently mentioned argument for termination of pregnancy is ' chance of survival'.

Chapter 6 presents a review of the current knowledge of the decision-making process of pregnant women and their partners after ultrasound diagnosis of fetal abnormality. Firstly, decision-making in the clinical situation is evaluated, after which general decision-making theories are described. 
Literature describing decision-making in the specific context of ultrasound diagnosis of fetal abnormality is scarce, but shows that parents may show variation in perceptions of choice. Futhermore, maternal age, maternal educational level, number of previously completed pregnancies, as well as the specialty of the physician involved in the counselling are determinants of termination of pregnancy.

Literature concerning the decision-making process in regard of future pregnancy in case of a known genetic risk, shows some important phenomena. Firstly, there is a dichotomous perception of risk. Information about the risk of a certain condition is translated in two options: the child is or the child is not affected. Parents focus more on the consequences of a specific outcome than on putting the estimated risk in perspective. This phenomenon results in a small risk of a very undesired outcome weighing more in the decision-making than may be expected rationally. Secondly, the way risks are expressed is of importance in the perception of risk. Thirdly, uncertainty appears to make choices less difficult for parents, It may be that uncertainty has a certain emotional benefit in that it provides parents with the opportunity to 'hope for the best'. In summary, in parental decision-making some non-rational mechanisms play a role.

A commonly adopted theory to describe decision-making is the theory of Subjective Expected Utility. This theory claims that someone evaluates all options based on a combination of the probability of a certain outcome and the (un)desirability of the outcome. By comparing this mathematically, the 'right' decision becomes apparent. Critique of this decision-making theory, however, has drawn attention to the phenomenon of 'framing': the finding that perception of risk depends on the context in which this risk is communicated. This phenomenon influences decision-making at several levels. The most important implication is that decisionmaking is not a strictly rational process. The influence of stress too results in decision-making not being a strictly rational process. For now, some degree of stress seems beneficial, but much stress not beneficial for the decision-making process. In reaction to the observations that decision-making is not a strictly rational process, recently more naturalistic decision-making theories have been proposed. These describe decision-making as a dynamic, context-dependent process, in which firstly a choice is made that is consistent with personal values, which is sustained afterwards with rational arguments.

Finally, in clinical practice, the notion of perceived control plays an important role. Perceived control is beneficial in many medical situations. However, in the specific situation of parental decision-making after ultrasound diagnosis of severe fetal abnormality, perceived control has not shown to be beneficial. Possibly, this results from the large amount of stress in this situation.

In conclusion, a number of mechanisms play a role in parental decisionmaking after ultrasound diagnosis of fetal abnormality, rendering this decisionmaking a not strictly rational process. These mechanisms may have an important function in creating a basic psychological stability. For this reason, decision-making should not only be evaluated in terms of degree of rationality, but also in terms of emotional (long-term) parental emotional outcome.

Based on a qualitative study Chapter 7 describes the experiences of pregnant women after ultrasound diagnosis of fetal abnormality as well as their perception of choice. In pregnant women, a wide range of themes plays a role after ultrasound diagnosis of fetal abnormality, among which grasping the diagnosis, emotions, decision-making and identity as a parent. Even in medically comparable situations, women show a great variation in perception of choice. Rational decision-making, usually strived for by physicians, may be in conflict with a more naturalistic, intuitive way of decision-making of the women involved. If women consider termination of pregnancy, the well-being of the unborn child, the well-being of themselves, the well- 
being of the other children in the family as well as their partner's opinion play a role. Women have different perceptions of benefits of either continuing or terminating pregnancy. Moral values about whether termination of pregnancy is allowed play a role as well.

The author concludes that fetal ultrasonography has dimensions that are difficult to combine. On the one hand, ultrasound is a technique that provides medical information that may result in termination of pregnancy. On the other hand, ultrasound is a bonding ritual personifying the fetus and affirming the reality that a baby is on its way. Precisely when ultrasound shows fetal abnormality, the tension between these two dimensions of fetal ultrasound, leads to complex reactions in pregnant women.

Based on a prospective study Chapter 8 describes how women perceive choice after ultrasound diagnosis of fetal abnormality. Onehundredseven/160 (67\%) women were interviewed by phone. $46 \%$ of these women experience a choice about whether or not to continue their pregnancy. Half of these women experience an ambiguous choice, that is they think that several possible courses of action exist, without feeling that they themselves have to make choices, because the course to follow is obvious. Perceiving a choice is strongly related to prognosis as perceived by the women. $85 \%$ of the women expecting their child not to be affected experience a choice. When women feel their child has no future, $10 \%$ experience a choice. Furthermore, experiences of derealization and/or depersonalization are present in half of the women. Perception of choice is not related with this phenomenon. $57 \%$ of the women look for additional information. Perception of choice is not related with this.

In Chapter 9 the most important findings of this thesis are discussed. End-of-life decisions after ultrasound diagnosis of fetal abnormality occur frequently in the Netherlands. The annual number of end-of-life decisions after ultrasound diagnosis of fetal abnormality is about 100 , but this may be an underestimate. Given the importance of end-of-life decisions, both at the individual as well as at the societal level, the author recommends the implementation of a national register of cases of both termination of pregnancy and non-aggressive obstetric management, either or not reported anonymously.

With regard to decision-making of physicians, the evaluation of fetal prognosis according to current guidelines appears problematic. From the evaluation of a random sample of the cases discussed within the multidisciplinary perinatal team of the ErasmusMC by experienced obstetricians of other tertiary centres, it is shown that in one-third of the cases a maximum of three of five obstetricians agreed. These differences stem, either or not partially, from the observation that some obstetricians tend to evaluate a prognosis as poor more than do others. Possibly, this finding reflects that not only objective medical facts, but implicit normativity play a role in evaluation of fetal prognosis. The author recommends maximizing transparency in the decision-making, in which medical facts are supported by evidence as much as possible and in which moral considerations are not presented as medical facts. Furthermore, the differences between obstetricians in evaluating fetal prognosis demands a certain humbleness towards the parents. In case of a difference of opinion between the physician and the parents, referral to another hospital for a second opinion should be facilitated.

Discussions in a multidisciplinary perinatal team result in more agreement about management decisions. Prenatal decision-making regarding neonatal management is problematic. Frequently, neonatal management is not decided upon before delivery, which may result in inconsistent perinatal management.

The most frequently mentioned argument for a standard obstetric or neonatal management is that there is no reason to depart from such management. The most frequently mentioned argument for a non-aggressive obstetric management is an 
expected poor quality of life, with or without a poor chance of survival and the most frequently mentioned argument for termination of pregnancy is poor chance of survival, with or without an expected poor quality of life.

Non-aggressive obstetric management represents a complex and problematic issue. Specifically in case of an uncertain but poor prognosis, differences in opinion between obstetricians and neonatologists may lead to an inconsistent management, possibly resulting in iatrogenic damage.

With regard to decision-making by pregnant women and their partners several psychological mechanisms play a role. In this context, decision-making appears not a strictly rational process. After ultrasound diagnosis of fetal abnormality, two patterns of decision-making occur: on the one hand a rational weighing of pros and cons, after which a choice is made, an on the other hand a more intuitive process. Furthermore, depersonalization/derealization and information-seeking play a role in the decisionmaking.

A remarkable finding of this thesis is the wide variation in perception of choice. Even in case of similar fetal prognosis, pregnant women have very different perceptions about whether or not they are facing choices. This limits the use of shared decision-making.

For women considering termination of pregnancy the well-being of the unborn child, the well-being of themselves and that of other children in the family play a role, as well as their partner's opinion and moral considerations.

With regard of methodological aspects of this thesis, the lack of a golden standard for good decision-making is apparent. The choice of outcome measurement, which often relates to moral considerations, bears an influence on both methodology and results of studies of decision-making. Furthermore, the exploratory nature of this thesis, which entails a to date hardly explored field, is mentioned.

In chapter 9 some recommendations are made for management policies and clinical practice. Firstly, adequate counselling is recommended when advanced ultrasonography is offered routinely at 20 weeks of gestational age, creating an awareness in pregnant women of the diagnostic tools of ultrasound, which may yield undesired results. Secondly, it is claimed that the guidelines for late termination of pregnancy are problematic, resulting from the lack of professional agreement on fetal prognosis. This results in lack of clarity about whether termination of pregnancy will be prosecuted or will be legally condoned. This may result in a defensive attitude of obstetricians with regard to late termination of pregnancy, even if they feel personally that such policy is justifiable.

In counselling the pregnant woman and her partner, it is recommended to take into account the occurrence of depersonalization/derealization as well as the fact that many women look for information themselves. Furthermore, counselling should take into account the wide variation in perception of choice. This may result in a limited applicability of the shared decision-making model. Furthermore, currently there are no data that a rational way of decision-making is better than a more intuitive one. This implies that decision-making does not necessarily need to be as rational as possible.

Finally, some recommendations for further research are made. Firstly, more research into the mechanisms of decision-making in medical teams is needed. Secondly, better guidelines for evaluating fetal prognosis are necessary. Thirdly, it is important to evaluate which manner of counselling results in the best way of decision-making. Finally, more longitudinal data, relating the way of decision-making to emotional outcome of the parents, are needed. These will help us to determine the best way of decision-making. 


\section{Samenvatting}

Hoofdstuk 1 is een inleiding tot de rol van echoscopie in de prenatale detectie van aangeboren afwijkingen en de besluitvorming die daaruit voortvloeit. Aangeboren afwijkingen zijn in geïndustrialiseerde landen de belangrijkste oorzaak voor zuigelingensterfte. Heden ten dage kan dankzij de ontwikkeling van echoscopisch onderzoek het merendeel van deze afwijkingen reeds voor de geboorte worden vastgesteld. Hoewel er discussie bestaat over de voor- en nadelen van routine echoscopie, wordt in de meeste geïndustrialiseerde landen zwangere vrouwen standaard een structureel echoscopisch onderzoek naar ernstige structurele afwijkingen aangeboden bij een zwangerschapsduur van 20 weken. In Nederland werd tot voor kort structureel echoscopisch onderzoek niet standaard aan alle zwangere vrouwen aangeboden omdat de vereiste ministeriële vergunningen hiervoor ontbraken ondermeer vanwege bezorgdheid over de positie van gehandicapten in de samenleving, alsmede de angst voor medicalisering van de zwangerschap. Veel zwangere vrouwen zien structureel echoscopisch onderzoek als integraal onderdeel van prenatale zorg, maar zijn daarbij meestal niet voorbereid voor een ongunstige uitslag die vaak heftige emotionele reacties oproept.

Als bij echoscopisch onderzoek tijdens de zwangerschap een ernstige afwijking blijkt, kan dit vragen oproepen omtrent het te voeren obstetrisch en neonataal beleid. Als het ongeboren kind een geringe overlevingskans of een heel beperkte kwaliteit van leven heeft, is het de vraag of alle medische middelen moeten worden toegepast om het in leven te houden. Zulke vragen hebben een nieuw onderzoeksgebied geopend, dat van 'end-of-life decisions' in de foetale geneeskunde. End-of-life decisions zijn beslissingen over medische interventies rondom het levenseinde die het overlijden zeker, of waarschijnlijk, versnellen. In de foetale geneeskunde wordt in dit kader onderscheid gemaakt tussen het noninterventiebeleid en de zwangerschapsbeëindiging. Bij een non-interventiebeleid wordt afgezien van medisch levensverlengend handelen vanwege een zeer sombere foetale prognose. Bij een zwangerschapsbeëindiging is het medisch handelen (op verzoek van de zwangere) gericht op het doen overlijden van de foetus vanwege een zeer sombere prognose.

Zwangerschapsbeëindiging na 24 weken zwangerschapsduur is in Nederland wettelijk verboden. Een dergelijk beleid wordt in de praktijk echter gedoogd, als er aan bepaalde voorwaarden wordt voldaan. Deze voorwaarden zijn opgenomen in richtlijnen die zijn opgesteld door het Ministerie van Justitie en het Ministerie van Volksgezondheid in samenspraak met de Nederlandse Vereniging van Obstetrie en Gynaecologie. Volgens deze richtlijnen kan aan een klemmend verzoek van ouders om zwangerschapsbeëindiging na 24 weken zwangerschapsduur worden voldaan indien het kind geen extra-uteriene overlevingskans heeft en de afwijking niet behandeld kan worden of indien het kind enige overlevingskans heeft maar dat de vooruitzichten dermate somber zijn dat neonataal levensverlengend handelen zinloos wordt geacht.

Hoofdstuk 2 beschrijft op grond van de bevindingen van een retrospectieve studie van 318 opeenvolgende casus, welke beslissingen het multidisciplinaire perinatale team van het ErasmusMC neemt ten aanzien van het obstetrische en neonatale beleid nadat echoscopische een structurele foetale afwijking is vastgesteld. Het multidisciplinaire team neemt een obstetrische end-of-life decision in $30 \%$ van de casus; in $20 \%$ van alle casus wordt besloten tot een obstetrisch non-interventiebeleid en in $10 \%$ wordt ingestemd met een ouderlijk verzoek tot zwangerschapsbeëindiging. In $36 \%$ van alle casus wordt het neonataal beleid bepaald voordat de partus plaatsvindt; in $89 \%$ van deze beslissingen betreft dit een standaard neonataal beleid en in $11 \%$ een beleid waarin afgezien wordt van neonataal levensverlengend handelen. Het daadwerkelijke beleid komt in $88-100 \%$ van de casus overeen met de 
beslissing van het multidisciplinaire perinatale team. Het feit dat in het merendeel van de casus het neonataal beleid niet voor de partus bepaald wordt, en dat derhalve het obstetrisch en neonataal beleid niet op elkaar afgestemd worden, weerspiegelt waarschijnlijk een verschil tussen neonatologen en obstetrici in benadering van endof-life decisions na echoscopische diagnose van een ernstige foetale afwijking. De auteur concludeert dat voor een consistent perinataal beleid afstemming tussen het obstetrisch en neonataal belangrijk is.

Hoofdstuk 3 beschrijft aan de hand van een prospectief onderzoek de overeenstemming tussen vijf deskundige obstetrici betreffende de classificatie van foetale prognose volgens richtlijnen die zijn opgesteld door de overheid in samenspraak met de Nederlandse Vereniging voor Gynaecologie en Obstetrie. Drie categorieën van foetale prognose worden onderscheiden: 1.1 de pasgeborene heeft geen overlevingskans, de afwijking(en) kan (kunnen) niet worden behandeld; 1.2 de pasgeborene heeft extra-uteriene overlevingskans, maar neonataal levensverlengend handelen wordt zinloos geacht; 2 . de pasgeborene heeft extrauteriene overlevingskans en neonataal levensverlengend handelen, indien nodig, wordt zinnig geacht. De obstetrici classificeerden tweemaal (waartussen vijf maanden) een steekproef van 100 casus, die besproken werden in het multidisciplinair perinataal team van het ErasmusMC. Voor de analyse werden categorieën 1.1 en 1.2 samengevoegd tot één categorie. In $67 \%$ van de casus bestaat er overeenstemming tussen minimaal vier van de vijf obstetrici. De totale kappa-coëfficiënt bedraagt 0.48 (matige overeenstemming). De verschillen in classificatie weerspiegelen systematische verschillen in classificatie, dat wil zeggen sommige obstetrici zijn meer geneigd tot het classificeren van een sombere prognose dan andere. De intra-observer agreement is $82-97 \%$.

Hoofdstuk 4 gaat in op een specifieke beslissing rondom het levenseinde in de foetale geneeskunde: het obstetrisch non-interventiebeleid. In het geval van een obstetrisch non-interventiebeleid bij een ernstige foetale afwijking ziet de obstetricus af van medische interventies die zich richten op het verlengen van het leven van het ongeboren kind en die mogelijk schade voor de zwangere tot gevolg hebben. Een retrospectieve studie van 78 opeenvolgende casus brengt de overleving na een obstetrisch non-interventiebeleid in kaart, alsmede het daarop volgende neonatale beleid. Zes $(8 \%)$ kinderen overlijden in utero, $16(21 \%)$ tijdens de bevalling (van wie 11 ten gevolge van cefalocentesis). Zesenvijftig (52\%) kinderen worden levend geboren. In 29/56(52\%) levendgeboren kinderen wordt neonataal levensverlengend handelen ingezet, hetgeen bij $21 / 29(72 \%)$ kinderen later wordt gestaakt. Wanneer neonataal levensverlengend handelen wordt ingezet, overlijden $23 / 29(79 \%)$ kinderen binnen zes maanden na de geboorte; wanneer geen neonataal levensverlengend handelen wordt ingezet, overlijden $25 / 27$ (93\%) kinderen binnen zes maanden na de geboorte. $10 / 78(10 \%)$ kinderen voor wie een obstetrisch non-interventiebeleid wordt afgesproken overleeft tot na zes maanden na de geboorte. Al deze kinderen hebben ernstige gezondheidsproblemen.

Hoofdstuk 5 beschrijft aan de hand van een prospectieve studie van 78 casus de invloed van discussie in een multidisciplinair perinataal team op de consensus over het te voeren obstetrisch en neonataal beleid en de argumenten voor het geprefereerde beleid. Alle deelnemers aan het overleg vulden na de presentatie van de medische gegevens, zowel voor als na de discussie, anoniem een formulier in waarin zij hun beleidsvoorkeur en de argumenten daarvoor aangaven.

Het blijkt dat voor de discussie geen systematische verschillen tussen de verschillende specialismen bestaan. Voor alle beleidsvarianten leidt discussie in het multidisciplinair perinataal team tot een toename van consensus. Analyse van de groep casus waarin een toename van consensus van $25 \%$ of meer is, laat een 
oververtegenwoordiging zien van het obstetrisch non-interventiebeleid. De argumenten die teamleden geven voor hun beleidsvoorkeur veranderen niet na de discussie. Voor een standaard obstetrisch en standaard neonataal beleid is het meest genoemde argument dat 'er geen reden is om van een standaard beleid af te zien'. Het meest genoemde argument voor een obstetrisch non-interventiebeleid en een neonataal beleid waarbij afgezien wordt van neonataal levensverlengend handelen is 'verwachte kwaliteit van leven' terwijl het meest genoemde argument voor zwangerschapsbeëindiging 'overlevingskans' is.

Hoofdstuk 6 geeft een overzicht van de huidige kennis van het besluitvormingsproces van zwangere vrouwen en hun partners nadat echoscopische een ernstige foetale afwijking is vastgesteld. Eerst wordt de situatie in de praktijk en daarna algemene besluitvormingstheorieën beschreven.

Literatuur die zich richt op het besluitvormingsproces in de specifieke situatie van een echoscopisch vastgestelde foetale afwijking is schaars, maar laat zien dat ouders verschillende opvattingen kunnen hebben ten aanzien van het hebben van een keuze. Verder worden maternale leeftijd, maternaal opleidingsniveau, voorafgaand aantal voltooide zwangerschappen en het specialisme van degene die de counseling doet beschreven als determinanten van zwangerschapsbeëindiging.

Vanuit literatuur aangaande het besluitvormingsproces ten aanzien van een eventuele zwangerschap in het geval van een verhoogd genetisch risico, komt een aantal belangrijke fenomenen naar voren. Ten eerste is er sprake van een dichotome opvatting van risico. Informatie over de kans op een bepaalde aandoening bij een toekomstig kind wordt vertaald in twee mogelijkheden: het kind is wel of het kind is niet aangedaan. Ouders laten het zwaartepunt hierbij meer vallen op de gevolgen van een bepaalde uitkomst dan op het in perspectief zetten van de gegeven kans. Dit fenomeen werkt in de hand dat een kleine kans op een zeer ongewenste uitkomst in de besluitvorming zwaarder weegt dan rationeel te verwachten. Ten tweede blijkt dat de manier waarop kansen worden uitgedrukt de perceptie van een kans beïnvloeden. Ten derde blijkt dat onzekerheid het voor ouders minder moeilijk maakt om keuzes te maken. Mogelijk heeft onzekerheid een bepaald emotioneel voordeel in de zin dat het ouders de kans geeft om er 'het beste van te hopen'. Samenvattend spelen in de besluitvorming van ouders niet-rationele mechanismen een rol.

Een algemeen aanvaarde algemene theorie om besluitvorming te beschrijven is de Subjective Expected Utility theorie. Deze theorie gaat ervan uit dat iemand alle opties evalueert op basis van een combinatie van de kans op een bepaalde uitkomst en de (on)gewenstheid daarvan. Door dit mathematisch op een rij te zetten, is vervolgens duidelijk wat de 'goede' beslissing is. Kritiek op deze theorie vraagt echter aandacht voor een bepaald cognitief fenomeen, framing: het gegeven dat de perceptie van een kans of een uitkomst afhangt van de context waarin deze gecommuniceerd wordt. Dit fenomeen heeft op verschillende niveaus invloed op besluitvorming. Het belangrijkste gevolg hiervan is dat besluitvorming niet een strikt rationeel proces is. Ook de invloed van stress maakt besluitvorming tot een niet strikt rationeel proces. Vooralsnog lijkt enige mate van stress gunstig, maar veel stress ongunstig voor een rationeel besluitvormingsproces. Als reactie op de observaties dat besluitvorming niet een strikt rationeel proces is, zijn recentelijk meer naturalistische besluitvormingstheorieën gelanceerd. Deze beschrijven besluitvorming als een dynamisch en contextafhankelijk proces, waarbij eerst een keuze passend bij de persoonlijke overtuigingen gemaakt wordt, welke achteraf onderbouwd wordt met rationele argumenten.

In de klinische praktijk speelt tot slot het begrip perceived control een belangrijke rol. Perceived control, het ervaren van controle over situatie, is in veel medische situaties gunstig voor de patiënt. In de specifieke situatie echter dat ouders besluiten moeten nemen na echoscopische diagnose van een ernstige foetale 
afwijking, is perceived control niet aantoonbaar gunstig. Wellicht ligt de grote mate van stress die deze specifieke situatie met zich meebrengt hieraan ten grondslag.

Concluderend speelt bij ouderlijke besluitvorming na echoscopische diagnose van een foetale afwijking een aantal mechanismen een rol die besluitvorming tot een niet strikt rationeel proces maken. Deze mechanismen hebben wellicht een belangrijke functie in het creëren van een basale psychologische stabiliteit. Derhalve dient een beslissing niet alleen geëvalueerd te worden op mate van rationaliteit, maar ook op basis van emotionele (langetermijn) uitkomst van de ouders.

Hoofdstuk 7 beschrijft aan de hand van een kwalitatieve studie de ervaringen van zwangere vrouwen na echoscopische detectie van een foetale afwijking alsmede hun perceptie van 'keuze'. Nadat echoscopisch een foetale afwijking is vastgesteld, speelt een breed scala aan thema's een rol bij zwangere vrouwen, waaronder het besef van de diagnose, emotie, het nemen van beslissingen en de identiteit als ouder. Zelfs in medisch opzicht vergelijkbare situaties laten vrouwen een grote variatie zien in hoe zij keuze ervaren. De rationele manier van beslissen, doorgaans nagestreefd door artsen, staat soms op gespannen voet met de soms meer naturalistische, intuïtieve manier van beslissen van vrouwen. Wanneer vrouwen zwangerschapsbeëindiging overwegen, spelen het welzijn van het ongeboren kind, het welzijn van henzelf en de andere kinderen in het gezin, alsmede de mening van hun partner een rol. Vrouwen ervaren de voor- en nadelen van het voortzetten danwel beeindigen van de zwangerschap verschillend. Morele waarden over of zwangerschapsbeëindiging geoorloofd is, spelen eveneens een rol.

De auteur concludeert dat echoscopisch onderzoek twee kanten heeft die moeilijk te verenigen zijn. Aan de ene kant is echoscopisch onderzoek een techniek die eventueel medische informatie geeft die aanleiding kan zijn tot het beëindigen van de zwangerschap. Aan de andere kant is echoscopisch onderzoek een hechtingsritueel dat de foetus personificeert en de realiteit van een kind dat op komst is bevestigt. Juist wanneer echoscopisch onderzoek een foetale afwijking laat zien, leidt het spanningsveld tussen de twee kanten van echoscopisch onderzoek tot complexe reacties bij het ouderpaar.

Hoofdstuk 8 beschrijft aan de hand van een prospectieve studie hoe vrouwen keuze ervaren na echoschopische diagnose van een foetale afwijking. Honderdzeven/161 $(69 \%)$ vrouwen werden telefonisch geinterviewd. $46 \%$ van deze vrouwen heeft het gevoel voor keuzes te staan wat betreft het continueren van de zwangerschap. De helft van deze vrouwen ervaart een ambigue keus; dat wil zeggen, zij vinden dat er wel keuzes denkbaar zijn, zonder echter het gevoel te hebben dat ze zelf een keus moeten maken, omdat de te volgen koers duidelijk is. Het ervaren van een keus hangt sterk samen met de door de vrouwen verwachte prognose. $85 \%$ van de vrouwen die verwachten dat de toekomst van hun kind niet aangedaan was, ervaart dat er geen keuze te maken is. Wanneer vrouwen verwachten dat hun kind geen toekomst heeft, ervaart $10 \%$ dat er geen keuze te maken is. Tevens blijkt dat gevoelens van derealisatie en/of depersonalisatie in de helft van de vrouwen aanwezig is. Het ervaren van een keuze is hieraan niet gerelateerd. $57 \%$ van de vrouwen zoekt zelf aanvullende informatie. Het ervaren van een keuze is hieraan niet gerelateerd.

Hoofdstuk 9 besluit dit proefschrift met een algemene discussie van de belangrijkste bevindingen.

End-of-life decisions na echoscopisch vastgestelde foetale afwijking komen regelmatig voor in Nederland. Na echoscopische diagnose van een foetale afwijking in Nederland wordt het aantal end-of-life decisions geschat op 100 per jaar, maar wellicht is dit een onderschatting. Gegeven het gewicht van end-of-life decisions, zowel op individueel als op maatschappelijk niveau, adviseert de auteur tot de 
invoering van een nationaal register, waarin niet alleen alle gevallen van late zwangerschapsbeëindiging, maar ook alle gevallen van non-interventie, al dan niet anoniem, geregistreerd worden.

Ten aanzien van besluitvorming door artsen blijkt het bepalen van foetale prognose volgens de huidige richtlijnen problematisch. Wanneer een steekproef van de casus, die binnen het multidisciplinaire team van het ErasmusMC besproken werden, aan ervaren obstetrici van andere academische centra wordt voorgelegd, zijn in eenderde van deze gevallen maximaal drie van de vijf obstetrici het met elkaar eens. Deze verschillen berusten, al dan niet gedeeltelijk, op het gegeven dat sommige obstetrici meer geneigd zijn tot het afgeven van een sombere prognose dan andere. Mogelijk weerspiegelt deze bevinding dat niet alleen objectieve medische gegevens, maar ook een impliciete normativiteit een rol speelt in het beoordelen van foetale prognose. De auteur adviseert om zoveel mogelijk transparantie in de besluitvorming na te streven, waarbij medische gegevens zo goed mogelijk onderbouwd worden en morele overwegingen niet verhuld als medische feiten gepresenteerd worden. Tevens noopt het verschil in opvatting tussen obstetrici over foetale prognose tot enige bescheidenheid jegens ouders. Als er een verschil van mening tussen de arts en de ouders is, dient de drempel voor verwijzing voor een second opinion in een ander centrum laag te zijn.

Overleg in een multidiscplinair perinataal team leidt tot meer consensus over het te voeren beleid. Prenatale besluitvorming met betrekking tot neonataal beleid is problematisch. Voorafgaand aan de bevalling wordt een neonataal beleid meestal niet afgesproken, hetgeen kan leiden tot een inconsistent perinataal beleid.

Het meeste genoemde argument voor een standaard obstetrisch of neonataal beleid is dat er geen reden is om hiervan af te zien. Het meest genoemde argument voor een non-interventie beleid is de verwachte slechte kwaliteit van leven al dan niet in combinatie met een lage overlevingskans en het meest genoemde argument voor een zwangerschapsbeëindiging is lage overlevingskans al dan niet in combinatie met een verwachte slechte kwaliteit van leven.

Het obstetrisch non-interventiebeleid is een gecompliceerd en problematisch vraagstuk. Met name in het geval van een onzekere doch sombere prognose kunnen verschillen in opvatting tussen obstetrici en neonatologen leiden tot een inconsistent beleid, mogelijjk resulterend in iatrogene schade.

Met betrekking tot besluitvorming door zwangere vrouwen en hun partners spelen verschillende psychologische mechanismen een rol. Besluitvorming blijkt hierbij niet een strikt rationeel proces. Twee manieren van besluitvorming komen voor na echoscopische diagnose van een foetale afwijking, enerzijds een rationeel afwegen van voors en tegens, waarna een keuze gemaakt wordt en anderzijds een meer intuïtief proces. Ook depersonalisatie/derealisatie en het zelf op zoek gaan naar informatie spelen een rol in de besluitvorming.

Een opmerkelijke bevinding van dit proefschrift is de grote variatie in perceptie van keuze. Zelfs in het geval van vergelijkbare foetale prognose hebben zwangere vrouwen zeer verschillende opvattingen ten aanzien van keuze. Dit gegeven bemoeilijkt de toepassing van shared decision-making.

Wanneer vrouwen een zwangerschapsbeëindiging overwegen, spelen het welzijn van het ongeboren kind, het welzijn van henzelf en dat van andere kinderen in het gezin, alsmede ook de mening van de partner en morele overwegingen een rol

Ten aanzien van de methodologische aspecten van het proefschrift speelt het gebrek aan een gouden standaard voor goede besluitvorming een rol. De keuze van uitkomstmaat, die vaak samenhangt met morele overwegingen, beïnvloedt zowel de methodologie als de bevindingen van besluitvormingsonderzoek. Tevens wordt gewezen op het exploratieve karakter van dit proefschrift dat een tot op heden grotendeels onontgonnen gebied beslaat.

Hoofdstuk 9 doet tevens enige aanbevelingen voor zowel het beleid als de klinische praktijk. Het proefschrift adviseert ten eerste goede counseling bij het 
standaard aanbieden van structureel echosscopisch onderzoek bij 20 weken, zodat zwangeren zich bewust zijn dat echoscopisch onderzoek een diagnosticum is, waarbij ook ongewenste bevindingen kunnen worden gedaan. Ten tweede stelt het proefschrift dat de richtlijnen voor late zwangerschapsbeëindiging problematisch zijn, vanwege het gebrek aan professionele overeenstemming ten aanzien van foetale prognose. Dit betekent dat het niet duidelijk is in welke situaties late zwangerschapsbeëindiging vervolgd of wettelijk gedoogd wordt. Dit leidt mogelijk tot een defensieve houding van obstetrici ten aanzien van late zwangerschapsbeëindiging, zefs wanneer zij deze persoonlijk wel gerechtvaardigd achten.

Het proefschrift beveelt met betrekking tot counselling van de zwangere vrouw en haar partner aan om rekening te houden met het optreden van depersonalisatie/derealisatie alsmede met het feit dat veel vrouwen zelf informatie opzoeken. Verder dient counselling rekening te houden met de grote variatie in perceptie van keuze. Dit betekent mogelijk dat het model van shared decisionmaking slechts in beperkte mate toepasbaar is. Tot slot zijn er vooralsnog geen harde aanwijzingen dat een rationele manier van besluitvorming beter is dan een meer intuïtieve manier. Dit betekent dat besluitvorming niet per se zo rationeel mogelijk moet zijn.

Tot slot doet hoofdstuk 9 enige aanbevelingen voor verder onderzoek. Ten eerste is er meer onderzoek nodig naar het mechanisme van besluitvorming in medische teams. Ten tweede zijn er betere richtlijnen nodig voor het bepalen van foetale prognose. Ten derde is het belangrijk te onderzoeken welke manier van counselen leidt tot de beste manier van besluitvorming. Tot slot zijn er meer longitudinale data nodig, waarbij de wijze van besluitvorming gekoppeld wordt aan de emotionele uitkomst van ouders, om hiermee ook te bepalen op wat voor manier het beste beslissingen genomen kunnen worden. 


\section{Dankwoord}

Een proefschrift is het resultaat van de inspanning van veel mensen. Ik wil ten eerste graag de vrouwen bedanken die deelnamen aan het onderzoek. Hun vertrouwen en openheid tijdens de interviews hebben veel indruk gemaakt. Verder ook mijn grote dank aan de artsen van de prenatale diagnostiek die tijdens de vaak drukke en moeilijke spreekuren toch kans zagen om vrouwen voor het onderzoek te vragen. De artsen van het perinataal overleg wil ik bedanken voor het invullen van de vragenlijsten. Verder natuurlijk de begeleiders: Agnes, Hajo, professor Van der Maas, professor Passchier en professor Wladimiroff. Jullie motiverende begeleiding heeft dit proefschrift in belangrijke mate gevormd, bedankt! De Sophia Stichting Wetenschappelijk Onderzoek, de afdeling Verloskunde en Vrouwenziekten en het Instituut Maatschappelijke Gezondheidszorg ben ik erkentelijk voor de financiële ondersteuning van het onderzoek. Tot slot: ik heb in mijn leven veel ontmoetingen gehad met bijzondere mensen. Deze ontmoetingen hebben me geïnspireerd en gevormd. Ook al deze mensen wil ik hierbij graag bedanken. 


\section{Curriculum vitae}

Hilmar Bijma is geboren op 24 januari 1973 in Groningen. Nadat zij in 1991 het Willem Lodewijk Gymnasium voltooit, gaat zij geneeskunde studeren aan de Faculteit der Geneeskunde te Groningen. Na het afronden van de doctoraalfase aldaar, vertrekt zij naar Amsterdam om aan de Universiteit van Amsterdam haar coschappen te lopen, alwaar in 1999 het artsexamen behaald wordt. Na een AGNIOschap in de verloskunde en gynaecologie begint zij in 2000 met het promotieonderzoek 'Decision-making after ultrasound diagnosis of fetal anomaly' in het ErasmusMC. Dit onderzoek combineert zij met een baan als arts prenatale diagnostiek, waarna zij in 2005 begint met de opleiding tot gynaecoloog in het Ikaziaziekenhuis en het ErasmusMC te Rotterdam. 


\section{Publications by the author}

Bijma HH, Verrijn Stuart AA, Gerritsen T, Meuzelaar JJ. Congenitale starre tracheastenose op basis van trachearingen. Tijdschr Kindergeneeskd 1997;665:115119.

Wladimiroff JW, Cohen-Overbeek TE, Ursem NT, Bijma H, Los FJ. Geavanceerd ultrageluidonderzoek naar aangeboren afwijkingen in Rotterdam; 20 jaar ervaring. Ned Tijdschr Geneeskd. 2003;25;147:2106-10.

Bijma $\mathrm{HH}$, Wildschut $\mathrm{HI}$, van der Heide A, van der Maas PJ, Wladimiroff JW. Obstetricians' agreement on fetal prognosis after ultrasound diagnosis of fetal anomalies. Prenat Diagn. 2004;24:713-8.

Bijma HH, Schoonderwaldt EM, van der Heide A, Wildschut $\mathrm{HI}$, van der Maas PJ, Wladimiroff JW. Ultrasound diagnosis of fetal anomalies: an analysis of perinatal management of 318 consecutive pregnancies in a multidisciplinary setting. Prenat Diagn. 2004;24:890-5.

Bijma HH, Wildschut HI, van der Heide A, Passchier J, Wladimiroff JW, van der Maas PJ. Parental decision-making after ultrasound diagnosis of a serious foetal abnormality. Fetal Diagn Ther. 2005;20:321-7.

Bijma $\mathrm{HH}$, van der Heide A, Wildschut $\mathrm{Hl}$, van de Vathorst $\mathrm{S}$, Tibboel $\mathrm{D}$, Wladimiroff JW, van der Maas PJ. Survival after non-aggressive obstetric management in cases of severe fetal anomalies: a retrospective study. BJOG. 2005;112:1630-5.

Bijma HH, Van der Heide A, Wildschut HI, Van der Maas PJ, Wladimiroff JW. Impact of decision-making in a multidisciplinary perinatal team. Prenat Diagn. 2007;27:97103. 